2013

\title{
The Impact of Emotional Intelligence on Auditor Judgment
}

Yang Ling

Virginia Commonwealth University

Follow this and additional works at: https://scholarscompass.vcu.edu/etd

Part of the Business Commons

(C) The Author

\section{Downloaded from}

https://scholarscompass.vcu.edu/etd/509

This Dissertation is brought to you for free and open access by the Graduate School at VCU Scholars Compass. It has been accepted for inclusion in Theses and Dissertations by an authorized administrator of VCU Scholars Compass. For more information, please contact libcompass@vcu.edu. 


\title{
The Impact of Emotional Intelligence on Auditor Judgment
}

A dissertation submitted in partial fulfillment of the requirements for the degree of Doctor of Philosophy in Business at Virginia Commonwealth University.

by

\author{
Ling Yang \\ Ph.D. Candidate \\ Accounting Department, School of Business \\ Virginia Commonwealth University \\ Chair: Benson Wier, Ph.D. \\ Co-Chair: Alisa G. Brink \\ Professors of Accounting \\ Accounting Department, School of Business
}

Virginia Commonwealth University

Richmond, Virginia

April, 2013 


\section{Acknowledgements}

I wish to acknowledge the support and guidance of my dissertation committee members, Dr. Dr. Ben Wier (chair), Dr. Alisa Brink (co-chair), Dr Carolyn Norman, and Dr. John Bachelor, and all faculty members of the Accounting departments of the Graduate School of Business who were mentoring me throughout the doctoral program.

I extend a special thank individually to my committee co-chair, Dr. Alisa Brink, who gave many hours to guide my development as a scholar and specifically to the undertaking of this research project. I also would like to thank Dr. Carolyn Norman, Department Chair, for her support and encouragement of doctoral students.

I am very appreciative of my fellow cohort members, Ira Abdullah, David J Emerson, Andrea Gouldman, and Robson Glasscock. We encouraged one another and kept each other on track during the past four years. It has been an honor to work with them.

My gratitude goes to dear mentors and friends Yumei Wu, Wenjie Zhang and others who helped my data collection in China. Without their helping to distribute data, I would not have been able to complete this dissertation.

The support of my parents, Baozhu Liu and Ziqiu Yang was instrumental in encouraging me to complete this process. Finally, I wish to thank my husband, Jihang for his continuous encouragement and support throughout this process. 


\section{Table of Contents}

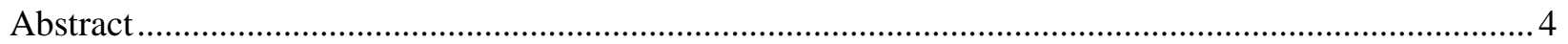

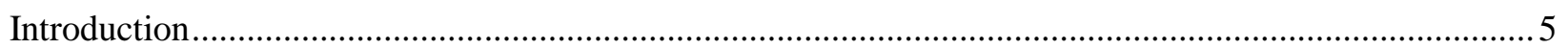

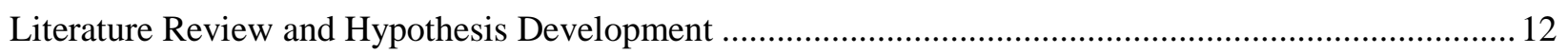

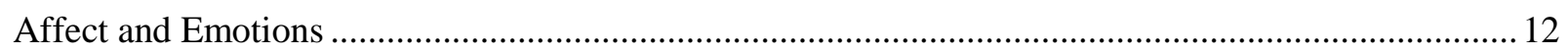

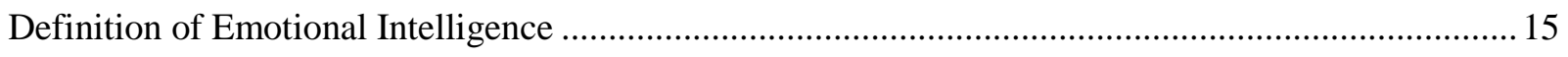

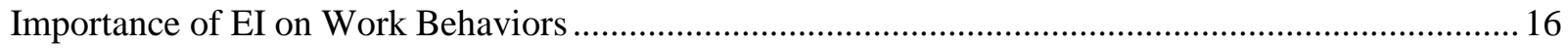

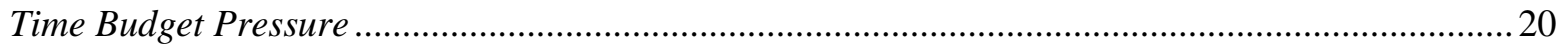

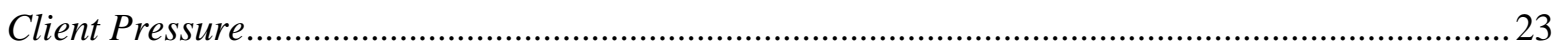

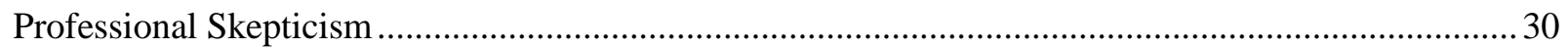

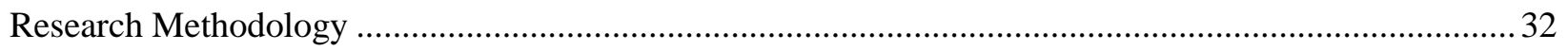

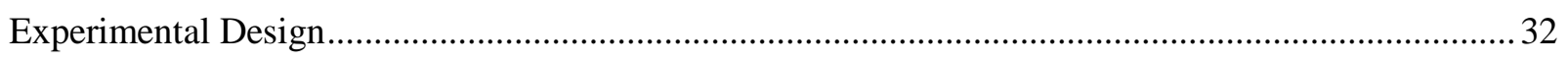

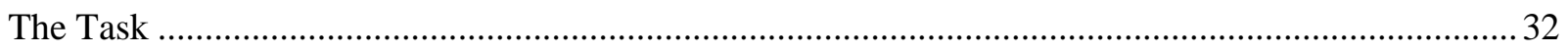

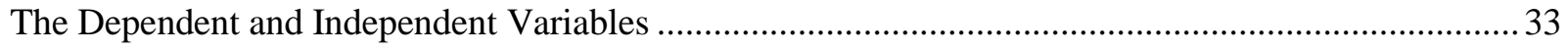

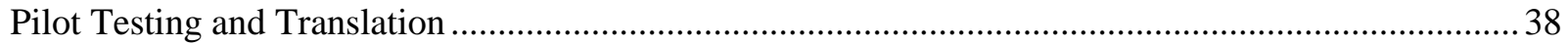

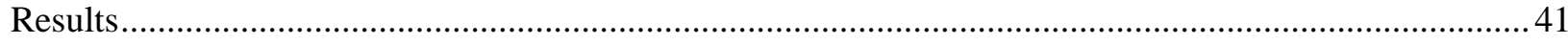

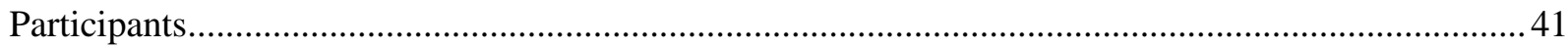

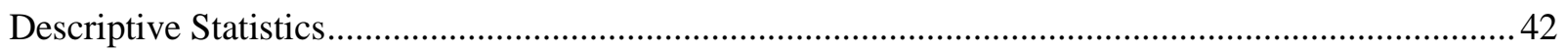

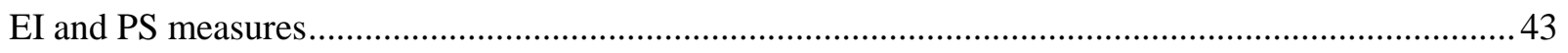

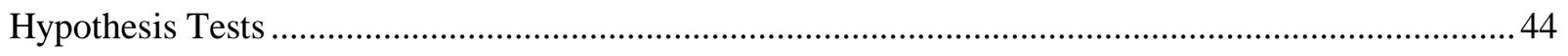

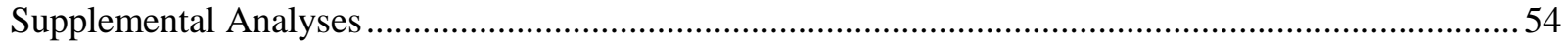

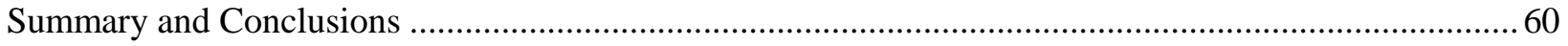

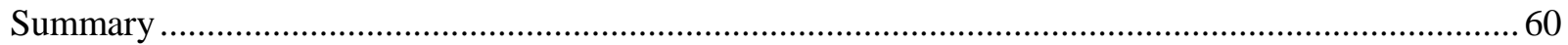

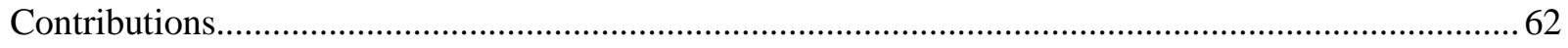

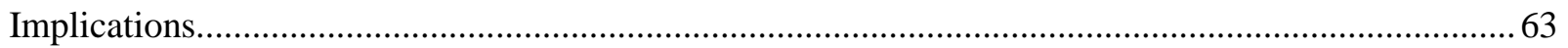

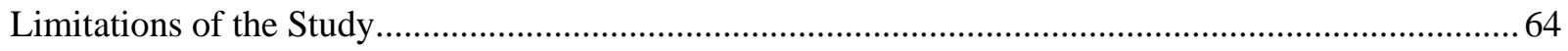

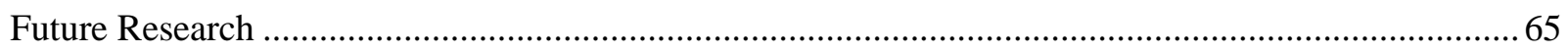

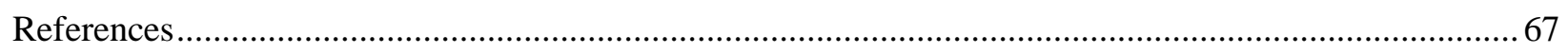

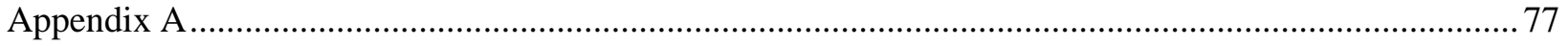

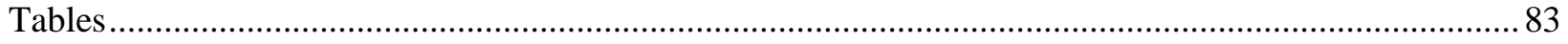

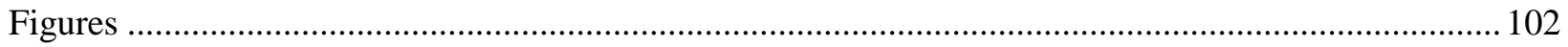




\begin{abstract}
Emotions are an important underlying factor that may interact with pressure and other situational variables to influence auditors' judgments and decisions. This study seeks to identify emotional intelligence (EI) as a key factor in dealing with emotions and pressures in an audit context. In this paper, I focus on how EI may influence the relation between job pressures (i.e., time budget pressure and client incentive pressure) on the auditor's judgment. Specifically, I investigate the moderating effect of emotional intelligence on auditor judgments when auditors experience both internal and external pressures. The results suggest that the moderating influence of EI on auditor judgments can effectively reduce auditors' tendency to engage in dysfunctional behavior in order to improve audit quality. Furthermore, there is a positive relation between EI and professional skepticism suggesting that auditors with high EI are more skeptical and assess higher risk than auditors with low EI. Finally, moderation analysis suggests that EI is a significant mechanism which drives the joint effects of different type of pressures on auditor judgments.
\end{abstract}

Key words: Emotion intelligence, Time budget pressure, Client pressure, Auditor judgment 


\section{Chapter I}

\section{Introduction}

Recent changes in regulation and audit processes underscore the importance of identifying and understanding the unobservable elements that influence audit quality (Cianci and Bierstaker, 2009; Trotman, 2011). Emotion is an important underlying factor that may interact with other situational variables to influence auditors' judgments and decisions. This study seeks to identify emotional intelligence (EI) as a key factor in dealing with emotions and pressures in an audit context.

Nelson and Tan (2005) describe the importance of understanding the effect of emotions on auditors' judgment and decision making (JDM) and call for additional research in this area. Bhattacharjee, Moreno and Riley (2011) find that interpersonal affect (interactions between auditors and clients) has a negative effect on auditors' inventory judgments. These results emphasize the importance of auditors recognizing and managing their affective reactions when dealing with clients. Despite this, very few studies investigate the effect of emotions on auditor decision making.

Emotional intelligence has received considerable attention in several other disciplines, including industrial and organizational psychology, organizational behavior, and management. EI refers to one's ability to perceive and manage emotions in oneself and others (e.g., Goleman, 1995; Mayer, Salovey, and Caruso, 2000). Prior research reveals the importance of EI as a predictor of job performance and its role in relieving job stress (e.g., Joseph and Newman, 2010; O’Boyle, Humphrey, Pollack, Hawver ,and Story, 2010). For example, many studies document the positive effect of EI on job performance (e.g., Semadar, Robins, and Ferris, 2006; Joseph and Newman, 2010). In addition, EI adds incremental explanatory power above and beyond 
personality and cognitive ability when predicting job performance (e.g. Locke, 2005; Rode, Mooney, Arthaud-Day, Near, Baldwin, and Rubin, 2007; O’ Boyleet al., 2010). Furthermore, Nikolaou and Tsaousis (2002) find a negative correlation between emotional intelligence and stress at work. That is, individuals with high EI experience less stress at work than those with low EI.

Pressure is a major dimension of occupational stress (Vagg and Spielberger, 1998; Larson, 2004). Pressure is defined as "an objective stimulus construct referring to individual characteristics or combinations of characteristics and events that impinge on the perceptual and cognitive processes of individual" (DeZoort and Lord 1997, p.31). The effect of pressure has received considerable attention in the area of public accounting (e.g., DeZoort and Lord, 1997; Schiltz and Syverud, 1999; Fogarty, Jagdip, Gary, and Ronald, 2000; Jones, Norman and Wier, 2010). For example, work-related pressure has been found to have a positive relation with stress perceptions of lower rank auditors including seniors and staff auditors ${ }^{1}$ (Margheim, Kelly, and Pattison, 2005).

In a review of research on the effects of pressure in accounting settings, DeZoort and Lord (1997) call for greater exploration into individual factors that may mitigate the negative effects of pressure in the accounting profession. They state that factors related to emotionfocused coping to reduce or manage emotional distress are of particular interest. In addition, a recent study by Low and Tan (2011) recognizes the adverse effects of time pressures and suggests that future research should identify strategies that allow professional accountant to better cope with time constraints. Thus, an investigation of the potential for EI to moderate these pressure effects is a direct answer to these calls for research.

\footnotetext{
${ }^{1}$ An auditor's career path typically beings with a staff auditor position, progresses to audit senior to audit manager to senior audit manager to partner.
} 
Moreover, given major changes in the auditing field (e.g., SOX, SAS No. 99) it is important to understand how to manage emotions and relationships, because emotions are essential to auditors' work (Damasio, 1994; Bhattacharjee et al., 2011). Therefore, one purpose of this study addresses a gap in the literature by investigating the effect of EI on auditor judgment under pressures.

DeZoort and Lord (1997) describe three pressure constructs that are applicable to the accounting context: organizational, environmental and role characteristics. Organizational pressures are primarily originated by forces in a firm (e.g., time budget pressure and accountability), while environmental pressures originate from forces external to the audit professional's firm (e.g., client incentive pressure and litigation). Role characteristic pressures cause role stress and influence auditor behaviors (e.g., ambiguity, conflict, and perceived environmental uncertainty).

In this dissertation, I focus on how EI influences the relations between auditor judgment and two prevalent forms of job pressures: time budget pressure and client incentive pressure. To investigate these relations, I first examine the individual and joint influence of time budget pressure and client incentive pressure on auditor judgment. It is critical for auditors to employ EI skills in their relationships with clients when conducting audits (Akers and Porter, 2003). Therefore, I also investigate the moderating effect of emotional intelligence on auditor judgments when auditors experience both forms of pressure. Thus, the research questions addressed in this dissertation are:

1. Does emotional intelligence moderate the effect of time budget pressure on auditor judgments?

2. Does emotional intelligence moderate the effect of client pressure on auditor judgments? 
3. Does emotional intelligence moderate the interactive effect of time budget pressure and client pressure on auditor judgments?

Figure 1 provides a graphical representation of the proposed model of the relations between the constructs investigated in this study.

\section{[Insert Figure 1 about here]}

To address the research questions, I conducted an experiment using two-hundred staff and senior auditors working at auditing firms in China. This participant group was selected for two important reasons. First, the current study focuses on auditors in China due to widespread concern in recent years regarding suspicious accounting practices and dysfunctional audit behaviors in China (Chow, Ho, and Mo, 2006; Firth, Mo, and Wong, 2012).Thus, this participant groups facilitates an investigation of the factors influencing such behaviors and a potential moderator that can mitigate dysfunctional auditor behavior to improve audit quality.

Second, staff accountants and audit seniors were selected as participants to provide the best match between participants and the task of interest. Less experienced auditors are more likely to interact with the lower levels of the client's management when conducting inquiries during the audit than audit managers and partners and are therefore more likely to be influenced by any pressures that may be present (Abdolmohammadi, 1999; Bennett and Hatfield, 2013; Bhattacharjee et al., 2011). Moreover, lower rank auditors are more susceptible to client pressures because they are less experienced and subject to performance evaluations that emphasize both cost control and good client relationships. Auditors' performance evaluations and compensation plans may impair auditors' objectivity when evaluating the client's reporting practices (Chang and Hwang, 2003). Prior studies document a negative relation between auditor 
experience and the influence of emotions on their judgment (Bhattacharjee and Moreno, 2002; Bhattacharjee et al., 2011).

The experimental task presents auditors with a hypothetical scenario involving a questionable accounts receivable transaction. The presence and absence of an internal pressure (time budget pressure) and an external pressure (client incentive pressure) were manipulated between participants. Participants are asked to indicate the material misstatement risk associated with this transaction and the likelihood that they will investigate further. Further, participants provide responses to a 16-item EI scale.

As hypothesized, the results reveal different judgment patterns for participants with high and low EI. Specifically, EI was found to moderate the relations between job pressures and auditor judgments. Auditors with high EI make more conservative judgments than auditors with low EI when they are exposed to job pressures. For example, participants with low EI are more likely to investigate a questionable account receivable transaction further when they experience high client incentive pressure and low time budget pressure. However, high EI participants assess higher misstatement risk and are more likely to investigate the questionable transaction further when they are exposed to both internal and external pressures at work. Therefore, these results indicate that the moderating influence of EI on auditor judgments can effectively reduce auditors' tendency to engage in dysfunctional behavior promoted by different pressures.

Furthermore, professional skepticism is found to be significantly related to the level of EI, suggesting that auditors with high EI are more skeptical and assess higher risk than auditors with low EI. In summary, moderation analysis suggests that EI is a significant mechanism which drives the joint effects of different type of pressures on auditor judgments. 
These results of this study are important for several reasons. First, prior research recognizes the impact of emotions on accounting professionals' decision-making processes. Academic researchers have raised the issue of whether EI, (the ability to recognize and manage emotions), has an impact on auditors' JDM (e.g. Nelson and Tan, 2005; Bay and McKeage, 2006; Cianci and Bierstaker, 2009; Bhattacharjee et al., 2011). Recent accounting studies argue that EI is a critical skill that allows accountants to have better job performance in decision making, teamwork and client relations (Cook et al., 2011; Daff et al., 2012). This study provides empirical evidence supporting these assertions of the importance of EI for professional accountants.

In addition, job-related pressures play a significant role in the accounting profession, and there is a need to improve our understanding of how to mitigate the ill-effects of these pressures because such pressures may lead to dysfunctional auditor behaviors and decreased audit quality (e.g., Davis, DeZoort and Kopp, 2006; Hartmann and Maas, 2010). Prior research has examined and documented how audit judgment is negatively influenced by time budget pressure (e.g., McNair, 1991; Coram, Ng, and Woodliff, 2003; 2004) and client pressure (e.g., Hackenbrack and Nelson, 1996; Moreno and Bhattacharjee, 2003). It is therefore important to understand factors mitigating the negative effects of these pressures on auditor judgments. The current study provides evidence confirming the critical role of EI in mitigating the joint effects of time budget pressure and client pressure on auditor judgments. Thus, this study provides valuable insight into a skill that can be utilized in improving auditing effectiveness. Further, these results suggest that EI training programs may be a valuable way to improve the judgments of auditors.

The rest of the paper is organized as follows: Chapter 2 discusses the background, prior literature on EI and job pressures in an audit context, and develops the hypotheses. Chapter 3 
describes the research methodology, the research instrument, and the data sources. Chapter 4 reports the results of the analyses. Chapter 5 highlights the contributions and implications of the study, and concludes with a discussion of the limitations of the study and potential topics for future research. 


\section{Chapter II}

\section{Literature Review and Hypothesis Development}

\section{Affect and Emotions}

Affect is a broad term, referring to emotions, feelings, and moods (Fiske and Taylor, 1991; Baxter and Hunton, 2011; Schultz, Schafer, and Schafer, 2011). Emotions are defined as "organized responses, crossing the boundaries of many psychological subsystems, including the physiological, cognitive, motivational, and experiential system” (Salovey and Mayer, 1990, p. 186). Moods differ from emotions, because moods are emotional states of a prolonged duration, whereas emotions are transient and more intense.

Barsade and Gibson (2007) reviewed the role of affect in organizational behavior and analyzed its impact on critical organizational outcomes such as job performance and decision making. They concluded that affect, including employees' moods and emotions, is positively correlated with important organizational outcomes such as performance, decision making, conflict resolution behavior, and leadership. Furthermore, positive affect has a relatively stronger influence on these outcomes because positive affect has a stronger relation to socially related processes. Emotional intelligence has been identified as an important mechanism that influences affect in organizations (Barsade and Gibson, 2007).

Prior studies in the accounting literature have identified the role of affect, including moods and emotions, on decision making (e.g., Chong, Monroe, and Soutar, 2004; Baxter and Hunton, 2011; Schultz, Schafer, and Schafer, 2011). Bhattacharjee and Moreno (2002) investigated the role of experience and emotional reactions in audit judgment and found that experience has an impact on negative affect during an audit judgment task. Specifically, less experienced auditors are more likely to be influenced by induced client affect. This study 
suggests EI as a factor that may mitigate the influence of affect on the judgment of accounting professionals.

Chong, Monroe, and Soutar (2004) examined the joint effects of emotional reaction and the cognitive role of occupational stress on public accountants' performance in Australia. The results from a structural equation model (SEM) demonstrate a significant negative relation between the emotional reaction to occupational stress and job performance. Their study emphasized the importance of reducing negative emotional reactions and the cognitive role of occupational stress among public accountants.

Chung, Cohen, and Monroe (2008) argued that mood is an emotional state that is generally task-irrelevant, but that emotions are generally task involved. Chung et al. (2008) tested whether different mood states influenced an auditor's decision making process. They surveyed over 100 Australian auditors and found positive-mood individuals had the lowest consensus and made the least conservative judgments of inventory valuation. Since these results indicate that mood states influence auditor judgment, the authors conclude that it is desirable to mitigate such affect in order to avoid potential bias on auditors' JDM (e.g., professional conservatism). Chung et al. (2008) call for additional research on the effects of emotion in auditrelated situations, such as during the stressful busy audit season. In response, Schafer and Schafer (2009) investigated whether two debasing mechanisms, justification (providing reasons for judgment) and self-review (careful consideration of alternative possibilities), mitigated the effects of affect and client likeability (auditor-client relationship) in a fraud judgment task. Consistent with previous studies, inexperienced auditors were found to generate biases of client preference in fraud judgment. However, by manipulating the levels of debasing mechanisms, only self-review was found to mitigate the client preference bias effectively. 
Cianci and Bierstaker (2009) found evidence that mood influences auditors' hypothesis generation and ethical judgments differentially. Specifically, a negative (versus positive) mood led to less ethical judgments and the authors explained that the mixed results of mood effect may be due to the nature of task. Furthermore, Cianci and Bierstaker (2009) acknowledged the need for auditors to manage their emotions and suggest that future research should explore ways in which auditors can be trained to manage their emotions.

Further, another study conducted by Bhattacharjee et al. (2011) tested the joint effects of interpersonal affect and source reliability on auditors' inventory judgment. Results show that interpersonal affective reactions to clients influenced lower rank auditors' judgments and induced inappropriate workpaper documentation. Bhattacharjee et al. (2011) advocated emotional competence training, because it is important for accounting professionals to understand and manage their emotions. Shawver and Clements (2012) explored the impact of emotions (regret, relief, and satisfaction) on moral judgment. They asked accountants to rate feelings of emotions and found that regret may deter unethical decisions when evaluating earnings manipulations (Shawver and Clements, 2012). Results of this study suggested that the intentional evaluation of emotions may be useful in discouraging future unethical choices.

The study of affect has broad implications to other specialties such as tax accounting. In an effort to extend our understanding of the role of affect in accounting decision making, Schultz et al.(2011) explored the influence of mood and client likeability on tax judgment. They found a positive relation between client likeability and tax judgment favorable to clients and a negative relation between mood (negative) and tax judgment (more favorable to their clients). Their results are consistent with those of Cianci and Bierstaker (2009) who found that affect influences professional judgments in an auditing setting. 
In summary, prior research provides evidence of the importance of affect and the potential for mood and emotion to influence the decision-making processes in accounting settings. However, there is scant literature exploring how to influence affect in behavioral accounting research. Emotional intelligence shows promise as a potential mitigating factor to address this issue (Barsade and Gibson, 2007). Further, recent changes in regulation and audit processes provide opportunities for the use of experiments to determine the unobserved effects that influence audit quality and to explicate the underlying reasons for these effects (Cianci and Bierstaker, 2009; Trotman, 2011).

\section{Definition of Emotional Intelligence}

Emotional intelligence has received considerable attention for over two decades in a variety of disciplines including management, organizational behavior, and psychology. In the early 1990s, Salovey and Mayer (1990) initially defined EI as "the subset of social intelligence that involves the ability to monitor one's own and others' feelings and emotions, to discriminate among them and to use this information to guide one's thinking and actions" (p. 189). EI is considered to be more important than Intelligence Quotient (IQ) in determining success in both professional and personal life (Goleman, 1995).

Later, Mayer and Salovey (1997) redefined EI as "the ability to perceive and express emotion, assimilate emotion in thought, understand and reason with emotion, and regulate emotion in the self and others" (p. 10). This conceptualization is now widely accepted (Cheriness, 2010). Based on this construction, a mental ability model of emotional intelligence was developed and presented with more psychologically integrated processes (Mayer and Salovey, 1997; Mayer et al., 2000). This model includes four components: (1) awareness of one's own and 
others' emotion; (2) emotional facilitation; (3) emotional understanding; (4) management of one's own and others' emotions.

Although there are alternative definitions of EI, many are related to the Mayer and Salovey (1997) model (Cherniss, 2010). For example, Bar-On (1997) defined EI as emotionalsocial intelligence comprised of the five key components of intrapersonal skills, interpersonal skills, adaptability, stress management, and general mood. Goleman (1995) defined EI as "selfcontrol, zeal and persistence, and the ability to motivate oneself" (p.xii). Goleman's model includes five different aspects of EI: knowing ones' emotions; management of emotions; motivating oneself; recognizing emotions in others; and handling relationships.

\section{Importance of EI on Work Behaviors}

Prior research in the fields of organizational behavior and management highlights the importance of EI as a predictor of job performance and its role in relieving job stress (e.g., Daus and Ashkanasy, 2005; Joseph and Newman, 2010; O' Boyle et al., 2010). Nikolaou and Tsaousis (2002) surveyed more than 200 health professionals and found strong relations between emotional intelligence, occupational stress, and organizational commitment. Results indicate that employees high in EI perceived lower stress and reported higher organizational commitment. In other words, individuals with high EI exhibit less stress, more organizational loyalty, and higher commitment compared to those with low EI. Medical and psychological personnel were found to have high EI and correspondingly low occupational stress. The authors concluded that this is because these professionals are trained to manage their own and other people's feelings. This training then serves as a mechanism which allows them to effectively decrease their occupational stress. 
Jordan et al. (2002) presented a two-stage model of the relation between job insecurity and workplace behavior based on the cognitive processes of emotions The authors reasoned that because job insecurity can result in increased stress and decreased performance, it is important to investigate the moderating effect of emotional intelligence on employees' perceptions of job insecurity, as well as the behavioral response to emotions. They concluded that employees with high EI are likely able to "recognize and to cope proactively with the emotional consequences of job insecurity, especially job-related tension" (p. 370).

To investigate the relations among employees' emotional intelligence, job satisfaction, and performance, 187 service employees from a restaurant franchise participated in a study by Sy, et al. (2006). Results confirmed the predicted hypotheses that employees' EI was positively related to both job satisfaction and job performance after controlling for personality factors. This study supports prior research by finding that employees' with higher EI have higher job satisfaction because they are better able to identify and regulate their emotions (Wong and Law, 2002).

Rode et al. (2007) tested the direct and moderated effects of EI on individual performance by surveying over 300 business undergraduate students. After controlling for general mental ability and personality, EI was found to explain incremental variance on students' public speaking effectiveness. Moreover, this study concluded that the interaction of EI and conscientiousness (one proxy for trait motivation) has a positive effect on academic performance. That is, individuals with high EI and high conscientiousness will be more likely to use their strong EI abilities because they are motivated to do so.

Guleryuz et al. (2008) examined the effect of EI on job satisfaction and organizational commitment. They collected 267 questionnaires from healthcare organizations and used SEM to 
test the relations between these three variables. Results demonstrated that EI was significantly and positively related to job satisfaction and organizational commitment.

Because EI has been documented as a predictor in major domains, including job performance, academic performance, emotional labor, trust, work-family conflict and stress, O’ Boyle et al. (2010) explored how EI is related to job performance in a manner not explained by personality traits and cognitive ability. The results from this meta-analysis of over 1,000 cited studies indicated that EI is significantly positively associated with work-related outcomes and is an important predictor of job performance.

Daus and Ashkanasy (2005) argued that jobs involving interaction with customers require employees having emotional skills and abilities_-both in one's self and in dealing with others. Thus, auditing is a job with strong emotional intelligence implications, because auditors constantly interact with client management during audit process (Nelson and Tan 2005). These interactions are critical not only to the successful completion of the current audit engagement, but also have implications for future engagements. For example, auditors have incentives to retain large clients (Chen, Sun, and $\mathrm{Wu}, 2010$ ) and to explore potential business opportunities with current clients (Moreno and Bhattacharjee, 2003).

Collectively, research indicates that EI is critical for effective job performance and that it can ameliorate negative stress outcomes (Daus and Ashkanasy, 2005). Indeed, awareness of EI (identifying and expressing emotions) has been found to facilitate employees' ability to cope with occupational stressors (Jordan et al., 2002; Nikolaou and Tsaousis, 2002).

Prior research indicates that it is important to identify factors that mitigate the negative effects of various forms of pressure in accounting. One important variable that can manage or reduce emotional pressure is emotion-focused coping (DeZoort and Lord, 1997; DeZoort, 1998). 
The importance of EI is also recognized by the American Institute of Certified Public Accountants (AICPA) and the Institute of Management Accountants (IMA), as "emotional intelligence skills are critical for the success of the accounting profession" (Akers and Porter, 2003, p. 65). Further, Bay and McKeage (2006) argued that the effects of EI on job performance are important to accounting practitioners for two reasons. First, since EI has a positive impact on job performance, it is rational to conclude that there is a link between EI and auditor decision making. Second, EI related programs could improve hiring and training processes in the accounting field.

Recently, Cook et al. (2011) examined the role of accounting education and work experience on EI. They surveyed more than four hundreds accounting and liberal arts students. The results suggest that work experience has a positive relation with the score of EI. However, current higher education does not necessarily increase students' EI level. Another study by Daff et al. (2012) also addressed the need for accountants to have both the generic skills and EI, as the importance of EI skills on job performance (e.g. decision making, client relation, leadership) has been recognized in public accounting (PricewaterhouseCoopers,2011). EI skill enables accountants to perform better in terms of dealing with their own emotions and others' emotions. Thus, this study examines the potential moderating role of EI on the relation between pressure and auditor judgment.

\section{Pressure}

There is a significant body of evidence suggesting that audit pressures can lead to dysfunctional behavior. According to DeZoort and Lord (1997), pressures serve as antecedents to stress responses within individuals and influence outcomes by providing situational incentives 
for a specific judgment or decision. Thus, pressure has been viewed as a major dimension of occupational stress (Vagg and Spielberger, 1998; Larson, 2004).

Work-related pressure has been found to have a positive relation with stress perceptions of lower rank auditors including seniors and staff (Margheim et al., 2005). Furthermore, contextual factors, such as the impact of time pressure on auditors' judgment, make public accounting an appropriate setting to evaluate the impact of pressure on JDM (Gibbins, 2001). This study investigates the effects of two types of pressure: time budget pressure and client incentive pressure.

\section{Time Budget Pressure}

Studies of auditors in American, Australian and European contexts indicate that the presence of time budget pressure (unattainable/unreasonable time budgets or deadlines) results in ethical dilemmas which significantly impair audit quality (McNair, 1991; Buchheit, Pasewark, and Strawser, 2003; Coram et al., 2003; 2004; Arnold, Bernardi, and Neidermeyer, 2009). Time budget pressure is defined as "a chronic, pervasive type of pressure that arises from limitations on the resources allocable to perform a task" (DeZoort and Lord, 1997, p.53). It occurs when auditors are assigned limited hours to complete audit procedures. Kelley and Margheim (1990) investigated factors that influence dysfunctional auditor behavior. Results indicate that time budget pressure leads to dysfunctional auditor behaviors (e.g., accepting weak client explanations, premature sign-off on audit steps, underreporting of time actually spent performing audit procedures). According to McNair (1991), time budget pressure can also undermine auditors' control environment. Moreover, time pressure is not only a critical factor that influences the results of auditors' JDM in experimental research, but it is also an important variable in actual audit engagements (Choo and Firth, 1998). 
Braun (2000) addressed the role of time budget pressure in fraud detection. This study revealed that auditors may not pay adequate attention to qualitative aspects of misstatements when subjected to time budget pressures. This finding supports the Treadway Commission's admonition regarding the negative effect of time budget pressure. The negative effect of unreasonable time constraints may also be related to professional skepticism, as auditors who are faced with a high pressure situation may overlook critical audit evidence and fail to keep a questioning mind (Braun, 2000, p.255). Accordingly, lower levels of professional skepticism may lead to dysfunctional audit behaviors and harm audit quality as a consequence.

Using a sample of Australian auditors, Coram et al. (2003) conducted an experiment and found that more than $90 \%$ of participants felt more pressure when there is more work to do than there is time budgeted to do it. Participants also admitted to accepting doubtful audit evidence in order to speed audit testing under time budget pressure. The use of such questionable methods decreases audit quality. In a subsequent study, Coram et al. (2004) investigated the impact of time budget pressure and risk of misstatement on auditors' propensity to commit reduced audit quality acts (RAQs) in the US. Results indicate that auditors accept doubtful audit evidence under high time budget pressure and fail to test all items in a selected sample when the level of misstatement risk is low. Thus, time budget pressure is negatively related to audit effectiveness.

Since audit effectiveness suffers under time constraints, Margheim et al. (2005) employed a case method to investigate the impact of different types of time pressure, (time budget pressure and time deadline pressure), on auditor behavior. Time budget pressure arises when restricted time resources are given to complete specified audit procedures, while time deadline pressure arises from the requirement for task completion by a specific point in time (DeZoort and Lord, 1997). Time budget pressure is found to induce a wider range of 
dysfunctional behaviors than time deadline pressure, because it significantly increases auditors' perceptions of stress (Margheim et al., 2005).

Similarly, Gundry, and Liyanarachchi (2007) used auditor data from New Zealand to analyze the relation between time budget pressure and RAQs. The authors found a negative relation between time budget pressure and one RAQ - premature auditor sign-off. They also concluded that auditors under high time budget pressure may sign off on audit steps with incomplete work or omitted procedures. Interestingly, the results also indicate a significant relation between Type-A personality type and RAQs. For example, when Type-A individuals are under pressure, they may be more likely to engage in dysfunctional behavior because the Type-A behavior pattern is associated with certain attributes, including being aggressive, ambitious, competitive, impatient, and experiencing higher levels of stress (Gundry and Liyanarachchi, 2007).

Prior research indicates that time budget pressure is an important factor affecting auditors' behavior in both developed and developing countries, since meeting time budgets is a critical element of auditors' performance evaluations (Shapeero, Koh , and Killough, 2003). In other words, time budget pressure may induce auditors' underreporting behavior, which undermines firms' employee performance evaluations. For example, Soobaroyen and Chengabroyan (2006) argued that there are differences in the extent and impact of time budget pressures among auditors in less developed countries. Based on a sample of auditors from Mauritius, they examined whether perceptions of time budget pressure influenced dysfunctional behaviors of auditors. The findings were consistent with studies in an Australian context which indicate that time budget pressure is significantly related to premature sign-offs (Coram et al., 2003). This 
issue deserves local policy makers' attention, because premature sign-offs diminish audit quality (Soobaroyen and Chengabroyan, 2006, p. 215).

Recently, Paino, Ismail and Smith (2010) conducted a survey to identify the key variables leading to RAQs among Malaysian auditors. Results showed that time budget pressures lead lower rank auditors to engage in dysfunctional behavior. Moreover, Malaysian auditor participants indicated a higher level of time budget attainability than US and Irish counterparts (Kelley and Seiler, 1982; Otley and Pierce,1996; Paino et al., 2010).

Time budget pressure is also of particular interest in China. For example, Liu and Zhang (2008) conducted an experiment to investigate the effects of time pressure and accountability on audit judgment performance finding a negative relation between audit effectiveness and time pressure. They argued that time pressure in an auditing context is becoming an increasingly important environmental factor in China warranting more research. Considering the convergence of auditing standards, it is of interest to reevaluate the negative effects of time budget pressure. Further, prior research reviewed opportunities for audit judgment research in China and one potential research question is the influence of time pressure and incentives on auditor judgment (Simunic and Wu, 2009; Trotman, 1999).

Because prior studies (e.g., Coram et al., 2003; 2004) have demonstrated that time budget pressure results in less conservative judgments, and that these quality-threatening effects compromise audit quality, my first hypothesis is:

\section{H1: Auditors will make more conservative judgments when they experience less time pressure.}

\section{Client Pressure}

An important environmental issue in an auditing context is client pressure, which refers to "the pressure to yield or the perceived pressure to yield to a client's wishes or influence, 
whether appropriate or not" (DeZoort and Lord, 1997, p.47). Prior research raises issues regarding pressures arising from auditors' conflicting incentives and acceptance of clients' aggressive financial reporting behaviors. The resulting dysfunctional behavior could impair audit quality because of biased judgment. For example, Hakenbrack and Nelson (1996) found that lower rank auditors may allow clients to use aggressive reporting methods in moderate engagement-risk situations when imprecise language is used in financial accounting standards.

Houston (1999) examined the joint effects of two environmental pressures (fee pressure and client risk) on audit seniors' JDM. The analysis reveals that auditors make time budget decisions subject to environmental pressures. That is, auditors' decisions were less responsive to increased client risk, and auditors planned fewer audit procedures if fee pressure was present. Accordingly, the study raised the concern of whether pressures that influence auditors' budget hours would also bias their risk assessment.

Chang and Hwang (2003) conducted a survey of fifty-five audit seniors and managers from Big 5 firms and found that an auditor might be willing to accept a client's aggressive reporting behaviors if retention incentives were high, and if there was less concern for client business risks. Similarly, Kadous, Kennedy, and Peecher (2003) predicted the influence of auditors' directional goals (preference of decision) on their acceptance decisions of clientpreferred accounting methods. Their results support the hypotheses that auditors with high commitment to directional goals will accept the method preferred by the client.

Another study by Moreno and Bhattacharjee (2003) investigated whether auditors' judgments were influenced by pressure from a potential client's additional business opportunities. Generating additional services for clients is very important to performance evaluations and the socialization process of lower rank auditors. Their results indicated that lower rank auditors may 
support a client's preferences in order to maintain a good relationship with the client and explore potential business opportunities. Accordingly, performance evaluations and the socialization process can play an important role in auditor behaviors that reduce audit quality (Moreno and Bhattacharjee, 2003). Thus, the pressure to not disappoint clients can negatively influence an auditors' judgment (Nelson, 2006). Future research should investigate how auditors can manage client pressure to maintain their independence.

Consistent with prior research, Cianci and Bierstaker (2009) claimed that auditors' ethical judgments are influenced by client pressure in spite of legislation intended to enhance audit quality. Sharma, Sharma, and Ananthanarayanan (2011) examined the relation between client importance and earnings management by inspecting data from the New Zealand Stock Exchange. The empirical evidence confirms a positive relation between the two variables, thus supporting previous experimental studies that showed that the economic importance of a client has a negative effect on audit quality (Sharma et al., 2011).

Recently, Hatfield, Jackson, and Vandervelde (2011) investigated the effect of client pressure on auditor judgment following the enactment of the Sarbanes-Oxley Act of 2002 (SOX). Their results provided evidence that client pressure significantly reduces the magnitude of proposed audit adjustments. That is, auditors subjected to high levels of client pressure propose significantly smaller audit adjustments than the auditors subjected to low levels of client pressure. Thus, Hatfield et al. (2011) concluded that client pressure still has a meaningful influence on auditor judgments in the post-SOX audit environment.

Since client pressures have been shown to impair audit quality, Asare, Cianci, and Tsakumis (2009) investigated the mediating effect of litigation consciousness and experience on the effect of client relations pressure on auditors' judgment. The findings show that less 
experienced auditors are more influenced by client goals. Furthermore, the results indicate that auditors' litigation consciousness is a significant mechanism that mediates the joint effect of client oriented goals and experience on auditors' judgment. Also, litigation concerns lead auditors to be more objective and skeptical (Johnstone, 2000). In other words, auditors' litigation risks help balance the tradeoff between experience and client relations, which leads to significantly more conservative judgments. This study calls for additional research on the other individual level factors that may reduce auditors' vulnerability to clients' pressures and explain the causes of auditors' biased judgments. Research of these mediation factors contribute to the improvement of auditors' judgment by encouraging the development of more efficient audit procedures, decision aids, and training programs.

Overall, previous research indicates that client-based incentives and pressures can compromise auditor judgment. Lower rank auditors are especially susceptible to client pressures because they are less experienced and subject to performance evaluations that emphasize both cost control and a good relationship with the client. In addition, Chinese auditors are more likely to perceive client pressure in conflict situations than their counterparts from the UK when facing a high degree of audit market competition (Lin and Fraser, 2008). Therefore, based on the preceding arguments, my second hypothesis is:

\section{H2a: Auditors will make more conservative judgments when the client has low incentives to influence the auditor.}

However, prior research has shown that auditors should exercise a high degree of professional skepticism when evaluating the likelihood of material misstatement, especially if clients' monetary incentives are based on financial results (Hirst, 1994). According to source credibility theory, an increase of a source's (i.e. client's) incentive should decrease their 
credibility (Birnbaum and Stegner 1979). Source bias is one component influencing the credibility of an information source (DeZoort, Hermanson, and Houston, 2003).

Robertson (2010) argued that clients' credibility decreases if they have personal and/or corporate incentives to influence the auditor. His study investigated whether auditors would be more likely to comply with client requests when the client has low rather than high incentive to influence the auditor. Results show that auditors were more likely to propose adjustments when the client has high incentive to influence the auditor indicating that client incentives were associated with greater auditor conservatism.

Consequently, a client's incentive to manage earnings may lead auditors to be more skeptical and collect more evidence on clients' reporting. Thus, as the client's incentive increases, auditors may be more likely to make conservative judgments. In my setting, this is a direct contradiction with the prediction offered in H2a. Thus, I propose the following competing hypothesis:

\section{H2b: Auditors will make less conservative judgments when the client has low incentive to influence the auditor.}

Further, I expect an interaction between time budget pressure and client incentive pressure. Litigation risk leads auditors to increase their objectivity and skepticism when the client has incentive to influence auditors. In other words, client incentive pressure may cause auditors to exhibit greater professional skepticism and make more conservative judgments, regardless the tightness of the time budget. As a result, I expect auditors subject to client incentive pressure to spend the additional time and effort necessary to make the more conservative judgment, even when they are subject to time budget pressure. Thus, I hypothesize 
that auditors will be influenced by time budget pressure to a greater extent when client incentive pressure is absent than when client incentive pressure is present. Stated formally:

H3: Auditor judgment will be influenced by time budget pressure to a greater extent when client incentive pressure is absent than when client incentive pressure is present.

\section{Auditors' JDM in China}

As Chinese capital markets continue to develop and mature, a concurrent development and maturation of a high quality system of attestation is imperative. This is especially true given the inadequate legal environment and system of inefficient corporate governance prevalent in China (Firth, Mo, and Wong, 2005; Lin, Liu, and Wang, 2009). High audit quality could help ensure the implementation of an effective principals-based accounting system in order to protect the interests of individual investors in China.

In a survey of experienced auditors in China, Chow et al. (2006) identified different pressures and factors that influenced auditors' risk assessment. Many of the pressures identified were consistent with research from developed economies, such as clients' incentives to manage earnings (e.g., management being under unusual pressures to meet profitability targets), the existence of complex transactions that are difficult to audit, and weak corporate governance (Chow et al., 2006).

Since the institutional environment for investor protection is weaker in China than in developed countries, Chen et al. (2010) examined whether the impact of client economic importance on audit quality changed from 1995 to 2004, a period in which the institutional environment became more investor-friendly. However, they found that the correlation between client importance and the propensity to issue modified audit opinions (MAOs) that was significant prior to 2001 was no longer significant after that date. This result suggests that 
individual auditors became more conservative and more likely to issue MAOs to large clients because of an improved legal and regulatory environment.

China started the convergence process with ISA in 2005. These standards are intended to enhance audit quality and public confidence in the global auditing and assurance profession. China completed the convergence process in 2010 with some exceptions not covered by international standards. Haw (2008) calls for research regarding how new auditing standards influence the quality of auditing in China. Thus, it is of interest to investigate whether the dysfunctional audit behaviors (e.g., premature sign-offs) exist and whether audit quality is affected by pressure after the full convergence of ISA.

In a study of EI and counterproductive behavior in China, Deshpande and Joesph (2005) found that participants with high EI were better corporate citizens and that EI is a good predictor of job performance. Specifically, employees with high EI had a positive impact on the workgroup, better understood others' emotions, and worked well with others. Due to the importance of EI in the workplace, the authors suggest that Chinese firms provide training to raise employees' EI. Their study recognizes the importance of EI in the workplace and suggests Chinese firms to provide training to raise employees' EI, which can create a competitive advantage for firms (Deshpande and Joesph, 2005).

In summary, prior research has consistently demonstrated a positive association between EI and job performance. Thus, it is logical to assume that EI will reduce auditors' tendency to engage in dysfunctional behavior promoted by pressure, such as accepting weak client explanations, resulting in improved audit quality. Based on the preceding arguments, hypotheses 3 through 5 are:

H4: Auditors with high EI will make more conservative judgments than auditors with low EI when they are exposed to time budget pressure. 


\section{H5: Auditors with high EI will make more conservative judgments than auditors with low EI when they are exposed to client incentive pressure.}

\section{H6: Auditors with high EI will make more conservative judgments than auditors with low EI when they are exposed to both time budget and client incentive pressure.}

\section{Professional Skepticism}

Professional skepticism (PS) is an important concept in audit practice which has been defined as "an attitude that includes a questioning mind and a critical assessment of audit evidence" (AICPA, 1998, AU230.7). A questioning mind is required in the definitions of PS in both Statements Auditing Standards (SAS) Nos. 82 and 99 in the US (AICPA, 1997, 2002) and international standards (ISA, 240.24). More specifically, for auditing standards in the U.S. and China due professional care requires auditors to exercise professional skepticism based on available evidence without being influenced by the client (PCAOB, 2006; Chinese CPA Standards on Auditing, 2006). Prior studies have argued that professional skepticism is critical to mitigate aggressive reporting by management (Kadous, 2000).

Hurtt (2010) pointed out that understanding people's motivations and behaviors is an important component of skepticism. However, it is difficult to detect individuals' motivations and perceptions when they have incentives to provide biased and misleading information. The skeptic can help to recognize the potential for biased judgment, because "the skeptical auditor is less influenced by the beliefs or persuasion attempts of others" (Hurtt, 2010, p.155).

Chung, Cohen, and Monroe (2005) argued that moods are expected to have a significant effect on professional skepticism. Their experiment with 102 audit professionals supported the hypothesis that mood states influence professional skepticism. They found that positive-mood individuals were likely to be less skeptical than neutral and negative-mood individuals by demonstrating that positive-mood individuals made the least conservative valuation of inventory. 
Nelson (2009) noted that auditors with high PS are more likely to question evidence of a truthful assertion and tend to gather more evidence on the assertion.

Time pressure can influence PS by judgment processes (Nelson, 2009). For example, Braun (2000) found that PS may be associated with the negative effect of time pressure because auditors who are faced with high pressure situations may fail to keep a questioning mind (Braun, 2000, p.255). Accordingly, a decline in professional skepticism may lead to dysfunctional audit behaviors and harm audit quality as a consequence. Therefore, professional skepticism is included in this study as a control variable. 


\section{Chapter III}

\section{Research Methodology}

\section{Experimental Design}

This study adopts a 2 x 2 between-subjects experimental design. Independent variables include time budget pressure (low vs. high) and client incentive pressure (low vs. high). Participants are randomly assigned to one of the four conditions. The participants were provided with general study instructions and a research instrument (case materials). Additionally, participants were asked to complete both the EI scale from Jordan and Lawrence (2009) (16 items) and the Hurtt (2010) Professional Skepticism Scale (5 items). At the end of experiment, manipulation check questions were asked and demographic information were gathered. A complete text of the survey instrument is provided in Appendix A.

Experimental research has an advantage over archival research in capturing natural settings and measuring intervening variables in order to draw strong and reliable causal inferences (Libby, Bloomfield, and Nelson, 2002). It affords the opportunity to examine how, when, and why important features of the manipulated variables can influence an individual's behavior (Trotman, 2011). More specifically, Solomon and Trotman (2003, p.396) indicated that "experimental research is the most powerful method to study auditors' judgments decisions."

\section{The Task}

The research instrument of this study is based on instruments used in prior studies of time budget pressure (Coram et al., 2004; Gundry and Liyanarachchi, 2007) and client incentive pressure (Robertson, 2010). The instrument consists of two parts. Part 1 provides background information about the client including general information, financial position, and a summary of key financial data. This information is the same for all versions of the instrument. 
The experimental case introduces information about Taylor, a staff auditor assigned to work on an audit of GTL, a technology based client for Taylor's audit firm. The case states that Taylor's firm has audited this client for three years and has always given standard, unqualified opinions for both its financial statements and internal controls. In addition, the case mentions that this is Taylor's first time working on the audit of GTL. Taylor has been asked to perform substantive testing for the accounts receivable audit.

The next part of the case contains a discussion of the time budget for the audit and client incentive manipulations. It indicates that when Taylor is testing a transaction, he finds one sale that does not have a sales report. The accounts receivable in question involves one of GTL's electronic product sales, which is a total of $\$ 1,200,000$ (i.e., 6 cents of EPS). However, there is no sales report documenting this sale. When Taylor approaches GTL's management about this problem, he is told the documents have been misplaced but management can vouch for the fact that the documents have been correctly recorded. To verify this, Taylor would have to contact an overseas customer. Taylor knows contacting this customer would take a considerable amount of time.

\section{The Dependent and Independent Variables}

Similar to Coram et al. (2004) and Robertson (2010), participants were asked to indicate the likelihood that Taylor will spend additional effort to further investigate the questionable accounts receivable transaction. Participants' judgments are measured on a scale from 1 to 7 , where $1=$ extremely unlikely and $7=$ extremely likely. As a second dependent variable, they assessed the level of material misstatement risk they think the auditor will associate with the transaction. They reported the risk on a scale from 1 to 7 , where $1=$ extremely low risk, and $7=$ extremely high risk. In addition, participants were asked to indicate the likelihood that Taylor 
will accept the client's explanation and not investigate the matter further as additional dependent variables.

\section{Independent Variable - Time Budget Pressure}

The level of time budget pressure variable is manipulated by describing characteristics of the audit resulting in "high time budget pressure" or "low time budget pressure" (Coram et al., 2004; Gundry and Liyanarachchi, 2007). In the high time budget pressure condition, the client renegotiated audit fees and the audit partner decided to reduce the audit fees and budgeted hours. As a result, the total audit budgeted hours are cut by approximately $20 \%$. Moreover, the high time budget pressure case states that the auditor, Taylor, has reached the end of his time budget for this section of the audit, and that he is meeting the manager in charge of the audit to finalize this section. To verify the accounts receivable transaction in question, Taylor would have to ask the manager for more time. Taylor knows that the manager has denied extensions of time in other areas of the audit due to time budget constraints.

In the low time budget pressure condition, the audit partner in charge decided to charge the same audit fee as last year (i.e., the audit fee will not increase or decrease this year), and he has allocated the same amount of hours to the audit that were budgeted last year. In previous years, the time budget has been reasonable for the amount of work involved, and the same amount of work is expected this year. Further, the low time budget case states that Taylor is meeting the manager in charge of the audit to discuss this accounts receivable section of the audit. Taylor may have to ask the manager for more time to verify the transaction. Taylor knows that the manager has granted extensions of time in other areas of the audit as the time budget is relatively flexible. 


\section{Independent Variable - Client Incentive Pressure}

Consistent with Roberson (2010), client incentive pressure is manipulated at low and high levels by using both a corporate (meeting the EPS forecast) and personal (receiving a bonus) incentive. In the case, the client executives' bonus is dependent on whether the company meets or exceeds its EPS forecast. In the high incentive pressure condition, if the receivable in question is written off, then the company will miss its EPS forecast and the client's executives will not receive a bonus. In the low incentive pressure condition, the company will still meet its EPS forecast and the executives will receive a bonus even if the accounting receivable in question is written off.

\section{Moderating Measured Variable - EI}

EI was measured using the 16-item version of the Workgroup Emotional Intelligence Profile (WEIP) scale (Jordan and Lawrence, 2009). Many measures of EI have been used in management and organizational behavior research (e.g., Jordan and Lawrence, 2009; Cherniss, 2010). For example, based on the framework from Mayer and Salovey (1997), the MultiFactorial Emotional Intelligence Scale (MEIS) is an ability test used to measure EI by evaluation of actual performance on multiple tasks (Mayer et al., 2000; Cherniss, 2010). However, questions regarding the validity and reliability of this measure have been raised due to its correlation with some personality measures (Davies, Stankov. and Roberts, 1998). A second measure of EI is Bar-On's Emotional Quotient Inventory (EQ-i), which is a self-reported measure of emotionally and socially intelligent behavior (Bar-On, 2006). However, some argue that the EQ-i examines overall psychological well-being, rather than EI (Jordan et al., 2002).

One potential issue for EI measurements is the assumption that EI remains constant across situations. The WEIP is based on the framework developed by Mayer and Salovey (1997). 
The self-reported measure consists of 2 subscales: the ability to deal with one's own emotions, and the ability to deal with others' emotions. The WEIP has been shown to have convergent validity by examining the correlations between the WEIP and other existing measures. Specifically, the WEIP is positively correlated with the acquisitive self-monitoring scale and two subcomponents of the Trait Meta-Mood Scale (clarity of moods, repair of moods), and negatively correlated with the personal distress scale (Jordan et al., 2002). Furthermore, the WEIP has been found to be an appropriate self-reported measure as it incrementally predicts job performance above and beyond over cognitive ability and personality traits (O'Boyle et al., 2010). Moreover, the WEIP has lower correlations with cognitive ability and personality traits than other EI measures. It is for these reasons that I chose to use Jordan's measure of EI, the WEIP, in my study.

Jordan and Lawrence (2009) designed a 16-item short-version of the WEIP. This version measures four distinct components of EI: awareness of one's own emotions, management of one's emotions, awareness of others' emotions, and management of others' emotions (see Figure 2). The reported Cronbach's alpha coefficients for these dimensions are $0.85,0.77,0.81$, and 0.81 , respectively. This short version of WEIP is used in the current study to measure auditors' EI. Some examples of EI items include: "I can explain the emotions I feel to team members," and "I respect the opinion of team members, even if I think they are wrong."

To identify the level of EI for each participant in this study, I used the median scores of EI as cut-off points, which is a common method used in previous studies (Angelisdis and Ibrahim, 2011; Marques and Azevedo-Perira, 2012). Participants who scored above the median were classified as "high" EI. Those scoring below the median were classified as "low" EI.

[Insert Figure 2 about here] 


\section{Control Variables: Professional Skepticism and Years of Experience}

Based on Hurtt (2010) and Robertson (2010), the professional skepticism scale (PS) includes the following five items: "I often question things that clients tell me," "I require proof that my clients' statements are true," "I am cautious when evaluating information obtained from clients," "Clients are generally honest (reverse item)," and "I tend to trust what clients tell me (reverse item)." The PS items are measured on seven-point Likert-type scales ranging from $1=$ strongly disagree to $7=$ strongly agree. The PS score is the mean of these five items with a higher score indicating greater skepticism. Robertson (2010) reports a Cronbach's alpha for PS as 0.64 .

Auditors' years of experience is also included as a control variable, because prior research has shown auditor judgment is influenced by the extent of the auditors' professional experience (Asare et al., 2009). That is, more experienced auditors are more aware of litigation risk and less likely to be affected by client pressure. Moreover, there is a negative relation between auditor experience and the influence of emotions on their judgment (Bhattacharjee and Moreno, 2002; Bhattacharjee et al., 2011). Although all participants in this study are lower rank auditors, there may be differences between participants based solely on experience. Hence, I include years of experience as a control variable.

\section{Manipulation Checks}

After several questions related to the dependent variables, two manipulation check questions were provided to ensure that the participants had attended to the details of the case. First, a client incentive manipulation question is asked. This question asks participants to indicate the impact of writing off the entire accounts receivable in question on the ability of the client to meet the consensus analysts' EPS forecast. Participants can select either "exceed" or "miss" the analyst forecast. A second manipulation check question concerns the level of time 
budget pressure in the case. Participants indicated whether or not the audit partner decided to cut the total audit budget hours by approximately $20 \%$.

In addition, participants were asked several questions about the case. For example, participants assessed the incentive of client management to misstate the sale on a seven-point Likert-type scale ranging from $1=$ extremely low to $7=$ extremely high. Participants were also asked to indicate the overall level of stress that Taylor experienced in this case on a scale of 1 to 7.

\section{Pilot Testing and Translation}

\section{Initial pilot testing}

The instrument was reviewed by a former Big-4 auditor to determine whether the case scenario was realistic. To ascertain the clarity of the instrument and to provide preliminary evidence of the effectiveness of the experimental manipulations, pilot tests were conducted with senior-level auditing students from a large state university in the eastern United States. Because of the timing of the experiment (end of the semester), it is believed that these senior-level auditing students should possess adequate auditing knowledge to complete the experiment and be reasonable surrogates for lower level auditors. In addition, prior research indicates that students are likely to be good surrogates for 'real-world' individuals with respect to decision-making behaviors (Libby et al., 2002; Liyanarachchi and Milne, 2005; Liyanarachchi, 2007). For example, Ashton and Kramer (1980, p. 11) investigated the decision-making judgment of both auditors and accounting students, and found that "students were adequate surrogates for the auditors." Similarly, Norman (1998) reports that both accounting students and internal auditors provide similar opinions when asked to assess fraudulent behavior.

Initial pilot tests results were analyzed to determine whether the independent variables, as manipulated in the instrument, were understandable. The results indicated participant confusion 
regarding the client incentive pressure manipulation. Finally, the instrument was revised and the manipulation was reworded.

\section{Translation}

The back-translation method was used for translating the revised experimental instrument into Mandarin Chinese. An English version of the instrument was independently translated into Chinese by two bi-lingual Chinese individuals who obtained Ph.D. degrees in the United States. After minor differences were resolved, the resulting Chinese version of the instrument was translated back into English by a bi-lingual Chinese professor who teaches English at a university in China. The back-translated English version was compared to the pre-translation English version to ensure that no inconsistencies occurred from the translation process.

\section{Secondary pilot testing}

After translating the revised instrument, a second pilot test was conducted with seventy senior accounting students in China. These participants had just completed an auditing course and were working at accounting firms as interns. The purpose of this second pilot test was to examine the clarity of the translated instrument and revised manipulation of client incentive pressures.

The results from the second pilot test indicated that the instrument and the manipulated variable were clearly understood by participants. Only five students failed the manipulation check questions. Further, the pilot test indicated that the independent variable manipulations significantly impacted participants' responses to the dependent variables. Specifically, there was

a significant difference in the mean reported likelihood of further investigation between low and high time budget pressure $(p=0.02)$. In addition, the mean reported likelihood of further investigation was significantly higher under high client incentive pressure than under low client 
incentive pressure (Mean= 4.0 vs. $2.9, t=-3.65, p=0.001)$. Finally, the pilot test results indicated a significant interaction between the two independent variables. Thus, the results from pilot testing indicated effective manipulations of the two independent variables and provided preliminary results consistent with the hypothesized responses.

\section{Data Collection}

The final instrument was distributed to lower rank auditors (staff accountants and audit seniors) in eastern China. There are two reasons this study focuses on staff and senior auditors. First, staff and seniors have less experience than more senior auditors, such as managers and partners. Bhattacharjee and Moreno (2002) and Bhattacharjee et al. (2011) report a negative relation between auditor experience and the influence of emotions on audit judgment. Second, lower rank auditors are responsible for the actual audit fieldwork, which is important to the audit process and provides the foundation for the audit opinion (Stefaniak and Robertson, 2010). 


\section{Chapter IV}

\section{Results}

\section{Participants}

Two-hundred auditors employed at auditing firms in China participated in the study. Ten respondents either failed the manipulation checks or did not complete the experiment, resulting in a final sample of 190 auditors. Eighty-four percent of the retained participants are employed by Big-4 firms and 16 percent are employees of national accounting firms in China.

\section{Demographic Information}

Of the 190 participants included in the analyses, 52.6 percent are female and the mean age is 26 years. All participants report completion of either 4-year undergraduate or masters degrees. Participants' mean professional experience is 2.41 years (range 1 to 5 years) and the mean tenure with their current organization is 2.21 years. Half of the participants (50 percent) are audit seniors and half are audit staff. In addition, the majority of the participants (77 percent) are certified by the Chinese Institute of Certified Public Accountants (CICPAs), and eight individuals hold other accounting professional certifications in China. Participants indicated that time budgets are attainable with effort in their organizations (mean response of 5.41 out of a 7point scale) and that it is very important for them to meet these time budgets (mean response of 5.62, range from 5 to 7). Finally, participants indicated a high level of job stress in their organizations (mean response of 5.41 out of a 7-point scale). Table 1 presents participants' demographic data.

[Insert Table 1 about here] 


\section{Manipulation Checks}

Of the 200 participants, 190 passed both the time budget pressure and the incentive manipulation checks. Participants who either failed at least one manipulation check or did not complete the entire instrument were eliminated for the purposes of the main statistical tests. Specifically, seven and three participants provided incorrect responses to the client incentive pressure and time budget pressure manipulation checks, respectively.

Another way of checking the effectiveness of the time budget pressure manipulation is to ask the level of time budget pressure that Taylor experienced in the case. Participants correctly indicated a higher mean pressure in the high time budget pressure treatment $($ Mean $=5.51, \mathrm{SD}=$ 0.92) than in the low pressure treatment $($ Mean $=3.03, \mathrm{SD}=0.83 ; t=19.40, p \leq 0.001)$. Thus, the manipulation successfully induced perceptions of time budget pressure. Also, participants reported a mean client pressure level of 5.31(SD = 1.19) in the high client incentive pressure treatment and $4.17(\mathrm{SD}=1.27)$ in the low client pressure treatment $(t=6.36, p \leq 0.001)$ indicating an effective manipulation of client incentive pressure.

\section{Descriptive Statistics}

\section{Dependent and independent variables}

Panel A of Table 2 presents the descriptive statistics of the likelihood of further investigation of the questionable transaction. Across treatments, the mean level of further investigation was 4.02 , where 4 equals "neutral" on the scale of response options. Thus, auditors indicated a neutral likelihood of spending additional time and effort to investigate accounts receivable further. In contrast to $\mathrm{H} 1$, a lower mean likelihood of further investigation was reported by the low time budget pressure treatment group $($ Mean $=3.51, \mathrm{SD}=1.225)$ than by the high time pressure treatment group $($ Mean $=4.44, \mathrm{SD}=1.538 ; t=11.359, p \leq 0.001)$. However, 
these results must be interpreted with caution due to the significant interactions described below (Figures 9 \& 10). As predicted by $\mathrm{H} 2 \mathrm{~b}$, the likelihood of additional investigation is higher under high client incentive condition (Mean $=4.54, \mathrm{SD}=1.53$ ) than under the low client incentive condition $($ Mean $=3.27, \mathrm{SD}=1.002 ; t=31.72, p \leq 0.001)$.

Panel B of Table 2 presents the descriptive statistics of the perceived level of risk associated with this transaction. The mean level of risk was 4.27 across treatments, where 1equals "low risk" and 5 equals "high risk" on the scale of response options. Thus, participants felt that there was a moderate level of material misstatement risk associated with the questionable account receivable transaction. The assessed risk level was higher under the high time budget pressure treatment than under the low time budget pressure treatment $($ Mean $=4.74$ vs. 3.70, $t=18.44, p \leq 0.001)$. Similar results are found in client incentive treatment. The risk assessment is significantly higher when participants experienced high client incentive pressure than when participants experienced low client incentive pressure (Mean $=4.87$ vs. $3.41 ; t$ $=25.276, p \leq 0.001)$ providing initial support of $\mathrm{H} 2 \mathrm{~b}$.

[Insert Table 2 about here]

\section{EI and PS measures}

Overall, the mean EI score was 63.2 and the median was 55.5 (total score equals 112). The 95 participants who had scores above the median are classified as "high" EI, while the other half of participants scoring below the median are classified as "low" EI for the analysis. The mean level of PS was 4.22, $\mathrm{SD}=1.256$, which is lower than that reported in Robertson (2008) (the mean was above 5.5). It may be affected by the culture factor since culture influences auditor professional skepticism and judgment in high power distance countries (Endrawes and Monroe, 2010). 
Additionally, there is the significant correlation between EI and PS ( $\mathrm{r}=0.77 ; \alpha=0.01$; two-tailed). The mean professional skepticism scores are significantly different across the two levels of EI. Specifically, the high EI group has a higher mean professional skepticism score than the low EI group (Mean = 5.30 high EI group vs. 3.41 low EI group; $t=14.98, p \leq 0.001)$. To reexamine whether PS affected the results of hypothesis testing, a one way ANOVA model was used and the results show the significant effect of PS on auditor judgment.

\section{Hypothesis Tests}

In initial analysis, all demographic variables are examined for inclusion as control variables in the analyses. However, gender and education are not significantly related to the dependent variables. Additionally, since age and audit experience are highly correlated $(r=0.88$, $p=0.01$, age is not included as a variable in the main analyses. Thus, the final models include only Professional skepticism (PS) and years of experience (Years) as control variables.

I employ a systematic progression of multivariate general linear models in this study to test the hypotheses. PS and Years are included in all equations for the analysis. Equation 1 examines whether time budget pressure (TB) has an influence on auditor judgments $\left(\mathrm{AJ}_{\mathrm{i}}\right)$. Equation 2 examines whether client incentive pressure (CI) has an influence on $\mathrm{AJ}_{\mathrm{i}}$. Equation 3 adds TB, CI, and the interaction between these two independent variables to the model.

$$
\begin{aligned}
& \mathrm{AJ}_{\mathrm{i}}=\alpha_{0}+\alpha_{1} \mathrm{~TB}+\alpha_{2} \mathrm{PS}+\alpha_{3} \text { Years }+\varepsilon_{\mathrm{i}} \\
& \mathrm{AJ}_{\mathrm{i}}=\beta_{0}+\beta_{1} \mathrm{CI}+\beta_{3} \mathrm{PS}+\beta_{3} \text { Years }+\varepsilon_{\mathrm{i}} \\
& \mathrm{AJ}_{\mathrm{i}}=\rho_{0}+\rho_{1} \mathrm{~TB}+\rho_{2} \mathrm{CI}+\rho_{3} \mathrm{CI} * \mathrm{~TB}+\rho_{4} \mathrm{PS}+\rho_{5} \text { Years }+\varepsilon_{\mathrm{i}}
\end{aligned}
$$

where, $\mathrm{AJ}_{\mathrm{i}}=$ Auditor judgments; Two dependent variables, likelihood of investigating further $\left(\mathrm{AJ}_{1}\right)$ and level of material misstatement risk $\left(\mathrm{AJ}_{2}\right)$, each measured used a 7-point Likert scale where $1=$ Extremely Unlikely and $7=$ Extremely Likely;

$\mathrm{TB}=$ Time budget pressure; Dichotomous independent variable equal to 0 if time budget pressure is low or 1 if time budget pressure is high; 
$\mathrm{CI}=$ Client incentive pressure; Dichotomous independent variable equal to 0 if client incentive pressure is low or 1 if client incentive pressure is high;

PS = Professional skepticism; Mean participant professional skepticism score ranging from 1 = low skepticism to 7 = high skepticism; and

Years $=$ Years of work experience,

Moderation analysis is also used to test the hypotheses posed in this study. According to Frazier, Tix and Barron (2004, p.116), “moderators address 'when' or 'for whom' a variable most strongly predicts or causes an outcome variable." A moderator changes the direction or strength of the relation between a predictor and an outcome (Frazier et al., 2004). This study tests whether EI moderates the relation between pressure and auditor judgment. Thus emotional intelligence is expected to mitigate the effects of pressure on auditor judgment (H4-H6).

Moderated multivariate analysis is the statistical tool of choice for estimating interaction effects in the organizational sciences (Aguinis and Gottfredson, 2010). The moderation analysis used to test H4-H6 includes two independent variables, time budget pressure and client incentive pressure, the dependent variable, a measure of EI, and control variables. According to Aguinis and Gottfredson (2010), I use the interaction term between EI and the other independent variables to test for moderation. The following equations are estimated:

$$
\begin{aligned}
\mathrm{AJ}_{\mathrm{i}}= & \alpha_{0}+\alpha_{1} \mathrm{~TB}+\alpha_{2} \mathrm{EI}+\alpha_{3} \mathrm{~TB} * \mathrm{EI}+\alpha_{4} \mathrm{PS}+\alpha_{5} \text { Years }+\varepsilon_{\mathrm{i}} \\
\mathrm{AJ}_{\mathrm{i}}= & \beta_{0}+\beta_{1} \mathrm{CI}+\beta_{2} \mathrm{EI}+\beta_{3} \mathrm{CI}^{*} \mathrm{EI}+\beta_{3} \mathrm{PS}+\beta_{3} \text { Years }+\varepsilon_{\mathrm{i}} \\
\mathrm{AJ}_{\mathrm{i}}= & \rho_{0}+\rho_{1} \mathrm{~TB}+\rho_{2} \mathrm{CI}+\rho_{3} \mathrm{EI}+\rho_{4} \mathrm{~TB} * \mathrm{EI}+\rho_{5} \mathrm{CI}^{*} \mathrm{EI}+\rho_{6} \mathrm{~TB} * \mathrm{CI}+ \\
& \rho_{7} \mathrm{~TB} \mathrm{CI}^{*} \mathrm{EI}+\rho_{8} \mathrm{PS}+\rho_{9} \text { Years }+\varepsilon_{\mathrm{i}}
\end{aligned}
$$

where, $\mathrm{AJ}_{\mathrm{i}}=$ Auditor judgments; Two dependent variables, likelihood of investigating further $\left(\mathrm{AJ}_{1}\right)$ and level of material misstatement risk $\left(\mathrm{AJ}_{2}\right)$, each measured used a 7-point Likert scale where $1=$ Extremely Unlikely and 7 = Extremely Likely;

$\mathrm{TB}=$ Time budget pressure; Dichotomous independent variable equal to 0 if time budget pressure is low or 1 if time budget pressure is high; 
$\mathrm{CI}=$ Client incentive pressure; Dichotomous independent variable equal to 0 if client incentive pressure is low or 1 if client incentive pressure is high;

$\mathrm{EI}=$ Emotional Intelligence; Dichotomous independent variable equal to 0 if emotional intelligence is low or 1 if emotional intelligence is high;

PS = Professional skepticism; Mean participant professional skepticism score ranging from 1 = low skepticism to 7 = high skepticism; and

Years $=$ Years of work experience.

Equations 1- 3 progressively examine the impact of time budget pressure and client incentive pressure on audit judgments, ignoring EI. Equations 4-6 allow for a test of the moderating effect of EI on our understanding of these relations. It is important to note that the conclusions that would be drawn in regard to $\mathrm{H} 1, \mathrm{H} 2$, and $\mathrm{H} 3$ based on the analyses differ once EI is included. The best interpretation of the data occurs when the significant interactions in the final model (equation 6) are taken into account (see Table 8). Thus, the progressive analysis presented in this dissertation provides an important illustration of how EI can significantly impact and clarify our understanding of the relations between these pressures and auditor judgments. Thus, I will first discuss the evidence provided for the first three hypotheses from

analyses based on equations 1-3. Then I will discuss the analyses based on Equations 4-6 and the overall evidence regarding the hypotheses presented in this study.

\section{Preliminary tests of H1-H3 based on equations 1-3}

Equation 1 investigates the impact of time budget pressure on auditor judgments using a MANCOVA performed using the multivariate general linear model function of SPSS. The assessment of risk and the likelihood of investigating further are the dependent auditor judgment variables. Table 3 presents the results. There is a significant main effect for time budget pressure for both dependent variables. Interestingly, auditors assessed the questionable transaction as less risky $(\mathrm{F}=21.517, p<0.001)$, and are less likely to investigate it further $(\mathrm{F}=9.465, p=0.002)$ 
when they experience less time budget pressure. This result suggests that auditors are more likely to be aware of misstatement risk and request more time for investigating a questionable transaction when they experience high time budget pressure. The first hypothesis predicts that auditors will make more conservative judgments when they experience less time budget pressure. Thus, the results presented in Table 3 do not support H1.

\section{[Insert Table 3 about here]}

Table 4 reports the analysis described by equation 2 . This analysis indicates that there is a significant main effect of client incentive pressure on the assessment of risk and the likelihood of investigating further $(\mathrm{F}=73.682 \& 40.571, p \leq 0.001)$. That is, auditors assessed the transaction as more risky and are more likely to investigate further when the client has high incentives to influence the auditor. This result is consistent with $\mathrm{H} 2 \mathrm{~b}$ and with results reported by Robertson (2010) who posits that a client's incentive to manage earnings may lead auditors to be more skeptical and collect more evidence on clients' reporting. Thus, as the client's incentive increases, auditors are more likely to make conservative judgments.

[Insert Table 4 about here]

$\mathrm{H} 3$ predicts that auditor judgment will be influenced by time budget pressure to a greater extent when client incentive pressure is absent than when client incentive pressure is present. The MANCOVA analysis of equation 3 is shown in Table 5. The interaction between time budget pressure and client incentive pressure is not significant in explaining the likelihood of investigating further $(\mathrm{F}=2.579, p=0.11)$ and is insignificant in explaining risk assessment $(\mathrm{F}=$ 0.395, $p=0.53$ ). Thus, the results reported in Table 5 fail to provide support for $\mathrm{H} 3$.

[Insert Table 5 about here] 
Figures 3 and 4 illustrate the interaction in relation to the likelihood of additional investigation and assessment of risk, respectively. Although the interactions are insignificant, these graphical depictions give us some evidence of the patterns underlying the data. Figure 3 illustrates that the difference in the likelihood of investigating further between time budget pressure treatments appears to be greater under low client incentive pressure than under high client incentive pressure. In other words, when auditors experienced low client incentive pressure, the level of time budget pressure has a greater effect on the likelihood of further investigation. Furthermore, the level of material misstatement risk is highest when auditors experience both high time budget pressure and high client incentive pressure (Figure 4).

[Insert Figure 3 and Figure 4 about here]

\section{Preliminary tests of $\mathrm{H} 4$ and $\mathrm{H} 5$ based on equations 4 and 5}

$\mathrm{H} 4$ predicts that auditors with high EI will make more conservative judgments than auditors with low EI when they are exposed to time budget pressure. As an initial investigation, I use independent sample T-tests to assess the effect of EI on auditor judgments. Auditors' risk 5.01 vs. 3.53, $t=9.195, p \leq 0.001)$. Participants high in EI are also significantly more likely to investigate the questionable transaction further than those with low in EI (Mean $=5.09$ vs. 2.95, $t$ $=14.610, p \leq 0.001)$. Consistent with $\mathrm{H} 4$, these results suggest a positive, significant association between EI and conservative auditor judgments.

Equation 4 presents an analysis of emotional intelligence in combination with time budget pressure on auditor judgments. The results, reported in Table 6, indicate that EI significantly influences both auditor judgments $(F=60.476$ further investigation; 21.261 risk level; $\mathrm{p} \leq 0.001)$. Moreover, the interaction of time budget pressure and EI is significant for further investigation $(\mathrm{F}=9.559, p=0.002)$, and is marginally significant for auditors' 
assessments of risk $(\mathrm{F}=4.566, p=0.034)$. Figures 5 and 6 illustrate the interactions between time budget pressure and emotional intelligence reported in Table 6. Participants who are high in EI assess higher risk and are more likely to investigate the transaction further. In other words, auditors high in EI are more conservative in comparison to those low in EI when they experience pressures at work. Thus, EI has a moderating effect on auditor judgment under time budget pressure.

[Insert Table 6, Figure 5, and Figure 6 about here]

The fifth hypothesis (H5) predicts that EI has a moderation effect on auditor judgment when auditors are exposed to client incentive pressure. Equation 5 specifically analyzes emotional intelligence and client incentive pressure. As can be seen from the MANCOVA analysis presented in Table 7, the main effects of CI and EI are significant for both dependent variables $(p \leq 0.001)$. In addition, the significant interaction between $\mathrm{CI}$ and EI indicates moderation effects for the likelihood of further investigation $(\mathrm{F}=32.966, p \leq 0.001)$ and auditors' risk assessments $(\mathrm{F}=38.645, p \leq 0.001)$. As Figure 7 shows, participants who are high in EI are more likely to further investigate whether or not they are subject to client incentive pressure. However, the difference between high and low EI auditors is greater when they experience high client incentive pressure. Similarly, as Figure 8 illustrates, auditors who are high in EI assess higher misstatement risk (Mean $=4.78)$ than those who are low in EI $($ Mean $=3.72)$, and this difference is greater under high client incentive pressure $(t=9.195, p \leq 0.001)$. In sum, these results support $\mathrm{H} 5$.

[Insert Table 7, Figure 7, and Figure 8 about here] 


\section{Tests of the hypotheses based on equation 6}

The last hypothesis states that auditors with high EI will make more conservative judgments than auditors with low EI when they are exposed to both time budget and client incentive pressure. In order to test H6, equation 6 examines EI, TB, CI, and the interactions of these variables. Table 8 presents the results of this MANCOVA analysis. The results indicate that when auditors' risk assessments are the dependent variable of interest, there is a significant three-way interaction among EI, TB, and CI $(\mathrm{F}=19.593, p \leq 0.001)$. Moreover, the three-way interaction is significant when considering auditors' likelihood of investigating further $(\mathrm{F}=$ $3.353, p=0.069)$.

Additionally, the two-way interaction of TB and CI is significant on explaining auditors' likelihood of further investigation $(\mathrm{F}=6.507, p \leq 0.001)$ and not on risk assessment $((\mathrm{F}=0.256$, $p=0.613$ ), which provide partial support of H3. The moderation effect of EI is only significant on likelihood of further investigation $(\mathrm{F}=11.187, p \leq 0.001)$, and marginal significant on risk assessment $(\mathrm{F}=2.824, p \leq 0.095)$. Thus, H4 is supported. Similarly, H5 is supported by the significant interaction on both dependent variables $(\mathrm{F}=38.671$ on Further Investigation and $\mathrm{F}=$ 46.920 on risk assessment, $\mathrm{p} \leq 0.001)$. Finally, the results indicate significant main effects for both independent variables (time budget pressure and client incentive pressure) and EI on both of the dependent variables $(p \leq 0.001)$.

\section{[Insert Table 8 about here]}

Understanding the significant interactions presented in Table 8 is key to fully understanding the data from this study and in testing the hypotheses. According to Kirk (1995), tests of simple main-effects can be used to explain a three-way interaction. For this study, the three-way interaction can be better understood by testing the effects of client and time pressures 
for individuals with high EI separately from individuals with low EI. To further simplify the analysis, I present the results of an ANCOVA for each dependent variable. The main results are the same under both the ANCOVA and the overall MANCOVA analyses. The ANCOVAs are presented in Tables 9-12 and the interactions from these ANCOVAs are illustrated in Figures 912.

\section{EI level and auditor risk assessment}

The ANCOVA results presented in Table 9 and Table 10 clarify this three-way interaction by separating low EI from high EI. The ANCOVA results in Table 9 report low EI auditor risk assessments. For this group, the F ratio of the three way interaction is $9.259^{2}$. To provide a more conservative assessment of significance, I calculate the adjusted $p$-value using the per family error rate method to determine the critical value for tests of simple main-effects (Kirk, 1995). I divide the alpha level, 0.05, by 2 as I need two tests of simple main-effects. The critical value of $(0.05 / 2=0.025 ; \mathrm{df}=1 ; \mathrm{n}=89)$ is 3.836 . As the $\mathrm{F}$ ratio of the three-way interaction, 10.433, exceeds this critical value, the results suggest that the interaction between time budget pressure and client incentive pressure is statistically significant for the low EI group.

Table 10 reports risk assessments for the high EI group. As the calculated $\mathrm{F}$ ratio is $11.889^{3}$, it is greater than the critical value of 3.836 , the interaction continues to be significant based on an adjusted $p$-value. It is also interesting to note that when the two levels of EI are separated, the interactions between time budget pressure and client incentive pressure differ significantly across the levels of EI. This result is consistent with H6.

[Insert Table 9 and Table 10 about here]

\footnotetext{
${ }^{2} \mathrm{~F}$ ratio is calculated by mean square of the interaction from table $9,4.546$ divided by mean square error calculated from table 8, 0.491 (Kirk, 1995).

${ }^{3} \mathrm{~F}$ ratio is calculated by mean square of the interaction from table $10,5.734$ divided by mean square error calculated from table 8, 0.467 .
} 
Figure 9 and Figure 10 graphically depict the interactions reported in Table 9 and Table 10. The plots clarify the underlying cause of the significant three-way interaction between EI, CI and TB reported in Table 8. Specifically, auditors demonstrate different patterns of risk assessments in response to time budget pressure and client incentive pressure across the two levels of EI. In the low EI group, the difference in the level of risk assessment due to time budget pressure is greater when client incentive pressure is absent (Figure 9). Auditors with low EI assesses similar risk in both high and low time budget pressure conditions when client incentive pressure is present. This behavior is predicted by $\mathrm{H} 3$.

[Insert Figure 9 about here]

More importantly, Figure 10 illustrates that auditors with high EI assess the highest risk of material misstatement when both time budget pressure and client incentive pressure are present. It is worthwhile to note that the effect of time budget pressure is greater when client incentive pressure is high, inconsistent with H3. When external (client's incentive) pressure and internal (time budget) pressure increase, auditors with high EI become more skeptical and assess higher risk than those with low EI. This phenomenon may be due to the high correlation of high EI and professional skepticism $(r=0.77, p \leq 0.01)$. Thus, it appears that high EI auditors exercise professional skepticism when faced with time budget and client incentive pressure leading them to assess greater risk. A similar pattern does not occur for low EI auditors.

[Insert Figure 10 about here]

\section{EI level and likelihood of further investigation}

The MANCOVA in Table 8 reports a marginal significant three-way interaction among time budget pressure, client incentive pressure and EI when further investigation is used as the dependent variable $(p=0.069)$. Thus, the expectation is that the interactions between time 
budget pressure and client incentive pressure will reveal different patterns of behavior for both low and high EI auditors. The ANCOVA results in Table 11 and Table 12 report low EI and high EI auditors' reported likelihood of further investigation, respectively.

The ANCOVA results in Table 11 report the likelihood of investigating further for low EI auditors. For this group, the $\mathrm{F}$ ratio of the three way interaction is $19.232^{4}$. Again, to provide a more conservative assessment of significance, I compare this to the critical value of 3.836 as described above. As the F value exceeds this critical value, therefore, the results suggest that the interaction between time budget pressure and client incentive pressure is statistically significant for the low EI group. Figure 11 illustrates this interaction, showing that auditors with low EI are more likely to investigate further when they experience high client incentive pressure and low time budget pressure. This behavior is consistent with $\mathrm{H} 3$.

[Insert Table 11 and Figure 11 about here]

However, a different pattern of behavior is observed in the high EI group. As Table 12 reveals, while the main effects of time budget pressure and client incentive pressure are significant $(\mathrm{F}=38.542 \& 117.625 ; p \leq 0.001)$, the interaction between the two independent variables is non-significant ( $\mathrm{F}$ ratio is $1.152^{5}<$ critical value). This interaction is illustrated in Figure 12. The likelihood of further investigation is highest when participants are exposed to high client incentive pressure and high time budget pressure. In other words, the higher the pressures, the more likely it is that high EI auditors will investigate the questionable transaction further. This result is similar to what was observed for high EI auditor risk assessments (e.g., compare Figure 10 and Figure 12). If one takes both dependent variables into consideration it

\footnotetext{
${ }^{4} \mathrm{~F}$ ratio is calculated by mean square of the interaction calculated from table $11,9.443$ divided by mean square error calculated from table $8,0.491$.

${ }^{5} \mathrm{~F}$ ratio is calculated by mean square of the interaction calculated from table $12,0.538$ divided by mean square error calculated from table $8,0.467$.
} 
suggests that high EI participants assessed higher risk and are therefore more likely to investigate further with regard to the questionable transaction when they are exposed to both internal and external pressures at work. Table 13 presents the summary results of the hypotheses.

[Insert Table 12, Table 13, and Figure 12 about here]

\section{Supplemental Analyses}

In order to better understand the moderation effects of EI, several additional questions were asked in the experimental instrument to evaluate the auditor judgments. These questions were measured on seven-point Likert scales and are described in more detail in the Method Chapter.

\section{Stress level}

Participants are asked to indicate the extent of overall stress that Taylor experienced in this case. They indicate an average stress level of $4.46(\mathrm{SD}=1.41)$. Participants correctly indicate higher stress when subject to high levels of time budget pressure or client incentive pressure $($ Mean $=5.33$ high time budget pressure treatment vs. 3.42 low time budget pressure treatment, $t=12.76, p \leq 0.001$; Mean $=4.97$ high client incentive pressure treatment vs. 3.73 low client incentive pressure treatment, $t=6.44, p \leq 0.001)$. Additionally, there is a significant difference in perceived stress level between the high and low EI groups (Mean $=4.67$ vs. $4.25, t$ $=2.072, p \leq 0.04)$.

Participants are also asked to indicate the level of pressure to keep the client happy. The mean response is $4.84(\mathrm{SD}=1.34)$. Consistent with the manipulation, pressure to keep the client happy is perceived to be significantly higher by auditors in the high client incentive pressure treatments $(t=6.36, p \leq 0.001)$. 


\section{Incentives for misstatement}

Prior research asserts that client incentives to misstate decrease their credibility from the auditor's perspective. As a result, auditors are more likely to act conservatively when they are aware that clients have incentives to misstate (Robertson, 2010). In order to assess the effect of client incentives on auditor judgment, participants are asked to measure their perceptions of the client's incentive for misstatement (Mean $=4.25, \mathrm{SD}=1.35)$. High EI auditors are significantly more aware of clients' incentives for misstatement $($ Mean $=4.78)$ than low EI auditors $($ Mean $=$ 3.72, $t=5.883, p \leq 0.001)$. Consequently, high EI auditors make more conservative judgments as is observed in the previously described results (consistent with H6).

\section{Risk of loss}

To obtain information about participants' perceptions of litigation risk associated with the case, participants assess the loss risk that the auditor's firm will suffer as a consequence of this audit. Table 14, Panel A presents descriptive statistics for auditors' loss risk assessments grouped by independent variable. As can be seen from the ANOVA presented in Panel B of Table 14, both independent variables significantly influence loss risk perceptions (TB-F $=44.402$, CI$\mathrm{F}=158.384 ; \mathrm{p} \leq 0.001)$. Moreover, the interaction between the two independent variables is significant $(\mathrm{F}=6.187 ; p=0.014)$. In other words, auditors' perceptions of loss risk are dependent upon the pressures they associate with the situation. I also find that loss risk assessment is positively associated with the level of EI (Mean $=4.54$ high EI group vs. 3.58 low EI group, $t=6.12, p \leq 0.001)$.

[Insert Table 14 about here] 


\section{Additional measures of auditor judgment}

Two additional dependent measures are used to test whether the main effects of EI on auditor judgment are robust. Similar to the primary dependent variables, participants were asked to indicate the likelihood that Taylor will ask the manager in charge for extra time before making a final recommendation. In addition, participants were asked to indicate the likelihood that Taylor will accept the client's explanation and not investigate the matter further as described in the Method Chapter. This variable has an inverse relation with conservative auditor judgment. That is, the higher the likelihood of accepting the client's explanation, the less conservative the judgment.

A MANCOVA test was used to test the main hypotheses on these two additional dependent variables (see Table 15). First, the control variable professional skepticism is significant $(\mathrm{F}=5.816$ on Requesting time, $p=0.017 ; 19.867$ on Accepting explanation; $p \leq 0.001$ ) and audit experience is marginally significant on both additional dependent variables $(F=2.734$ on Requesting time, $p=0.01 ; 3.964$ on Accepting explanation; $p=0.048)$. Second, the independent variables are significant $p \leq 0.01$, consistent with $\mathrm{H} 1$ and $\mathrm{H} 2$. The results of the MANCOVA reported in Table 15 also indicate that EI significantly moderates the impact of the pressure variables on both additional dependent variables ( $\mathrm{F}=54.195$ on Requesting time; 21.647 on Accepting explanation ; $p \leq 0.001)$. In addition, independent T-tests indicate that, as compared to low EI auditors, high EI auditors are less likely to accept the client's explanation (Mean $=3.53$ vs. $5.01, t=-12.399, p \leq 0.001$ ) and are more likely to ask the manager for extra time before making a final recommendation (Mean $=4.79$ vs. $2.49, t=16.461, p \leq 0.001)$. In other words, EI reduces auditors' tendency to engage in dysfunctional behaviors promoted by pressure, such as accepting weak client explanations. 
[Insert Table 15 about here]

Furthermore, the interaction between the two independent variables has a significant effect on auditors' willingness to request extra time ( $\mathrm{F}=18.960, p \leq 0.001)$, but not on their propensity to accept the client's explanation $(\mathrm{F}=0.254, p=0.615)$. These results partially support H3 indicating that auditor judgment will be influenced by time budget pressure differently when client incentive pressure is absent rather than present.

Inconsistent with $\mathrm{H} 4$, neither dependent variable is influenced by the interaction of time budget pressure and EI. Both acceptance of the client's explanation and likelihood of requesting extra time are not affected by the interaction of client incentive pressure and $\mathrm{EI}(\mathrm{F}=1.797, p=$ $0.182 ; \mathrm{F}=.281, p=0.597$ respectively). Finally, there is a significant three-way interaction on auditors' willingness to request extra time $(\mathrm{F}=9.084, p=0.003)$, but not on their acceptance of the client's explanation $(\mathrm{F}=1.474, p=0.226)$. In order to better understand the three-way interaction, separate ANCOVA tests for low and high EI groups are performed for each of the dependent measures.

\section{EI level and willingness to request additional time}

Table 16 and Table 17 report the ANCOVA results for auditors' willingness to request extra time, and Figure $13 \& 14$ illustrate the mean responses. The interaction of client incentive pressure and time budget pressure is significant for auditors with low EI $\left(\mathrm{F}=76.936^{6}>\right.$ critical value of 3.836) and is not significant for auditors with high $\mathrm{EI}\left(\mathrm{F}=1.238^{7}<\right.$ critical value $)$. It is interesting to note that auditors with low EI indicate a higher likelihood of requesting extra time to gather additional audit evidence if they are exposed to low time budget pressure and high

\footnotetext{
${ }^{6} \mathrm{~F}$ ratio is calculated by mean square of the interaction calculated from table $16,36.706$ divided by mean square error calculated from table $15,0.4771$.

${ }^{7} \mathrm{~F}$ ratio is calculated by mean square of the interaction calculated from table $17,0.770$ divided by mean square error calculated from table $15,0.622$.
} 
client incentive pressure (Figure 13). However, Figure 14 indicates auditors with high EI are more likely to request extra time before making a final recommendation when the client has high incentive to influence the auditor than when the client has low incentive. Accordingly, EI moderates how external and internal pressures influence auditor judgment.

[Insert Table 16, Table 17, Figure 13, and Figure 14 about here]

\section{EI level and the likelihood of accepting the client's explanation}

Table 18 and Table 19 report the ANCOVA results for auditors' likelihood of accepting the client's explanation, and Figure 15 and Figure 16 illustrate the mean responses. For low EI auditors, time budget pressure significantly interact with client incentive pressure to influence low EI auditors' likelihood of accepting the client's explanation (F ratio $2.013^{8}<$ critical value of 3.386). As Figure 15 illustrates, low EI auditors report a higher likelihood of accepting the client's explanation when the client has low incentive to influence the auditors.

[Insert Table 18 and Figure 15 about here]

Table 19 reports that time budget pressure significantly impacts high EI auditors' likelihood of accepting client explanation $(\mathrm{F}=8.375, p \leq 0.001)$. The lower the time budget pressure, the more likely the auditor will accept the client's explanation. The interaction between the two independent variables is not significant $\left(\mathrm{F}=0.378^{9}<\right.$ critical value). Figure 16 illustrates that the difference between the likelihood of accepting the client's explanation due to time budget pressure is similar under both low and high client incentive pressure. In other words, high EI auditors consider both internal and external pressures before exercising their judgment. High EI auditors are least likely to accept the client's explanation when they are subject to both high

\footnotetext{
${ }^{8} \mathrm{~F}$ ratio is calculated by mean square of the interaction calculated from table $18,0.961$ divided by mean square error calculated from table 16, 0.4771 .

${ }^{9} \mathrm{~F}$ ratio is calculated by mean square of the interaction calculated from table $19,0.235$ divided by mean square error calculated from table $17,0.622$.
} 
time budget pressure and high client incentive pressure. In sum, different behavior patterns are observed between high and low EI auditors, a finding consistent with H6.

[Insert Table 19 and Figure 16 about here] 


\section{Chapter IIV}

\section{Summary and Conclusions}

\section{Summary}

Prior accounting research recognizes the importance of the impact of emotions on accounting professionals' decision-making processes. Recent accounting studies highlight the importance of EI on accountants' job performance related to decision making, teamwork and client relations (Cook et al., 2011; Daff et al., 2012). Moreover, EI is considered to be a critical skill that allows practitioners to improve their ethical behavior when they deal with ethical dilemmas in public accounting (Angelidis and Ibrahim, 2011). The current study focuses on auditors in China. China has received much criticism in recent years for suspicious accounting practices, and there is much concern regarding audit quality in China because of dysfunctional audit behaviors in China (Chow et al,, 2006; Firth et al,, 2012). Thus, it is critical to understand factors influencing such behaviors and potential moderators that can mitigate dysfunctional auditor behavior to improve audit quality.

This study uses an experiment to investigate the moderation effect of EI on Chinese auditors' judgments under different types of pressures. Specifically, auditors are presented with a hypothetical scenario involving a questionable accounts receivable transaction. They are asked to indicate the material misstatement risk associated with this transaction and the likelihood that they will investigate further. The presence and absence of an internal pressure (time budget) and an external pressure (client incentive) were manipulated between participants. The instrument included the 16-item version of the WEIP scale, which is commonly used in management and organizational behavior research to measure EI (e.g., Jordan and Lawrence, 2009; Cherniss, 2010). This study's experimental setting, therefore, extends the extant literature by 
simultaneously incorporating different types of pressures and examining the effect of EI on auditor judgments.

The study's participants indicated that the pressures investigated in this study are of practical importance. Specifically, they indicated that meeting time budgets is very important and they experience high levels of job stress in their organizations. The results suggest that EI is key to understanding the impact of pressures on auditor judgments. Different behavior patterns are found between participants with high EI and low EI. As expected, participants with low EI are more likely to request extra time to gather additional audit evidence and investigate the questionable account receivable transaction further when they experience high client incentive pressure and low time budget pressure.

The results indicate that auditors with high EI make more conservative judgments than those with low EI when they are exposed to pressures. Specifically, high EI auditors assess higher material misstatement risk and are more likely to investigate the questionable transaction further when they are exposed to both internal and external pressures at work. In other words, EI can effectively reduce auditors' tendencies to engage in dysfunctional behaviors promoted by job pressures. Additionally, the results suggest that professional skepticism is positively associated with EI.

The supplemental analyses provide additional evidence of EI's moderating effects and positive correlation with conservative auditor judgments. These results indicate that high EI auditors are more conservative in their overall judgment and decision making and are more aware of clients' incentives for misstatement. Furthermore, alternative dependent measures also indicate that EI level is positively correlated with conservative auditor judgments. 


\section{Contributions}

The current study contributes to the literature on audit judgment and pressures in the audit environment in several important ways. First, this study is the first of which I am aware that examines the effect of EI on auditor judgment. Prior research demonstrates that EI training can help health professionals to manage their own and other people's feelings, which allow them to effectively decrease their occupational stress, increase commitment, and enhance job performance (Nikolaou and Tsaousis, 2002; Jordan, Ashkanasy, Hartel, and Hooper, 2002). Auditing has long been considered a stressful occupation (Fisher, 2001), and it is considered to be a profession at risk. ${ }^{10}$ Auditing, as a profession, has unique features that can exacerbate work pressure. For example, demands to complete tasks within specified time periods during the busy season can have adverse consequences on the judgment of auditing professionals. Further, auditors must interact with client management throughout the audit process, and this interaction can cause job stress (Fisher, 2001; Nelson and Tan, 2005). This stress is the result of the requirement for the auditor to remain independent and skeptical, while simultaneously developing and maintaining a good relationship with the client (Nelson, 2009). Auditors are also exposed to different legal challenges, such as litigation risk (DeZoort and Lord, 1997). Thus, it is worthwhile to test whether EI can play a specific role to influence professionals' behavior within the unique context of the auditing profession. This study builds upon research on the impact of EI on job performance in other disciplines by evaluating how EI influences auditor judgment under two forms of pressure encountered in practice: time budget pressure and client incentive pressure. By using a 2x2 experiment, I found that participants with low EI are more conservative and skeptical when they experience high client incentive pressure and low time budget pressure.

\footnotetext{
${ }^{10}$ Auditing: a profession at risk. U.S. Chamber of Commerce. http://www.uschamber.com/sites/default/files/reports/0601auditing.pdf
} 
However, high EI participants assess higher misstatement risk and are more likely to investigate the questionable transaction further when they are exposed to both internal and external pressures at work.

Moreover, understanding the role of EI in mitigating auditors' pressure and influencing judgment and decision making is important to public accounting firms' practices with regard to recruiting, training, and promotion decisions. EI is an important skill that may lead to social and emotional satisfaction (Sy, Tram, and Hara, 2006; Guleryuz, Guney, Aydın, and Asan, 2008). EI training could help auditors to recognize and deal with the different affective reactions they may experience when dealing with clients (Bhattacharjee et al., 2011). Thus, this study supports a public accounting firms' decision to invest in developing training programs in order to improve the EI of their accountant (e.g. Deloitte, 2010), as EI is positively related to auditor conservative judgment.

\section{Implications}

The results of this study have implications for researchers, practitioners, and regulators. From the research standpoint, this study provides evidence of the joint and unique effects of organizational and environmental pressures on auditor judgments, building upon prior research on the individual effects of different pressures. It also underscores the importance of the understanding of EI's effect on judgment and decision making in the accounting profession. From a practical standpoint, finding that auditors with high EI make rational judgments may be of particular interest to the auditing profession.

According to a new release of The Committee of Sponsoring Organizations of the Treadway Commission, it is very challenging to avoid judgment biases in order to make high quality professional judgments (COSO, 2012). Awareness and understanding of common JDM 
errors and biases is an important step toward avoiding them, which is also a critical component in auditing. As pressures lead to dysfunctional auditor behaviors and impair audit quality, specific strategies, such as EI training could be indicated as a means to raise auditors' awareness of judgment biases and mitigate the quality-threatening effects of these pressures.

This study also has implications for international accounting research. China completed the international convergence of auditing standards in $2010 .{ }^{11}$ The importance of improving audit quality and awareness of professional skepticism are highlighted in current Chinese auditing standards (CASB ${ }^{12}$; Chinese CPA Standards on Auditing, 2006). The regression results of the moderation effect of EI on auditor judgment could assist in helping standard setters to promote the awareness of EI training.

\section{Limitations of the Study}

This study is subject to some limitations. Like most experimental studies, generalizability is a limitation in this study. The experiment utilized a hypothetical case with limited information about the client. In practice, auditors would have access to other information before making their judgment. For instance, auditors may review previous financial reports or have discussions with their colleagues before determining managers' incentive to manipulate earnings. Moreover, the self-report questionnaire was used to obtain respondents' EI scores. Thus, common method variance is a concern, as it may result in biased estimated relationships (Spector, 1987). The use of a self-report questionnaire may also constrain the results due to social desirability. Specifically,

\footnotetext{
${ }^{11}$ Chinese Auditing Standards Board and International Auditing and Assurance Standards Board Issue Joint Statement Regarding Convergence of International Standards (2010) http://www.ifac.org/

12 the Chinese Auditing Standards Board (CASB) issues auditing Standards in China http://www.audit.gov.cn/n1992130/n1992165/n1993676/2601539.html
} 
the respondents may have tried to provide answers they thought the experimenter wanted, which may have caused over-reporting of good behavior.

In addition, participants are auditing professionals in China. Due to unique cultural influences in China, the results of this study may not be generalizable in other countries. It is possible that culture factor may have more influence on auditor judgment in China than other counterparts. However, prior studies of accounting professionals in other cultures conclude that both time budget pressure and client incentive pressure increase auditors' propensity to make unethical decisions (Robertson, 2010). Thus, it is reasonable to expect the hypothesized relations to hold with other countries.

Finally, another limitation concerns the use of the median points split to create the two subgroups (high vs. low EI groups). The creation of a categorical variable from a continuous measure results lower statistical power, which also "decreases the sensitivity of the measurement instrument” (e.g. Aguinis, 1995; Angelidis and Ibrahim, 2011, p.117). In this study, two independent variables are manipulated at low and high levels. For consistency, I also create low and high EI groups using a median split of the EI responses.

\section{Future Research}

There are several avenues for future research. First, this study demonstrates that EI has a moderation effect on auditor judgment under two types of pressure, and future research could examine the effects of EI on judgment and decision making in other characteristics. For example, future research could extend this study into social influence settings. The potential moderation effect of EI under social pressures and incentives would be of interest for future studies.

Second, while the current study only focuses on staff and senior auditors, future research could investigate whether EI influences decision-making of other levels of auditors, such as 
managers and partners. More experienced auditors may react to job pressures differently and EI may play a different role in their judgments. Moreover, future research may wish to explore whether culture differences, as well as other factors, such as individual personality, will affect the role of EI in accounting setting.

Third, a different pattern of behavior is observed in the high EI group than in the low EI group. Specially, the interaction between the two different pressures is non-significant. Future research should investigate other factors that may influence this interaction.

This study provides evidence of a moderation effect of EI on auditor judgments, which answers calls from prior research suggesting that additional studies examine the impact of emotions on auditor judgments (Cianci and Bierstaker, 2009; Bhattacharjee et al., 2011). The results suggest that the moderating influence of EI on auditor judgments can effectively reduce auditors' tendencies to engage in dysfunctional behavior in order to improve audit quality. Specially, I found that auditors with high EI make more conservative judgments than auditors with low EI when facing time pressure and client pressure. Hence, EI training programs are recommended to improve the judgments of auditors.

Furthermore, there is a positive relation between EI and professional skepticism suggesting that auditors with high EI are more skeptical and assess higher risk than auditors with low EI. In conclusion, moderation analysis suggests that EI is a significant mechanism which drives the joint effects of different types of pressures on auditor judgments. 


\section{References}

Abdolmohammadi, M. (1999). A comprehensive taxonomy of audit task structure, professional rank and decision aids for behavioral research. Behavioral Research in Accounting, 11, 51-92.

American Institute of Certified Public Accountants (AICPA). (1997). Consideration of fraud in a financial statement audit. Statement on Auditing Standards No. 82. New York, NY: AICPA.

—. (1998). AICPA professional standards. New York: AICPA.

- (2002). Consideration of fraud in a financial statement audit. Statement on Auditing Standards No. 99. New York, NY: AICPA.

Aguinis, H. (1995). Statistical pwer problems with moderated multiple regression in management research; Journal of Management, 21(6), 1141-1158.

and Gottfredson, R. K. (2010). Best-practice recommendations for estimating interaction effects using moderated multiple regression. Journal of Organizational Behavior, 31, 776-786.

Akers, M. D. and Porter, G. L. (2003). Your EQ skills: got what it takes? Journal of Accountancy, 195(3), 65-70.

Angelidis, J. and Ibrahim, N.A. (2011). The Impact of Emotional Intelligence on the Ethical Judgment of Managers. Journal of Business Ethics, 99, 111-119

Arnold, D., Bernardi, R.A. and Neidermeyer, P.E. (2009). Do European auditors' decisions reflect harmony? The impact of country and culture. International Journal of Disclosure and Governance, 6(1), 58-68.

Asare, S.K., Cianci, A.M. and Tsakumis, G. (2009). The impact of competing goals, experience, and litigation consciousness on auditors' judgments. International Journal of Auditing, $13,223-236$.

Ashton, R. H. and Kramer, S. S. (1980). Students as surrogates in behavioral accounting research: some evidence, Journal of accounting Research, 18(1), 1-15.

Bar-On, R. (1997). Bar-On Emotional Quotient Inventory technical manual. Toronto: MultiHealth Systems.

. (2006). The Bar-On model of emotional-social intelligence (ESI). Psicothema, 18, $13-25$. 
Barsade, S. and Gibson, D. E. (2007). Why does affect matter in organizations? Academy of Management Perspectives, 21, 36-59.

Baxter, R. and Hunton, J. (2011). Capturing affect via the experience sampling method; Prospects for accounting information systems researcher. International Journal of Accounting Information Systems, 12(2), 90-98.

Bay, D. and McKeage, K. (2006). Emotional intelligence in undergraduate accounting students: Preliminary assessment. Accounting Education: An International Journal, 15(4), 439-454.

Bennett, G.B. and Hatfield, R.C. (2013). The effect of the social mismatch between staff auditors and client management on the collection of audit evidence. The Accounting Review, 88, (1), 31-50.

Bhattacharjee, S. and Moreno, K. (2002). The impact of affective information on the professional judgments of more experienced and less experienced auditors. Journal of Behavioral Decision Making, 15, 361-377.

and Riley, T. (2011). The interplay of interpersonal affect and source reliability on auditors' inventory judgments. Contemporary Accounting Research. doi: 10.1111/j.1911-3846.2011.01139.x

Birnbaum, M. H. and Stegner, S. E. (1979). Source credibility in social judgment: Bias, expertise, and the judge's point of view. Journal of Personality and Social Psychology, 37(1), 4874.

Braun, R. (2000). The Effect of time pressure on auditor attention to qualitative aspects of misstatements indicative of potential fraudulent financial reporting. Accounting, Organizations and Society, 25, 243-259.

Buchheit, S., Pasewark W.R. and Strawser, J.R. (2003). No need to compromise: evidence of public accounting's changing culture regarding budgetary performance. Journal of Business Ethics, 42, 151-163.

Chang, C.J. and Hwang, N.C. (2003). The impact of retention incentive and client business risk on auditors' decisions involving aggressive reporting practice. Auditing: A Journal of Practice and Theory, 22(2), $207-218$.

Chen, S., Sun, S. and Wu, D. (2010). Client importance, institutional improvements, and audit quality in China: An office and individual auditor level analysis. The Accounting Review, 85 (1), 127-158.

Cheriness, C. (2010). Emotional intelligence: New insights and further clarifications. Industrial and Organizational Psychology, 3, 183-191. 
Chow, C. W., Ho, J. L. and Mo, P. L. L. (2006). Toward understanding Chinese auditors' structuring of audit approaches, client acceptance decisions, risk assessment, and stringency of imposed reporting standards. Journal of International Accounting Research, $5(1), 1-23$.

Chong, V.K., Monroe, G.S. and Soutar, G.N. (2004). The impact of emotional reaction and cognitive role of occupational stress on public accountants' performance. Asian Review of Accounting, 12(1), $64-78$.

Choo, F. and Firth, M. (1998). The effect of time pressure on auditor's configural information processing. International Journal of Auditing, 2, 21-33.

Chinese CPA Standards on Auditing (2006). Consideration of fraud in an audit of financial statements No. 1141. http://www.cicpa.org.cn/news/newsaffix/7699_2006817_24.pdf (in Chinese).

Chung, J. O. Y., Cohen, J. and Monroe, G. S. (2005). A research note on the effect of mood states on professional skepticism. Paper at AAA 2005 Annual Meeting, at San Francisco. Available at: https://www2.bc.edu/ cohen/Research/Research1.pdf

. (2008). The effect of mood on auditors' inventory valuation decisions. Auditing: A Journal of Practice and Theory, 27(2), 137-159.

Cianci, A. M. and Bierstaker, J. L. (2009). The impact of positive and negative affect on auditors' cognitive and ethical judgments. Auditing: A Journal of Practice and Theory, 28(2), 119-145.

Committee of Sponsoring Organizations of the Treadway Commission (COSO) (2012). Enhancing board oversight: Avoiding judgment traps and biases. March.

Cook, G. L., Bay, D. B., Myburgh, J. E. and Njoroge J. (2011). Emotional intelligence: The role of accounting education and work experience. Issues in Accounting Education, 26 (2), 267-286.

Coram, P., Ng, J. and Woodliff, D. (2003) A survey of time budget pressure and reduced audit quality among Australian auditors. Australian Accounting Review, 13 (1), 38-45.

- (2004). The effect of risk of misstatement on the propensity to commit reduced audit quality acts under time budget pressure. Auditing: A Journal of Practice and Theory, 23(2), 159-67.

Daff, L., de Lange, D. and Jackling, B. (2012). A Comparison of Generic Skills and Emotional Intelligence in Accounting Education. Issues in Accounting Education, 27(3), 627-645. 
Damasio, A. (1994). Descartes' Error: Emotions, Reason, and the Human Brain. New York: G. P. Putnam.

Daus, C. and Ashkanasy, N.M. (2005). The case for the ability-based model of emotional intelligence in organizational behavior. Journal of Organizational Behavior, 26, 453-466.

Davis S., DeZoort, F. T. and L. S. Kopp. (2006). The effect of obedience pressure and perceived responsibility on management accountants' creation of budgetary slack. Behavioral Research in Accounting, 18, 19-35.

Davies, M., Stankov, L. and Roberts, R. D. (1998). Emotional intelligence: In search of an elusive construct. Journal of Personality and Social Psychology, 75, 989-1015.

Deshpande, S. and Joseph, J. (2005). The impact of emotional intelligence on counterproductive behavior in China. Management Research News, 28, 75-85.

DeZoort, F. T., Hermanson, D. and Houston, R. (2003). Audit committee member support for proposed adjustments: A source credibility perspective. Auditing: A Journal of Practice and Theory, 22, 189-205.

and Lord, A. T. (1997). A review and synthesis of pressure effects research in accounting. Journal of Accounting Literature 16, 28-85.

- (1998). Time pressure research in auditing: Implications for practice. The Auditor's Report, 22 (1), 11-12, 14.

Endrawes, M., \& Monroe, G. S. (2010). Professional Skepticism of Auditors: A Cross-cultural Experiment. Doctoral dissertation, University of Western Sydney.

Firth, M., Mo, P.L.L. and Wong, R. M. K. (2005). Incentives for auditor independence: An analysis of the effectiveness of formal sanctions in China. Journal of Business Ethics, 62, 367381.

. (2012). Auditors' organizational form, legal liability, and reporting conservatism: Evidence from China. Contemporary Accounting Research, 29( 1), 57-93.

Fisher, R. T. (2001). Role stress, the Type A behavior pattern, and external auditor job satisfaction and performance. Behavioral Research in Accounting, 13, 143-170.

Fiske, S. T. and Taylor, S. E. (1991). Social cognition (2 $2^{\text {nd }}$ ed.). New York: McGraw-Hill.

Fogarty, T. J., Jagdip, S., Gary, K. R. and Ronald, K. M. (2000). Antecedents and consequences of burnout in accounting: Beyond the role stress model. Behavioral Research in Accounting , 12, 31-68. 
Frazier, P. A., Tix, A. P. and Barron, K. E. (2004). Testing moderator and mediator effects in counseling psychology research. Journal of Counseling Psychology, 51, 115-134.

Gibbins, M. (2001). Incorporating context into the study of judgment and expertise in public accounting. International Journal of Auditing, 5(3), 225-236.

Goleman, D. (1995). Emotional intelligence: Why it can matter more than IQ. New York, NY: Bantam Books.

Güleryuz, G., Güney, S., Aydm, E.M. and Asan, O. (2008). The mediating effect of job satisfaction between emotional intelligence and organizational commitment of nurses: a questionnaire survey. International Journal of Nursing Studies, 45(11), 1625-1635.

Gundry, L. C. and Liyanarachchi, G. A. (2007). Time budget pressure, auditors' personality type, and the incidence of reduced audit quality practices. Pacific Accounting Review, 19, $125-152$.

Hackenbrack, K. and Nelson, M. W. (1996). Auditors' incentives and their application of financial accounting standards. The Accounting Review, 71 (January): 43-59.

Hatfield, R. C., Jackson, S. B. and Vandervelde, S. D. (2011). The effects of prior auditor involvement and client pressure on proposed audit adjustments. Behavioral Research in Accounting, 23(2), 117-130.

Hartmann, F.G. and Maas, V.S. (2010). Why Business Unit Controllers Create Budget Slack: Involvement in Management, Social Pressure, and Machiavellianism. Behavioral Research in Accounting, 22(2), 27-49.

Haw, I. (2008). Discussant comments for "Do auditing standards improve the accounting disclosure and information environment of public companies? Evidence from the emerging markets in China". The International Journal of Accounting, 43 (2), 170-177.

Hirst, D. (1994). Auditor sensitivity to earnings management. Contemporary Accounting Research, 11(1/2), 405-422.

Houston, R. (1999). The effects of fee pressure and client risk on audit seniors' time budget decisions. Auditing: A Journal of Practice and Theory, 18(2), 70-86.

Hurtt, R. K. (2010). Development of a scale to measure professional skepticism. Auditing: A Journal of Practice and Theory, 29 (1), 149-171.

International Auditing and Assurance Standards Board (IAASB). (2004). International Accounting Standard (ISA) 240: The Auditor's Responsibility to consider fraud in an audit of financial statements. New York, NY: IFAC. 
Kadous, K. (2000). The effects of audit quality and consequence severity on juror evaluations of auditor responsibility for plaintiff losses. Accounting Review 75 (3): 327-41.

- Kennedy, S. and Peecher, M. (2003). The effect of quality assessment and directional goal commitment on auditors' acceptance of client-preferred accounting methods. The Accounting Review, 78 (3), 759-778.

Kelley, T. and L. Margheim. (1990). The impact of time budget pressure, personality, and leadership variables on dysfunctional auditor behavior. Auditing: A Journal of Practice and Theory, (Spring), 21-42.

and Seiler, R. (1982). Auditor stress and time budgets. The CPA Journal, December. 24-34. Business Research, 18(2), 105-113.

Kirk, R. E. (1995). Experimental Design: Procedures for the Behavioral Sciences, Third Edition. Monterey, California: Brooks/Cole Publishing.

Johnstone, K. M. (2000). Client-acceptance decisions: Simultaneous effects of client business risk, audit risk, auditor business risk, and risk adaptation. Auditing: A Journal of Practice and Theory, 19, 1-26.

Jones, A., III, Norman, C. and Wier, B. (2010). Healthy lifestyle as a coping mechanism for role stress in public accounting. Behavioral Research in Accounting, 22(1), 21-41.

Jordan, P. J., Ashkanasy, N. M., Hartel, C. E. J. and Hooper, G. S. (2002). Workgroup emotional intelligence: Scale development and relationship to team process effectiveness and goal focus. Human Resource Management Review, 12, 195-214.

and Lawrence, S.A. (2009). Emotional intelligence in teams: development and initial validation of the workgroup emotional intelligence profile - short version (WEIP-S). Journal of Management and Organization, 15(4), 452-469.

Joseph, D. L. and Newman, D. A. (2010). Emotional intelligence: An integrative meta-analysis and cascading model. Journal of Applied Psychology, 95, 54-78.

Libby. R., Bloomfield, R. and Nelson, M.W. (2002). Experimental research in financial accounting. Accounting, Organizations and Society, 27, 775-810.

Larson, L.L. (2004). Internal auditors and job stress. Managerial Auditing Journal, 19(9), 1119-1130.

Lin, K. Z. and Fraser, I. A. (2008). Auditors' ability to resist client pressure and culture: Perceptions in China and the United Kingdom. Journal of International Financial Management \& Accounting, 19, 161-183. 
Lin, Z.J., Liu, M. and Wang, Z. (2009). Market implications of the audit quality and auditor switches: Evidence from China. Journal of International Financial Management and Accounting, 20(1), 35-78.

Liu, C. and Zhang, J. (2008). Time pressure, accountability and audit judgmentp: An experimental study. China Accounting Review, 6(4), 405-424.

Liyanarachchi, G. A. (2007). Feasibility of using student subjects in accounting experiments: a review. Pacific Accounting Review, 19(1), 47 - 67.

and Milne, M.J. (2005). Comparing the investment decisions of accounting practitioners and students: an empirical study on the adequacy of student surrogates. Accounting Forum, 29, 121-135.

Locke, E. A. (2005). Why emotional intelligence is an invalid concept. Journal of Organizational Behavior, 26, 425-431.

Low, K.Y. and Tan, H.T. (2011). Does time constraint lead to poorer audit performance? Effects of forewarning of impending time constraints and instructions. Auditing: A Journal of Practice \& Theory, 30(4), 173-190.

Margheim, L., Kelley, T. and Pattison, D. (2005). An empirical analysis of the effects of auditor time budget pressure and time deadline pressure. Journal of Applied Business Research, 21(1), 23-35.

Marques, P. and Azevedo-Pereira, J. (2008). Ethical ideology and ethical judgments in the Portuguese accounting profession. Journal of Business Ethics, 86(2), 227-242.

Mayer, J. D. and Salovey, P. (1997) What is emotional intelligence?, in: P. Salovey and D. J. Sluyter (Eds) Emotional Development and Emotional Intelligence (New York: Basic Books).

and Caruso, D. R. (2000). Models of emotional intelligence. In R. J.

Sternberg (Ed.), Handbook of intelligence (2nd ed., pp. 396-420). New York: Cambridge University Press.

McNair, C. J. (1991). Proper compromises: The management control dilemma in public accounting and its impact on auditor behavior. Accounting, Organizations and Society, 16, 635-653.

Moreno, K. and Bhattacharjee, S. (2003). The impact of pressure from potential client business opportunities on the judgments of auditors across professional ranks. Auditing: A Journal of Practice and Theory, 22(1), 13-28. 
Nelson, M. W. and Tan, H. T. (2005). Judgment and decision making research in auditing: A task, person and interpersonal interaction perspective. Auditing: A Journal of Practice and Theory, 24, 41-71.

- (2006). Ameliorating conflicts of interest in auditing: effects of recent reforms on auditors and their clients. Academy of Management Review, 31(1), 30-42.

. (2009). A model and literature review of professional skepticism in auditing. Auditing: A Journal of Practice and Theory, 28(2), 1-34.

Nikolaou, I. and Tsaousis, I. (2002). Emotional intelligence in the workplace: Exploring its effects on occupational stress and organizational commitment. The International Journal of Organizational Analysis, 10, 327-342.

Norman, C.S. (1998). An experimental analysis of the relative abilities of managers and accountants to recognize risk factors associated with misappropriation of assets. Doctoral dissertation Texas A\&M University.

O’Boyle, E. H., Jr., Humphrey, R. H., Pollack, J. M., Hawver, T. H. and Story, P. A. (2010). The relation between emotional intelligence and job performance: A meta-analysis. Journal of Organizational Behavior. doi:10.1002/job.714.

Otley, D. T. and Pierce, P. J. (1996). Auditor time budget pressure: Consequences and antecedents. Accounting, Auditing and Accountability Journal, 9(1), 31-58.

Public Company Accounting Oversight Board (PCAOB). (2006). Consideration of Fraud in a Financial Statement Audit. AU Section 316. http: / /www.pcaobus.org/ standards/interim standards / auditing standards /index au.asp?series=300\&section=316.

Paino, H., Ismail, Z. and Smith, M. (2010). Dysfunctional audit behavior: An exploratory study in Malaysia. Asian Review of Accounting, 18(2), 162-173.

Rode, J. C., Mooney, C. H., Arthaud-Day, M. L., Near, J. P., Baldwin, T. T., Rubin, R. S., et al. (2007). Emotional intelligence and individual performance: Evidence of direct and moderated effects. Journal of Organizational Behavior, 28, 399-421.

Robertson, J.C. (2008). The effects of ingratiation and client incentive on auditor judgment. Doctoral dissertation The University of Alabama.

- (2010). The effects of ingratiation and client incentive on auditor judgment. Behavioral Research in Accounting, 22, 69-86.

Salovey, P. and Mayer, J. D. (1990). Emotional intelligence. Imagination, Cognition, and Personality, 9, 185-211. 
Semadar, A., Robins, G and Ferris, G. R. (2006). Comparing the validity of multiple social effectiveness constructs in the prediction of managerial job performance. Journal of Organizational Behavior , 27, 443-461.

Schafer, B. A. and Schafer, J. K. (2009). Justification and self-review: Mitigating irrelevant affect in accounting judgments. Advances in Accounting Behavioral Research, 12, 41-59.

Shapeero, M., Koh, H. C. and Killough, L. N. (2003). Underreporting and premature sign-off in public accounting. Managerial Auditing Journal, 18(6/7), 478-489.

Sharma, D. S., Sharma, D. and Ananthanarayanan, U. (2011). Client importance and earnings management: The moderating role of audit committees. Auditing: A Journal of Practice and Theory, 30(3), 125-156.

Shawver, T. and Clements, L.H. (2012). How do emotions affect ethical evaluations for accountants? Journal of Forensic \& Investigative Accounting, 4(1), 20-38.

Schiltz, P. J. and Syverud, K. D. (1999). On being a happy, healthy, and ethical member of an unhappy, unhealthy, and unethical profession. Vanderbilt Law Review,52(4), 869-951.

Schultz, J. J., Schafer, B. A. and Schafer, J. K. (2011). Mood likability: The impact of two affect types on tax judgments. Advances in Accounting, Incorporating Advances in International Accounting, 27, 81-89.

Spector, P. E. (1987). Method variance as an artifact in self-reported affect and perceptions at work: Myth of significant problem? Journal of Applied Psychology, 72, 438-443.

Simunic, D. A. and Wu, X. (2009). China-related research in auditing: A review and directions for future research. China Journal of Accounting Research, 2(2), 1-25.

Stefaniak, C. and Robertson, J. C. (2010). When auditors err: How mistake significance and superiors' historical reactions influence auditors' likelihood to admit a mistake. International Journal of Auditing 14 (1): 41-55.

Solomona, I. and Trotman, K.T. (2003). Experimental judgment and decision research in auditing:the first 25 years of AOS. Accounting, Organizations and Society, 28, 395-412.

Soobaroyen, T. and Chengabroyan, C. (2006). Auditors' perceptions of time budget pressure, premature sign offs and underreporting of chargeable time: Evidence from a developing country. International Journal of Auditing, 10, 201-218.

Sy, T., Tram, S., and O'Hara, L. A. (2006). Relation of employee and manager emotional intelligence to job satisfaction and performance. Journal of Vocational Behavior , 68, 461-473. 
Trotman, K.T. (2011). A different personal perspective through the behavioral accounting literature. Behavioral Research in Accounting, 23(1), 203-208.

Vagg, P. R. and Spielberger, C. D. (1998). Occupational stress: Measuring job pressure and organizational support in the workplace. Journal of Occupational Health Psychology, 4, 294-305.

Wong, C. S. and Law, K. S. (2002). The effect of leader and follower emotional intelligence on performance and attitude: An exploratory study. Leadership Quarterly, 13, 243-274. 


\section{Appendix A}

\section{THE AUDIT OF GTL TECHNOLOGIES}

\section{Section 1: The Audit of GTL Ltd}

Assume that Taylor, as an audit staff, is working on the audit engagement for a public client, GTL Technologies, for the fiscal year ended December 31, 2011. GTL sells electronic accessories for cell phones, computers, and other technologies. GTL purchases its inventory from manufacturers and sells to businesses and individuals.

Over the past few years, GTL's financial performance and share prices have been improving steadily, and it has been profitable. Taylor's firm has audited GTL during this time, and has always given standard, unqualified opinions for both its financial statements and internal controls.

The following table presents selected account balances from GTL's financial statements:

\begin{tabular}{|lcrr|}
\hline \multicolumn{3}{|c|}{$\mathbf{1 2 / 3 1 / 2 0 1 1}$ (Before Audit Adjustments) } \\
\hline Sales & $\$ 384,992,000$ & Merchandise Inventory & $\$ 60,115,000$ \\
Net Income & $\$ 29,200,000$ & Total Assets & $\$ 242,130,000$ \\
& & \\
Average Number of Common Shares Outstanding & $20,000,000$ \\
& & \\
& & \\
Earnings Per Share (EPS) & $\mathbf{\$ 1 . 4 6}$ &
\end{tabular}

\section{High (Low) Incentive}

Consensus analysts' EPS forecast for 12/31/11: \$1.44 (\$1.39). Many of GTL's executives, including the controller receive a bonus if the company equals or exceeds the consensus analysts' EPS forecast.

\section{High (Low) Time Budget Pressure}

The audit fee for GTL has increased slightly every year during the three years Taylor' s firm has audited them. This is due to inflation and increasing market rates for audit services. However, this year GTL contacted the partner in charge of the audit to re-negotiate the fees on the basis that Taylor' $\mathrm{s}$ firm should now be more efficient in performing the audit, due to the long involvement the firm has had in auditing GTL. After negotiating with GTL, the audit partner in charge decided to reduce the audit fees and the hours allocated to the audit. Thus, the total audit budgeted hours will be cut by about $20 \%$. (After negotiating with GTL, the audit partner in charge decided to charge the same audit fee as last year (e.g., the audit fee will not increase 
this year), and he has allocated the same amount of hours to the audit that were allocated last year. In previous years, the time budget has been reasonable for the amount of work involved, and the same amount of work is expected this year.)

\section{Accounts Receivable audit}

This is Taylor's first time working on the audit of GTL Ltd. He has been asked to perform substantive testing for the accounts receivable audit.

Please assume that no audit adjustments have been proposed at this point, and there is only one audit issue to be resolved before completing the audit. This issue is described below. Prior to field work, your firm set materiality for accounts receivable at $\$ 1,000,000$ (i.e., 5 cents effect on EPS).

When testing a transaction, Taylor finds one sale does not have a sales report. The accounts receivable in question involves one of GTL's electronic product sales. Specifically, GTL shows 60,000 units of the electronic accessory sold at year end. GTL's recorded sales price is $\$ 20$ per unit, or a total of $\$ 1,200,000$ (i.e., 6 cents of EPS). However, there is no sales report documenting this sale.

When Taylor approaches GTL's management about this problem, he is told the documents have been misplaced but management can vouch for the fact that the documents have been correctly recorded. To verify the validity of this undocumented sale, Taylor would have to contact an overseas customer. Contacting this customer would take a considerable amount of time.

\section{High (Low) Client Incentive}

If the entire sale in question is written off, GTL will miss (exceed) the EPS forecast, and the executives will not (will) receive a bonus. Also, the controller told Taylor: "if the executives do not (do) receive their bonus they will be displeased with (pleased with) the outcome of the audit."

\section{High (Low) Time Budget Pressure}

Taylor is meeting the manager in charge of the audit at $5 \mathrm{PM}$ to finalize (discuss) this accounts receivable section of the audit. Assume it is nearing 5 PM, and Taylor has reached the end of his time budget for this section of the audit. For this transaction to be verified, Taylor would (may) have to ask the manager for more time. Taylor knows that the manager has denied (granted) extensions of time in other areas of the audit due to the tightness of the time budget (as the budget is relatively flexible). 
1. In this situation, how likely is it that Taylor will further investigate this account receivable transaction?

$\begin{array}{ccccccc}\begin{array}{c}\text { Extremely } \\ \text { Unlikely }\end{array} & & & & & \begin{array}{c}\text { Extremely } \\ \text { Likely }\end{array} \\ 1 & 2 & 3 & 4 & 5 & 6 & 7\end{array}$

2. In this situation, how likely is it that Taylor will ask the manager in charge of the audit for extra time before making a final recommendation?

$\begin{array}{ccccccc}\begin{array}{c}\text { Extremely } \\ \text { Unlikely }\end{array} & & & & & \begin{array}{c}\text { Extremely } \\ \text { Likely }\end{array} \\ 1 & 2 & 3 & 4 & 5 & 6 & 7\end{array}$

3. In this situation, how likely is it that Taylor will accept the client's explanation of the missing sales report and not investigate the matter further?

$\begin{array}{ccccccc}\begin{array}{c}\text { Extremely } \\ \text { Unlikely }\end{array} & & & & & \begin{array}{c}\text { Extremely } \\ \text { Likely }\end{array} \\ 1 & 2 & 3 & 4 & 5 & 6 & 7\end{array}$

4. In this situation, what level of material misstatement risk do you think Taylor will associate with this accounts receivable testing?

$\begin{array}{ccccccc}\begin{array}{c}\text { Extremely } \\ \text { Low }\end{array} & & & & & \begin{array}{c}\text { Extremely } \\ \text { High }\end{array} \\ 1 & 2 & 3 & 4 & 5 & 6 & 7\end{array}$

5. Please indicate the extent of overall stress that Taylor experienced in this case.

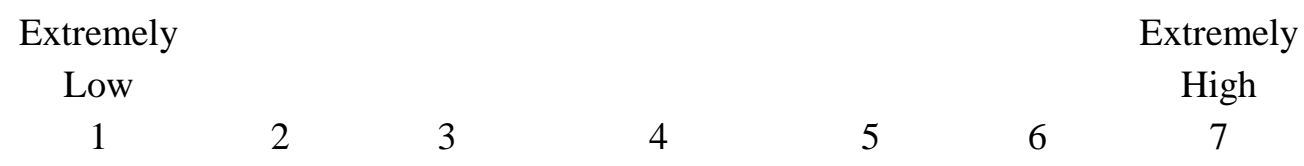

6. How much pressure do you think Taylor feels to keep the client happy?

$\begin{array}{ccccccc}\begin{array}{c}\text { Extremely } \\ \text { Low }\end{array} & & & & & \text { Extremely } \\ \text { High }\end{array}$


7. The risk that Taylor' s firm will suffer a loss (e.g., litigation risk) as a consequence of the GTL audit is

$\begin{array}{ccccccc}\text { Extremely } & & & & & \text { Extremely } \\ \text { Low } & & & & & & \text { High } \\ 1 & 2 & 3 & 4 & 5 & 6 & 7\end{array}$

8. If the entire sale in question is written off, will GTL miss or exceed the EPS forecast (select one)?

a. GTL will exceed the EPS forecast if the entire sale is written off.

b. GTL will miss the EPS forecast if the entire sale is written off.

9. Did the audit partner decide to cut the total audit budget hours by about $20 \%$ (select one)?
a. Yes
b. No

10. GTL's incentive to misstate this sale is
Extremely
Extremely
Low
3
4
5
High
1
2

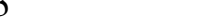

$5-6$
7

11. With respect to the scenarios given in this survey, how tight did Taylor consider the time budgets to be overall?

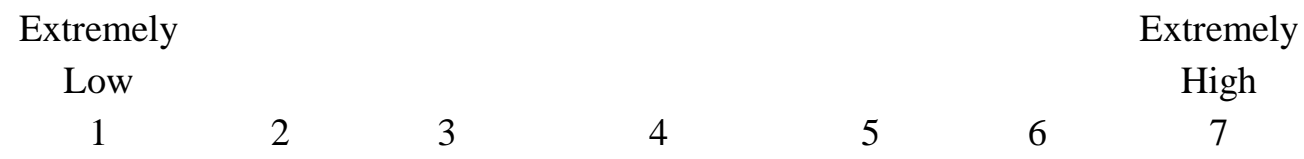

\section{Section 2}

Please indicate your agreement with each of the statements below. (Participants respond using a 7-point Likert response format ranging from 1 (strongly disagree) to 7 (strongly agree) for each item).

\section{Emotional Intelligence Scale}

Awareness of Own Emotions (Own Aware)

1. I can explain the emotions I feel to team members.

2. I can discuss the emotions I feel with other team members.

3. If I feel down, I can tell team members what will make me feel better.

4. I can talk to other members of the team about the emotions I experience. 
Management of Own Emotions (Own Manage)

5. I respect the opinion of team members, even if I think they are wrong.

6. When I am frustrated with fellow team members, I can overcome my frustration.

7. When deciding on a dispute, I try to see all sides of a disagreement before I come to a conclusion.

8. I give a fair hearing to fellow team members' ideas.

Awareness of Others' Emotions (Other Aware)

9. I can read fellow team members 'true' feelings, even if they try to hide them.

10. I am able to describe accurately the way others in the team are feeling

11. When I talk to a team member I can gauge their true feelings from their body language.

12. I can tell when team members don't mean what they say.

Management of Others' Emotions (Other Manage)

13. My enthusiasm can be contagious for members of a team.

14. I am able to cheer team members up when they are feeling down.

15. I can get fellow team members to share my keenness for a project.

16. I can provide the 'spark' to get fellow team members enthusiastic.

\section{Professional skepticism scale}

1. I often question things that clients tell me.

2. I require proof that my clients' statements are true.

3. I am cautious when evaluating information obtained from clients.

4. Clients are generally honest (reverse item).

5. I tend to trust what clients tell me (reverse item).

\section{Section 3}

Please answer a few final questions about yourself.

1. Please indicate the best description of your current work position:
Auditor Staff
Auditor Senior
Auditor Manager

Other (please explain)

2. How many years of full time work experience do you have in each of the following categories:

In Auditing In Accounting

Other (please explain)

3. How would you describe your current employer?
a. Single office firm
b. Regional firm
c. National firm
d. Big 4 firm
e. Other (please specify) 
4. How long have you been employed with your current employer?

5. Please indicate any professional designations you possess (Choose all that apply):

\section{CICPA}

Certified Junior Management Accountant

$\square$ Certified Senior Management Accountant

Other (Please explain)

6. In your experience, how attainable are the time budgets at your organization?

Easily

Attainable

1

2

Attainable with effort

3

Impossible to achieve 7

7. What level of importance is placed on meeting time budgets in your organization?

$\begin{array}{ccccccc}\begin{array}{c}\text { Extremely } \\ \text { Low }\end{array} & & & & & \text { Extremely } \\ \text { High }\end{array}$

8. Please indicate the extent of overall stress you experienced in your organization.

Extremely<smiles>[GeH2]</smiles>

1

2

3

4

5

6

Extremely

High

7

9. In what year were you born?

10. What is your gender?

$\square$ Male $\quad \square$ Female

11. Please select the highest education level you have attained:

$\square$ High School

$\square$ Associate Degree

$\square$ Undergraduate Degree

$\square$ Master Degree or higher

Thank you for your participation in this survey! 


\section{Tables}

Table 1

Demographic Information

Female

Auditors $(\mathrm{n}=190)$

Mean Age (Range)

100

$52.6 \%$

26.06 (24 to 29 )

Highest Degree Completed:

Undergraduate Degree

Master Degree

150

40

$78.9 \%$

Certifications:

CICPA (Chinese CPA)

Certified Senior Management

Accountant

Certified Junior Management

Accountant

146

$21.1 \%$

3

$76.8 \%$

$1.6 \%$

5

$2.60 \%$

Auditing Experience in Years

Mean (Std. Deviation)

2.26(1.04)

Accounting Experience in Years

1.4

Mean (Std. Deviation)

$0.13(0.373)$

$(0.5)$

Job Title:

Auditor Staff

160

$15.8 \%$

Auditor Team Leader (Senior)

30

$84.2 \%$

Employer:

Big-4

160

$84.2 \%$

Non Big-4

30

$15.8 \%$ 
\Table 2

\begin{tabular}{ccccc}
\hline $\begin{array}{l}\text { Panel A: Means (and standard deviations) for further } \\
\text { investigation }\end{array}$ & \multicolumn{4}{l}{} \\
\hline Time Budget & \multicolumn{4}{c}{ Client Incentive Pressure } \\
\cline { 2 - 5 } Pressure & Descriptives & Low & High & Total \\
\hline Low & Mean & 2.80 & 4.13 & 3.51 \\
& $(n)$ & 40 & 46 & 86 \\
High & $(\mathrm{SD})$ & .758 & 1.222 & 1.225 \\
& Mean & 3.76 & 4.83 & 4.44 \\
& $(n)$ & 38 & $66^{13}$ & 104 \\
Total & $(\mathrm{SD})$ & .998 & 1.660 & 1.538 \\
& Mean & 3.27 & 4.54 & 4.02 \\
& $(n)$ & 78 & 112 & 190 \\
& $(\mathrm{SD})$ & 1.002 & 1.530 & 1.476 \\
\hline
\end{tabular}

Table 2

Panel B: Means (and standard deviations) for risk assessment

\begin{tabular}{ccccc}
\hline \multirow{2}{*}{$\begin{array}{c}\text { Time Budget } \\
\text { Pressure }\end{array}$} & \multicolumn{4}{c}{ Client Incentive Pressure } \\
\cline { 2 - 5 } & Descriptives & Low & High & Total \\
\hline Low & Mean & 3.05 & 4.26 & 3.70 \\
& $(n)$ & 40 & 46 & 86 \\
& $(\mathrm{SD})$ & .677 & 0.953 & 1.030 \\
High & Mean & 3.79 & 5.29 & 4.74 \\
& $(n)$ & 38 & 66 & 104 \\
& $(\mathrm{SD})$ & .811 & 1.345 & 1.379 \\
Total & Mean & 3.41 & 4.87 & 4.27 \\
& $(n)$ & 78 & 112 & 190 \\
& $(\mathrm{SD})$ & 0.829 & 1.298 & 1.336 \\
\hline
\end{tabular}

Table 3

${ }^{13}$ Box's test from MANCOVA shows equal covariance metrics $(\mathrm{F}=0.884, p=0.613)$, so unequal sample size does not cause the problem. 
Results of MANCOVA using auditors' judgment of the level of risk and the likelihood of further investigation as dependent variables.

\begin{tabular}{clrccc}
\hline Source of variation & Dependent variable & \multicolumn{1}{c}{ SS } & df & \multicolumn{1}{c}{$\boldsymbol{F}$} & $\boldsymbol{p}$ \\
\hline \multirow{2}{*}{ Audit } & Further investigation & 4.495 & 1.000 & 3.964 & 0.048 \\
& Risk level & 0.098 & 1.000 & 0.086 & 0.770 \\
PS & Further investigation & 156.287 & 1.000 & 137.815 & 0.000 \\
& Risk level & 72.764 & 1.000 & 63.446 & 0.000 \\
TB & Further investigation & 10.733 & 1.000 & 9.465 & 0.002 \\
& Risk level & 24.677 & 1.000 & 21.517 & 0.000 \\
Error & Further investigation & 210.931 & 186.000 & & \\
& Risk level & 213.318 & 186.000 & & \\
Error & & & & & \\
\hline
\end{tabular}


Table 4

Results of MANCOVA using auditors' judgment of the level of risk and the likelihood of further investigation as dependent variables.

\begin{tabular}{clcccc}
\hline Source of variation & Dependent variable & SS & df & $\boldsymbol{F}$ & $\boldsymbol{p}$ \\
\hline \multirow{2}{*}{ Audit } & Further investigation & 4.59193 & 1 & 4.694 & 0.032 \\
& Risk level & 0.124084 & 1 & 0.135 & 0.713 \\
PS & Further investigation & 151.0075 & 1 & 154.351 & 0.000 \\
& Risk level & 69.31849 & 1 & 75.635 & 0.000 \\
CI & Further investigation & 39.69267 & 1 & 40.571 & 0.000 \\
& Risk level & 67.52876 & 1 & 73.682 & 0.000 \\
& Further investigation & 181.9713 & 186 & & \\
& Risk level & 170.4662 & 186 & & \\
\hline
\end{tabular}


Table 5

Results of MANCOVA using auditors' judgment of the level of risk and the likelihood of further investigation as dependent variables.

\begin{tabular}{clcccc}
\hline Source of variation & Dependent variable & SS & df & $\boldsymbol{F}$ & $\boldsymbol{p}$ \\
\hline \multirow{2}{*}{ Audit } & Further investigation & 4.562086 & 1 & 4.903 & 0.028 \\
& Risk level & 0.079284 & 1 & 0.097 & 0.756 \\
PS & Further investigation & 130.4747 & 1 & 140.225 & 0.000 \\
& Risk level & 50.4013 & 1 & 61.753 & 0.000 \\
TB & Further investigation & 9.546189 & 1 & 10.260 & 0.002 \\
& Risk level & 18.79357 & 1 & 23.026 & 0.000 \\
& Further investigation & 38.18552 & 1 & 41.039 & 0.000 \\
TB $*$ CI & Risk level & 62.20955 & 1 & 76.220 & 0.000 \\
& Further investigation & 2.39961 & 1 & 2.579 & 0.110 \\
& Risk level & 0.322761 & 1 & 0.395 & 0.530 \\
& Further investigation & 171.2059 & 184 & & \\
& Risk level & 150.1772 & 184 & & \\
\hline
\end{tabular}


Table 6

Results of MANCOVA using auditors' judgment of the level of risk and the likelihood of further investigation as dependent variables.

\begin{tabular}{|c|c|c|c|c|c|}
\hline Sources of variation & Dependent Variable & SS & Df & $\boldsymbol{F}$ & $p$ \\
\hline \multirow[t]{2}{*}{ Audit } & Further investigation & 2.661 & 1 & 3.191 & 0.076 \\
\hline & Risk level & 0.000 & 1 & 0.000 & 0.999 \\
\hline \multirow[t]{2}{*}{ PS } & Further investigation & 4.376 & 1 & 5.247 & 0.023 \\
\hline & Risk level & 2.415 & 1 & 2.371 & 0.125 \\
\hline \multirow[t]{2}{*}{$\mathrm{TB}$} & Further investigation & 17.973 & 1 & 21.552 & 0.000 \\
\hline & Risk level & 31.226 & 1 & 30.648 & 0.000 \\
\hline \multirow[t]{2}{*}{ EI } & Further investigation & 50.433 & 1 & 60.476 & 0.000 \\
\hline & Risk level & 21.661 & 1 & 21.261 & 0.000 \\
\hline \multirow[t]{2}{*}{$\mathrm{TB} * \mathrm{EI}$} & Further investigation & 7.972 & 1 & 9.559 & 0.002 \\
\hline & Risk level & 4.652 & 1 & 4.566 & 0.034 \\
\hline \multirow[t]{2}{*}{ Error } & Further investigation & 153.445 & 184 & & \\
\hline & Risk level & 187.466 & 184 & & \\
\hline
\end{tabular}


Table 7

Results of MANCOVA using auditors' judgment of the level of risk and the likelihood of further investigation as dependent variables.

\begin{tabular}{cccccc}
\hline Sources of variation & Dependent Variable & SS & Df & $\boldsymbol{F}$ & $\boldsymbol{p}$ \\
\hline \multirow{2}{*}{ Audit } & Further investigation & 1.906006 & 1 & 3.083 & 0.081 \\
& Risk level & 0.068638 & 1 & 0.101 & 0.751 \\
PS & Further investigation & 3.910914 & 1 & 6.326 & 0.013 \\
& Risk level & 1.843086 & 1 & 2.714 & 0.101 \\
CI & Further investigation & 47.41132 & 1 & 76.694 & 0.000 \\
& Risk level & 75.70019 & 1 & 111.484 & 0.000 \\
EI & Further investigation & 45.38385 & 1 & 73.415 & 0.000 \\
& Risk level $*$ EI & 17.55224 & 1 & 25.849 & 0.000 \\
& Further investigation & 20.37942 & 1 & 32.966 & 0.000 \\
\multirow{2}{*}{ Error } & Risk level & 26.24093 & 1 & 38.645 & 0.000 \\
& Further investigation & 113.7462 & 184 & & \\
\hline
\end{tabular}


Table 8

Results of MANCOVA using auditors' judgment of the level of risk and the likelihood of further investigation as dependent variables.

\begin{tabular}{|c|c|c|c|c|c|}
\hline Sources of variation & Dependent Variable & SS & Df & $F$ & $p$ \\
\hline \multirow{2}{*}{ Audit } & Further investigation & 1.784 & 1 & 3.634 & 0.058 \\
\hline & Risk level & 0.180 & 1 & 0.373 & 0.542 \\
\hline \multirow{3}{*}{ PS } & Further investigation & 0.851 & 1 & 1.733 & 0.190 \\
\hline & Risk level & 0.002 & 1 & 0.004 & 0.951 \\
\hline & Further investigation & 15.778 & 1 & 32.134 & 0.000 \\
\hline $\mathrm{TB}$ & Risk level & 22.375 & 1 & 46.391 & 0.000 \\
\hline \multirow{2}{*}{ CI } & Further investigation & 43.610 & 1 & 88.821 & 0.000 \\
\hline & Risk level & 65.213 & 1 & 135.211 & 0.000 \\
\hline \multirow{2}{*}{ EI } & Further investigation & 49.379 & 1 & 100.570 & 0.000 \\
\hline & Risk level & 21.234 & 1 & 44.027 & 0.000 \\
\hline \multirow{2}{*}{$\mathrm{TB} * \mathrm{CI}$} & Further investigation & 3.195 & 1 & 6.507 & 0.012 \\
\hline & Risk level & 0.124 & 1 & 0.256 & 0.613 \\
\hline \multirow{2}{*}{$\mathrm{TB} * \mathrm{EI}$} & Further investigation & 5.493 & 1 & 11.187 & 0.001 \\
\hline & Risk level & 1.362 & 1 & 2.824 & 0.095 \\
\hline \multirow{2}{*}{$\mathrm{CI} * \mathrm{EI}$} & Further investigation & 18.987 & 1 & 38.671 & 0.000 \\
\hline & Risk level & 22.630 & 1 & 46.920 & 0.000 \\
\hline \multirow{2}{*}{$\mathrm{TB} * \mathrm{CI} * \mathrm{EI}$} & Further investigation & 1.646 & 1 & 3.353 & 0.069 \\
\hline & Risk level & 9.450 & 1 & 19.593 & 0.000 \\
\hline \multirow{2}{*}{ Error } & Further investigation & 88.378 & 180 & & \\
\hline & Risk level & 86.815 & 180 & & \\
\hline
\end{tabular}


Table 9

Results of ANCOVA using auditors' judgment of the level of risk as dependent variables when $\mathrm{EI}=0$

\begin{tabular}{ccccc}
\hline $\begin{array}{c}\text { Sources of } \\
\text { variation }\end{array}$ & SS & Df & $\boldsymbol{F}$ & $\boldsymbol{p}$ \\
\hline Audit & 0.058 & 1 & 0.125 & 0.725 \\
PS & 2.763 & 1 & 5.953 & 0.017 \\
TB & 5.430 & 1 & 11.698 & 0.001 \\
CI & 5.342 & 1 & 11.509 & 0.001 \\
TB $*$ CI & 4.546 & 1 & 9.795 & 0.002 \\
Error & 41.310 & 89 & & \\
\hline
\end{tabular}


Table 10

Results of ANCOVA using auditors' judgment of the level of risk as dependent variables when $\mathrm{EI}=1$

\begin{tabular}{ccccc}
\hline $\begin{array}{c}\text { Sources of } \\
\text { variation }\end{array}$ & SS & Df & $\boldsymbol{F}$ & $\boldsymbol{p}$ \\
\hline Audit & 0.510 & 1 & 1.090 & 0.299 \\
PS & 1.015 & 1 & 2.170 & 0.144 \\
TB & 18.296 & 1 & 39.132 & 0.000 \\
CI & 80.208 & 1 & 171.553 & 0.000 \\
TB $*$ CI & 5.734 & 1 & 12.264 & 0.001 \\
Error & 41.611 & 89 & & \\
\hline
\end{tabular}


Table 11

Results of ANCOVA using auditors' judgment of the likelihood of further investigation as dependent variables when $\mathrm{EI}=0$

\begin{tabular}{ccccc}
$\begin{array}{c}\text { Sources of } \\
\text { variation }\end{array}$ & SS & Df & $\boldsymbol{F}$ & $\boldsymbol{p}$ \\
\hline Audit & 0.865 & 1 & 1.668 & 0.200 \\
PS & 0.158 & 1 & 0.304 & 0.583 \\
TB & 1.540 & 1 & 2.969 & 0.088 \\
CI & 2.757 & 1 & 5.315 & 0.023 \\
TB $*$ CI & 4.899 & 1 & 9.443 & 0.003 \\
Error & 46.171 & 89 & & \\
\hline
\end{tabular}


Table 12

Results of ANCOVA using auditors' judgment of the likelihood of further investigation as dependent variables when $\mathrm{EI}=1$

\begin{tabular}{ccccc}
\hline $\begin{array}{c}\text { Sources of } \\
\text { variation }\end{array}$ & SS & Df & $\boldsymbol{F}$ & $\boldsymbol{p}$ \\
\hline Audit & 0.916 & 1 & 1.932 & 0.168 \\
PS & 0.670 & 1 & 1.414 & 0.238 \\
TB & 18.275 & 1 & 38.542 & 0.000 \\
CI & 55.772 & 1 & 117.625 & 0.000 \\
TB * CI & 0.121 & 1 & 0.256 & 0.614 \\
Error & 42.199 & 89 & & \\
\hline
\end{tabular}




\section{Table13}

Hypotheses Summary

\begin{tabular}{|c|c|c|}
\hline Hypotheses & p-value & Supported \\
\hline $\begin{array}{l}\text { H1: Auditors will make more conservative } \\
\text { judgments when they experience less time } \\
\text { pressure. }\end{array}$ & $<0.001$ on both dependent variables & $\sqrt{ }$ \\
\hline $\begin{array}{l}\text { H2b: Auditors will make less conservative } \\
\text { judgments when the client has low incentive } \\
\text { to influence the auditor. }\end{array}$ & $<0.001$ on both dependent variables & $\sqrt{ }$ \\
\hline $\begin{array}{l}\text { H3: Auditor judgment will be influenced by } \\
\text { time budget pressure to a greater extent when } \\
\text { client incentive pressure is absent than when } \\
\text { client incentive pressure is present. }\end{array}$ & $\begin{array}{c}<0.012 \text { on Further investigation; } \\
0.613 \text { on Risk level }\end{array}$ & Partial \\
\hline $\begin{array}{l}\text { H4: Auditors with high EI will make more } \\
\text { conservative judgments than auditors with } \\
\text { low EI when they are exposed to time budget } \\
\text { pressure. }\end{array}$ & $\begin{array}{c}<0.001 \text { on Further investigation; } \\
0.095 \text { on Risk level }\end{array}$ & $\sqrt{ }$ \\
\hline $\begin{array}{l}\text { H5: Auditors with high EI will make more } \\
\text { conservative judgments than auditors with } \\
\text { low EI when they are exposed to client } \\
\text { incentive pressure. }\end{array}$ & $<0.001$ on both dependent variables & $\sqrt{ }$ \\
\hline $\begin{array}{l}\text { H6: Auditors with high EI will make more } \\
\text { conservative judgments than auditors with } \\
\text { low EI when they are exposed to both time } \\
\text { budget and client incentive pressure. }\end{array}$ & $\begin{array}{c}<0.069 \text { on Further investigation; } \\
<0.001 \text { on Risk level }\end{array}$ & $\sqrt{ }$ \\
\hline
\end{tabular}


Table 14

\begin{tabular}{ccccc}
\hline \multirow{2}{*}{$\begin{array}{c}\text { Panel A: Means (and standard deviations) for loss risk } \\
\text { Pressure }\end{array}$} & \multicolumn{3}{c}{ CI } \\
\cline { 2 - 5 } Low & Descriptives & Low & High & Total \\
& Mean & 2.88 & 4.02 & 3.49 \\
& $(\mathrm{SD})$ & 0.757 & 0.802 & 0.967 \\
High & $n$ & 40 & 46 & 86 \\
& Mean & 3.421 & 5.17 & 4.53 \\
& $(\mathrm{SD})$ & 0.758 & 0.756 & 1.132 \\
Total & $n$ & 38 & 66 & 104 \\
& Mean & 3.14 & 4.70 & 4.06 \\
& $(\mathrm{SD})$ & 0.80 & 0.96 & 1.18 \\
& $n$ & 78 & 112 & 190 \\
\hline
\end{tabular}

Panel B: Results of ANCOVA using auditors' judgment of loss risk

\begin{tabular}{ccccc}
\hline Source of variation & SS & df & $\boldsymbol{F}$ & $\boldsymbol{p}$ \\
\hline Audit & 1.19286 & 1 & 2.320 & 0.129 \\
PS & 14.0645 & 1 & 27.348 & 0.000 \\
TB & 22.8348 & 1 & 44.402 & 0.000 \\
CI & 81.4521 & 1 & 158.384 & 0.000 \\
TB * CI & 3.18192 & 1 & 6.187 & 0.014 \\
Error & 94.6259 & 184 & & \\
\hline
\end{tabular}


Table 15

Results of MANCOVA using auditors' judgment of requesting extra time and accepting client explanation as dependent variables.

\begin{tabular}{|c|c|c|c|c|c|}
\hline Sources of variation & Dependent Variable & SS & Df & $F$ & $p$ \\
\hline \multirow[t]{2}{*}{ Audit } & Requesting time & 1.304 & 1 & 2.734 & 0.100 \\
\hline & Accepting explanation & 2.464 & 1 & 3.964 & 0.048 \\
\hline \multirow[t]{2}{*}{$\operatorname{avgPS}$} & Requesting time & 2.775 & 1 & 5.816 & 0.017 \\
\hline & Accepting explanation & 12.351 & 1 & 19.867 & 0.000 \\
\hline \multirow[t]{2}{*}{$\mathrm{TB}$} & Requesting time & 8.449 & 1 & 17.708 & 0.000 \\
\hline & Accepting explanation & 9.374 & 1 & 15.078 & 0.000 \\
\hline \multirow[t]{2}{*}{ CI } & Requesting time & 40.761 & 1 & 85.427 & 0.000 \\
\hline & Accepting explanation & 47.386 & 1 & 76.221 & 0.000 \\
\hline \multirow[t]{2}{*}{ EI } & Requesting time & 54.195 & 1 & 113.584 & 0.000 \\
\hline & Accepting explanation & 21.647 & 1 & 34.819 & 0.000 \\
\hline \multirow[t]{2}{*}{$\mathrm{TB} * \mathrm{CI}$} & Requesting time & 9.046 & 1 & 18.960 & 0.000 \\
\hline & Accepting explanation & 0.158 & 1 & 0.254 & 0.615 \\
\hline \multirow[t]{2}{*}{$\mathrm{TB} * \mathrm{EI}$} & Requesting time & 0.857 & 1 & 1.797 & 0.182 \\
\hline & Accepting explanation & 0.175 & 1 & 0.281 & 0.597 \\
\hline \multirow[t]{2}{*}{$\mathrm{CI} * \mathrm{EI}$} & Requesting time & 9.631 & 1 & 20.186 & 0.000 \\
\hline & Accepting explanation & 1.615 & 1 & 2.598 & 0.109 \\
\hline \multirow[t]{2}{*}{$\mathrm{TB} * \mathrm{CI} * \mathrm{EI}$} & Requesting time & 4.335 & 1 & 9.084 & 0.003 \\
\hline & Accepting explanation & 0.917 & 1 & 1.474 & 0.226 \\
\hline \multirow[t]{2}{*}{ Error } & Requesting time & 85.885 & 180 & & \\
\hline & Accepting explanation & 111.906 & 180 & & \\
\hline
\end{tabular}


Table 16

Results of ANCOVA using auditors' judgment of the likelihood of requesting extra time as dependent variables when $\mathrm{EI}=0$

\begin{tabular}{ccccc}
\hline $\begin{array}{c}\text { Sources of } \\
\text { variation }\end{array}$ & SS & Df & $\boldsymbol{F}$ & $\boldsymbol{p}$ \\
\hline Audit & 0.053 & 1 & 0.150 & 0.700 \\
PS & 0.023 & 1 & 0.066 & 0.798 \\
TB & 2.583 & 1 & 7.254 & 0.008 \\
CI & 5.881 & 1 & 16.513 & 0.000 \\
TB * CI & 13.072 & 1 & 36.706 & 0.000 \\
Error & 31.696 & 89 & & \\
\hline
\end{tabular}


Table 17

Results of ANCOVA using auditors' judgment of requesting extra time as dependent variables when $\mathrm{EI}=1$

\begin{tabular}{cccrc}
\hline $\begin{array}{c}\text { Sources of } \\
\text { variation }\end{array}$ & SS & Df & $\boldsymbol{F}$ & $\boldsymbol{p}$ \\
\hline Audit & 2.217 & 1 & 3.745 & 0.056 \\
PS & 3.906 & 1 & 6.599 & 0.012 \\
TB & 6.126 & 1 & 10.349 & 0.002 \\
CI & 40.204 & 1 & 67.921 & 0.000 \\
TB * CI & 0.456 & 1 & 0.770 & 0.383 \\
Error & 52.681 & 89 & & \\
\hline
\end{tabular}


Table 18

Results of ANCOVA using auditors' judgment of the likelihood of accepting client's explanation as dependent variables when $\mathrm{EI}=0$

\begin{tabular}{cccrl}
\hline $\begin{array}{c}\text { Sources of } \\
\text { variation }\end{array}$ & SS & Df & $\boldsymbol{F}$ & $\boldsymbol{p}$ \\
\hline Audit & 1.310 & 1 & 2.150 & 0.146 \\
PS & 3.251 & 1 & 5.336 & 0.023 \\
TB & 3.760 & 1 & 6.173 & 0.015 \\
CI & 35.388 & 1 & 58.094 & 0.000 \\
TB $*$ CI & 0.961 & 1 & 1.577 & 0.212 \\
Error & 54.215 & 89 & & \\
\hline
\end{tabular}


Table 19

Results of ANCOVA using auditors' judgment of the likelihood of accepting client's explanation as dependent variables when $\mathrm{EI}=1$

\begin{tabular}{cccrl}
\hline $\begin{array}{c}\text { Sources of } \\
\text { variation }\end{array}$ & SS & Df & \multicolumn{1}{c}{$\boldsymbol{F}$} & $\boldsymbol{p}$ \\
\hline Audit & 1.113 & 1 & 1.717 & 0.193 \\
PS & 8.693 & 1 & 13.415 & 0.000 \\
TB & 5.660 & 1 & 8.735 & 0.004 \\
CI & 14.803 & 1 & 22.844 & 0.000 \\
TB $*$ CI & 0.152 & 1 & 0.235 & 0.629 \\
Error & 57.671 & 89 & & \\
\hline
\end{tabular}




\section{Figures}

Job Pressures

Strain Outcomes

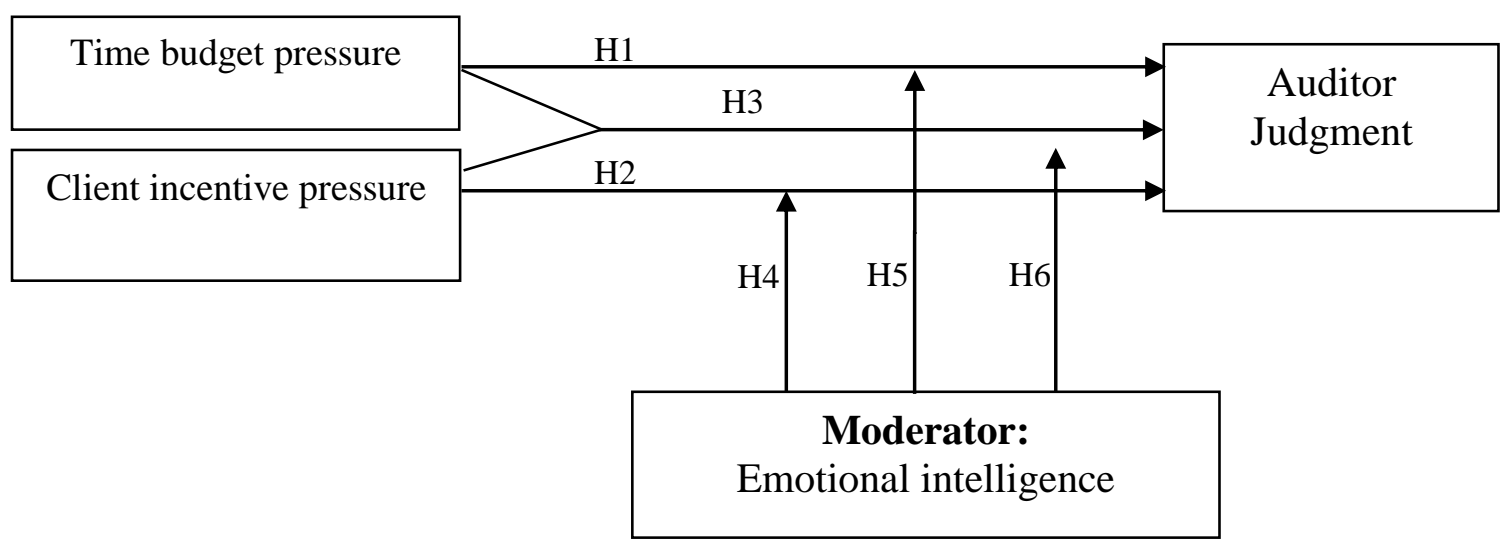

Control variables:

Professional skepticism

Years of Experience

Figure 1. Research Model

Theoretical model adapted from DeZoort and Lord (1997) 


\begin{tabular}{|c|c|c|}
\hline \multirow[b]{2}{*}{ Self } & Emotional Awareness & Emotional Management \\
\hline & $\begin{array}{l}\text { Awareness of Own } \\
\text { Emotions }\end{array}$ & Management of Own Emotions \\
\hline $\begin{array}{l}\text { Focus of } \\
\text { Attention }\end{array}$ & & \\
\hline Others & Awareness of Other's Emotions & Management of Other's Emotions \\
\hline
\end{tabular}

Figure 2. A model of Emotional Intelligence from Jordan and Lawrence (2009) 


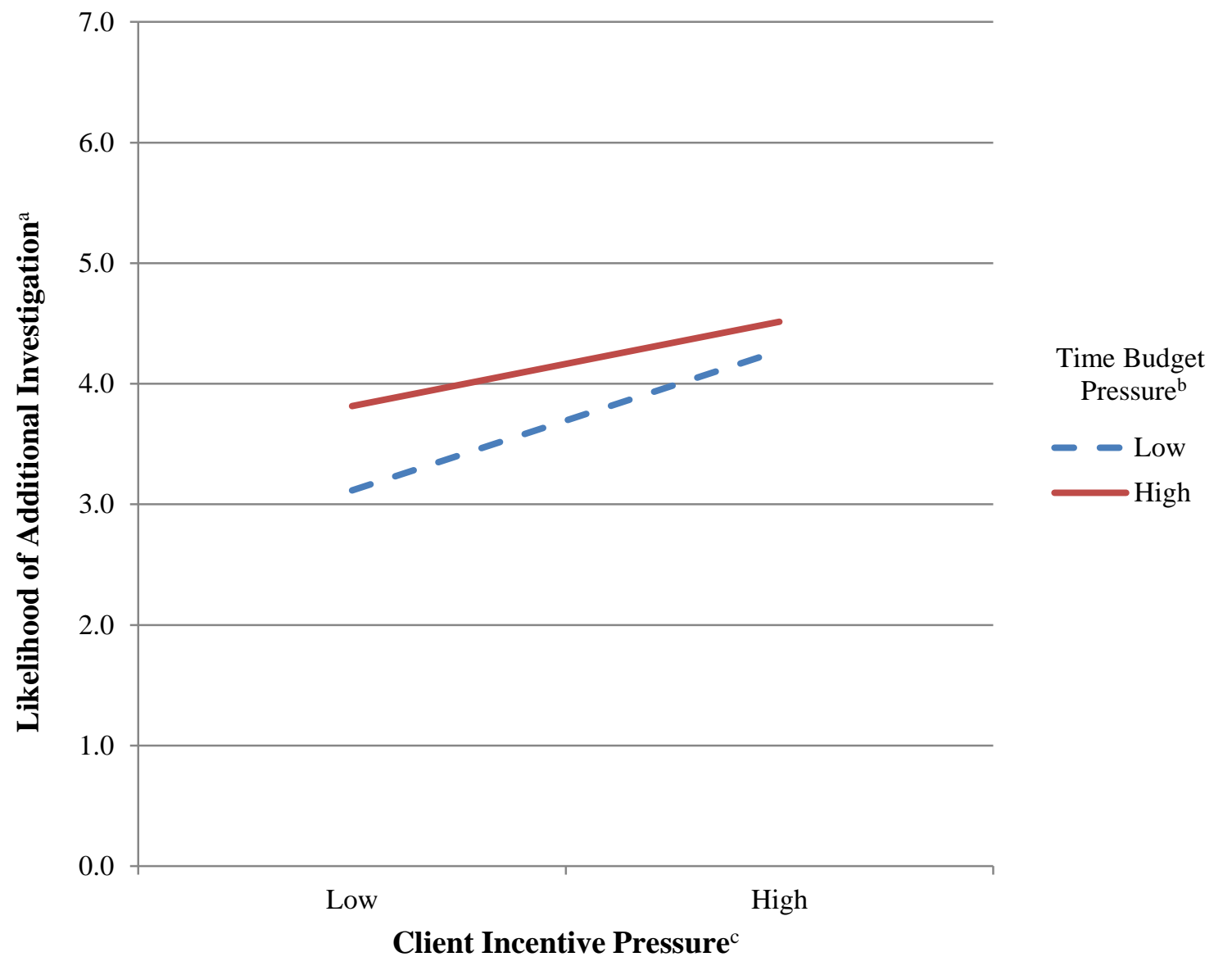

\begin{abstract}
a Auditors indicated the likelihood that additional time and effort that would be spent to further investigate this questionable transaction. Participants responded using a seven point scale anchored by "extremely unlikely" (1) and "extremely likely" (7). This figure graphs the estimated marginal means of the likelihood of additional investigation with covariates appearing in the model evaluated at the following values:Auditing experience and Professional skepticism. See Table 3 for the MANCOVA results.

b Time budget pressure was manipulated between subjects at two levels: low and high.

${ }^{\mathrm{c}}$ Client incentive pressure was manipulated between subjects at two levels: low and high.
\end{abstract}

Figure 3. Interaction of client incentive pressure and time budget pressure on auditors' assessment of the likelihood of additional investigation 


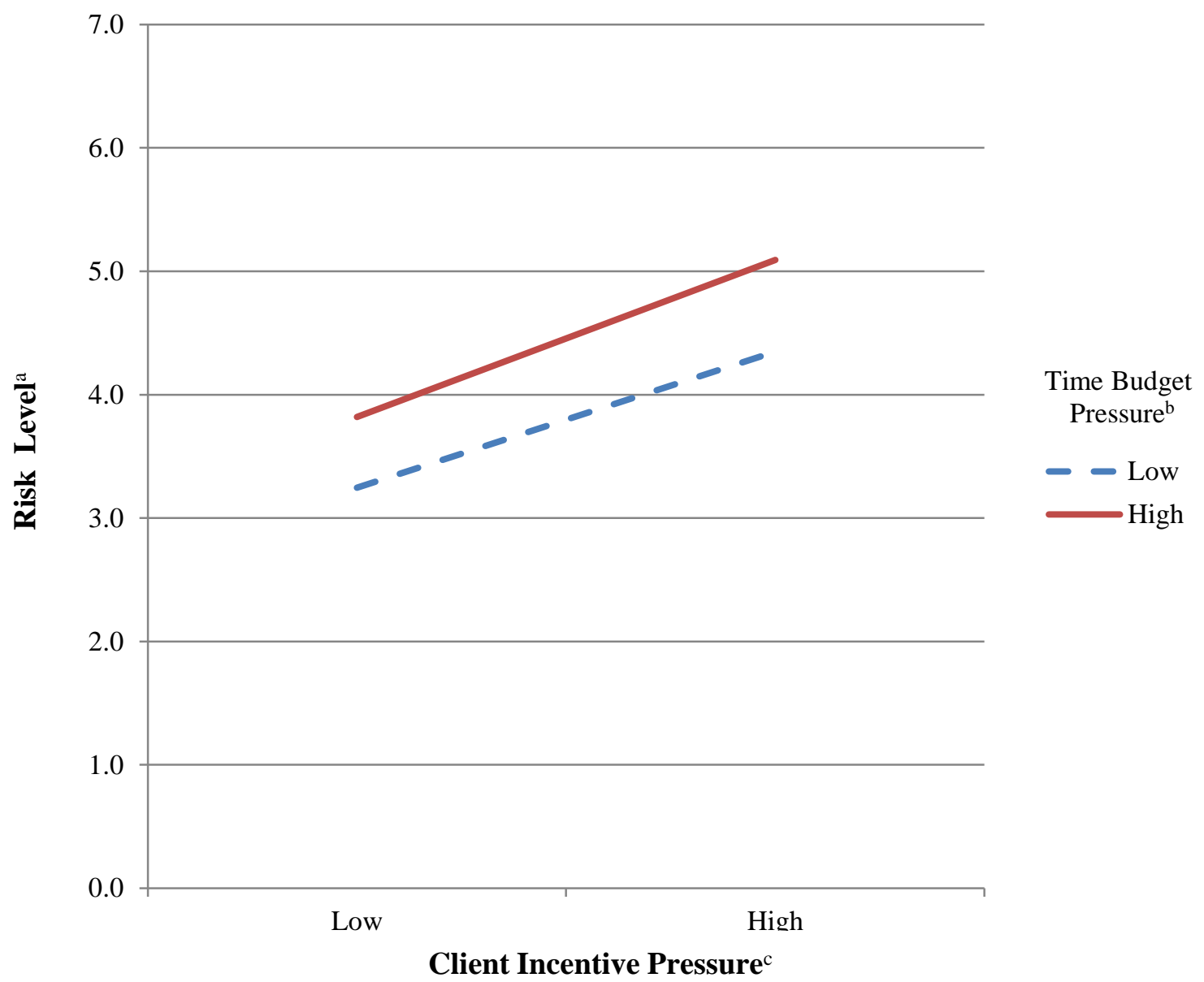

${ }^{a}$ Auditors indicated the level of material misstatement risk they think will be associated with this account receivable transaction. Participants responded using a seven point scale anchored by "extremely unlikely" (1) and "extremely likely" (7). This figure graphs This figure graphs the estimated marginal means of the auditors' risk assessment with covariates appearing in the model evaluated at the following values:Auditing experience and Professional skepticism. See Table 3 for the MANCOVA results.

${ }^{\mathrm{b}}$ Time budget pressure was manipulated between subjects at two levels: low and high.

${ }^{\mathrm{c}}$ Client incentive pressure was manipulated between subjects at two levels: low and high.

Figure 4. Interaction of client incentive pressure and time budget pressure on auditors' assessment of risk level 


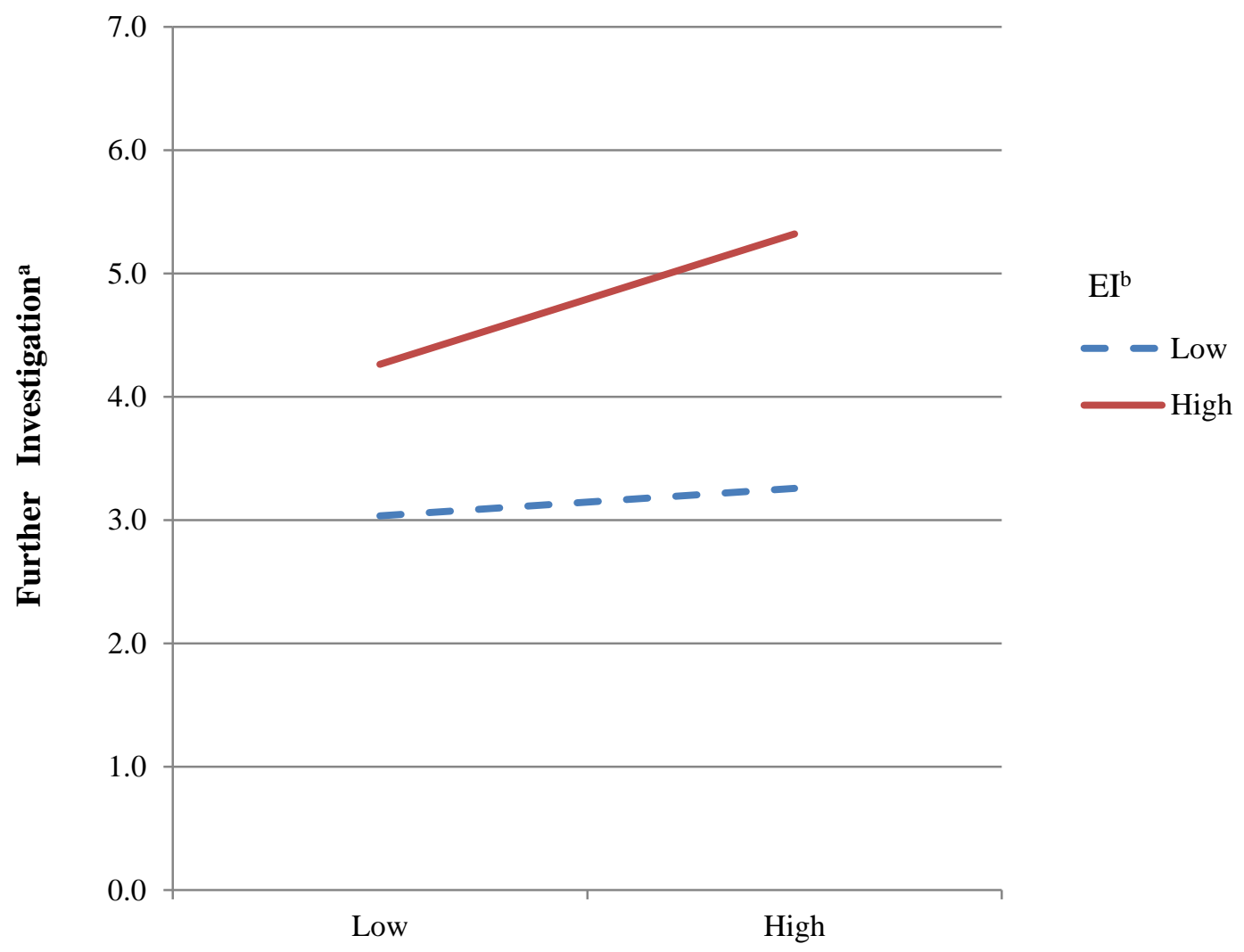

Time Budget Pressure ${ }^{c}$

a Auditors indicated the likelihood that additional time and effort that would be spent to further investigate this questionable transaction. Participants responded using a seven point scale anchored by "extremely unlikely" (1) and "extremely likely" (7). This figure graphs the estimated marginal means of the likelihood of additional investigation with covariates appearing in the model evaluated at the following values:Auditing experience and Professional skepticism. See Table 6 for the MANCOVA results.

b Time budget pressure was manipulated between subjects at two levels: low and high.

${ }^{\mathrm{c}}$ EI was measured between subjects at two levels: low and high.

Figure 5. Interaction of time budget pressure and EI on auditors' assessment of the likelihood of additional investigation 


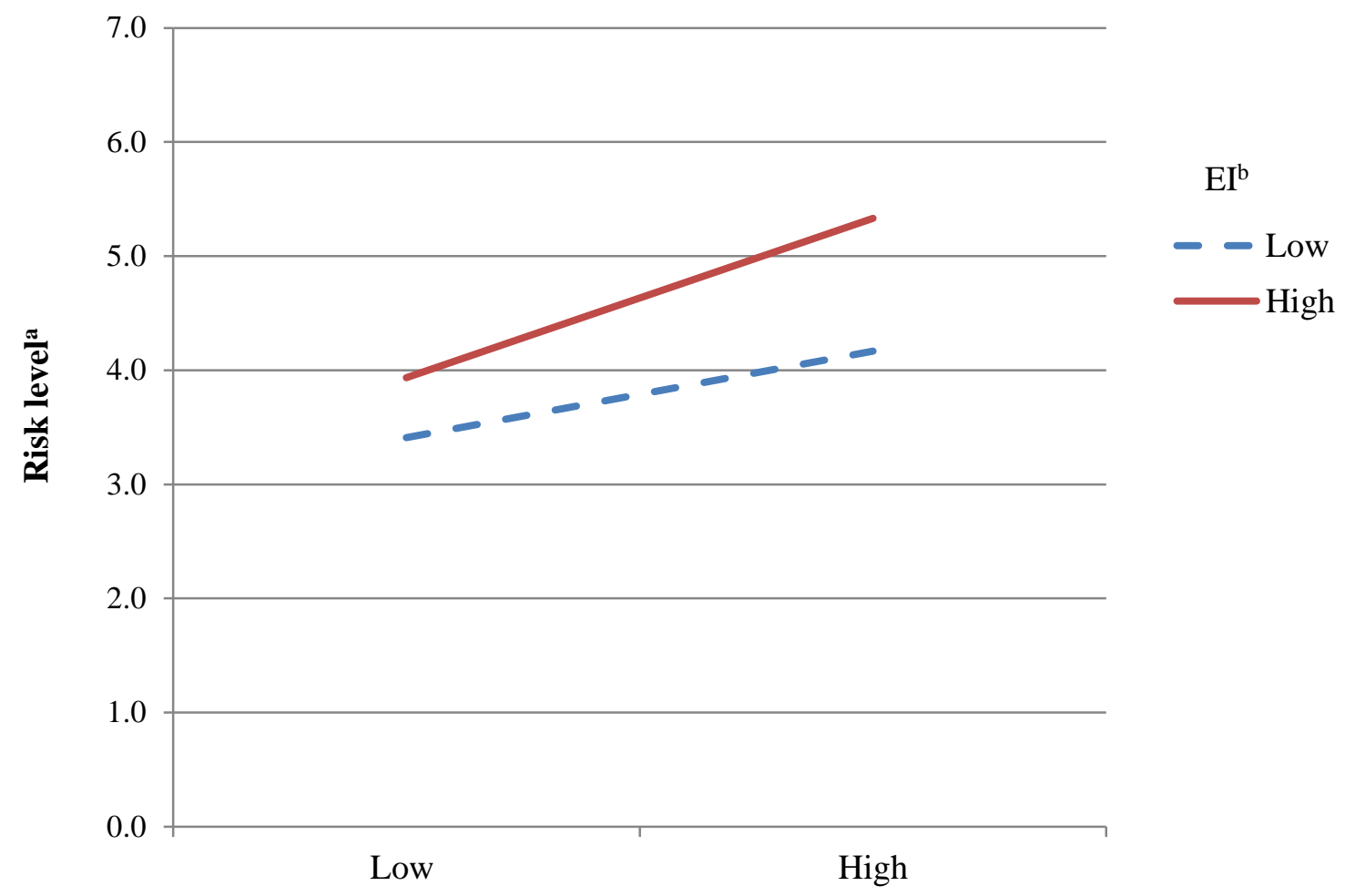

Time Budget Pressure ${ }^{c}$

${ }^{a}$ Auditors indicated the level of material misstatement risk they think will be associated with this account receivable transaction. Participants responded using a seven point scale anchored by "extremely unlikely" (1) and "extremely likely" (7). This figure graphs This figure graphs the estimated marginal means of the auditors' risk assessment with covariates appearing in the model evaluated at the following values:Auditing experience and Professional skepticism. See Table 6 for the MANCOVA results.

$\mathrm{b}$ Time budget pressure was manipulated between subjects at two levels: low and high.

${ }^{\mathrm{c}}$ EI was measured between subjects at two levels: low and high.

Figure 6. Interaction of time budget pressure and EI on auditors' assessment of risk level 


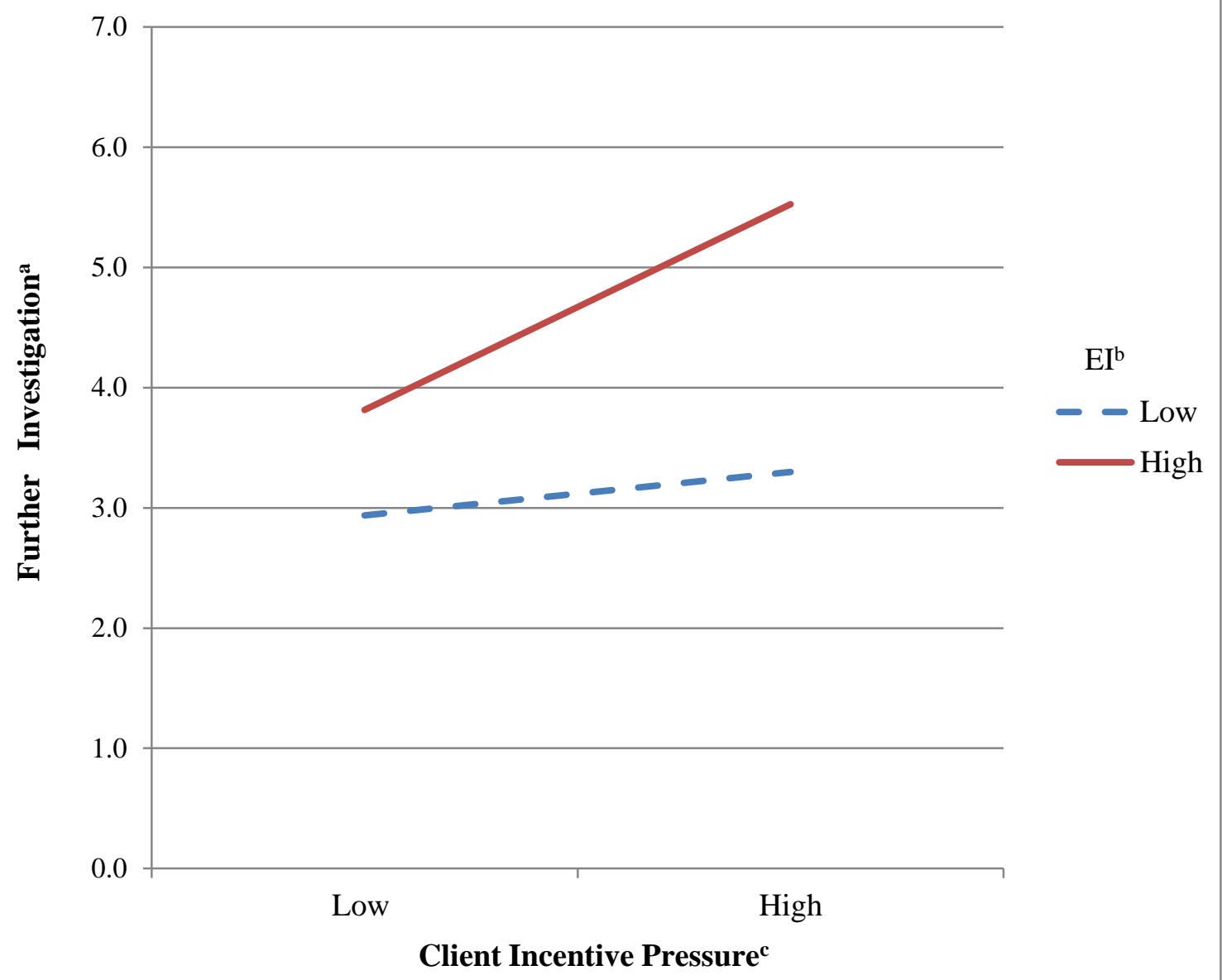

a Auditors indicated the likelihood that additional time and effort that would be spent to further investigate this questionable transaction. Participants responded using a seven point scale anchored by "extremely unlikely" (1) and "extremely likely" (7). This figure graphs the estimated marginal means of the likelihood of additional investigation with covariates appearing in the model evaluated at the following values:Auditing experience and Professional skepticism. See Table 7 for the MANCOVA results.

${ }^{\mathrm{b}}$ Client incentive pressure was manipulated between subjects at two levels: low and high.

${ }^{\mathrm{c}}$ Client incentive pressure was manipulated between subjects at two levels: low and high.

Fig. 7. Interaction of client incentive pressure and EI on auditors' assessment of risk level 


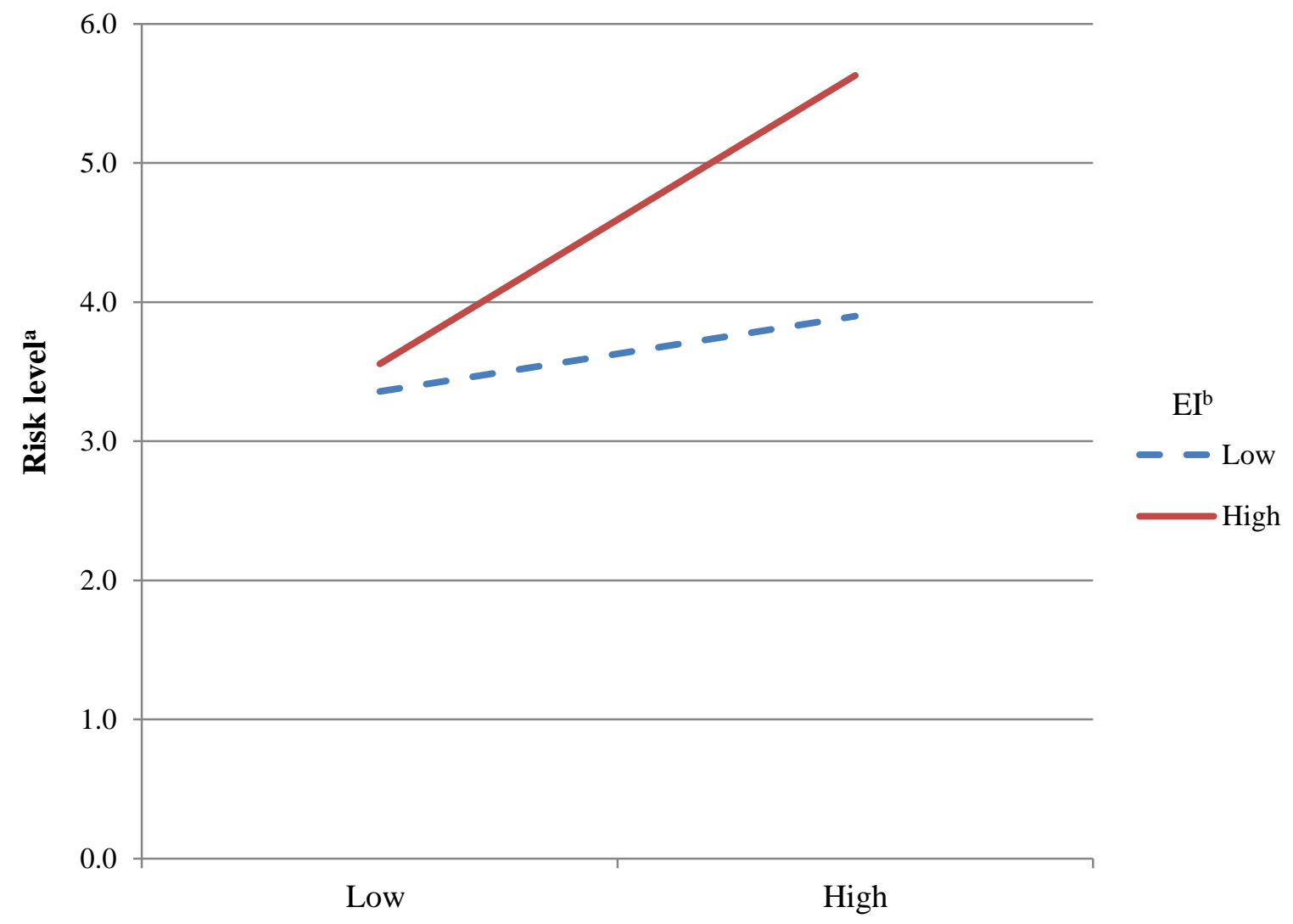

Client Incentive Pressure ${ }^{c}$

a Auditors indicated the level of material misstatement risk they think will be associated with this account receivable transaction. Participants responded using a seven point scale anchored by "extremely unlikely" (1) and "extremely likely" (7). This figure graphs This figure graphs the estimated marginal means of the auditors' risk assessment with covariates appearing in the model evaluated at the following values:Auditing experience and Professional skepticism. See Table 7 for the MANCOVA results.

${ }^{\mathrm{b}}$ EI was measured between subjects at two levels: low and high.

${ }^{\mathrm{c}}$ Client incentive pressure was manipulated between subjects at two levels: low and high.

Figure 8. Interaction of client incetnive pressure and EI on auditors' assessment of risk level 


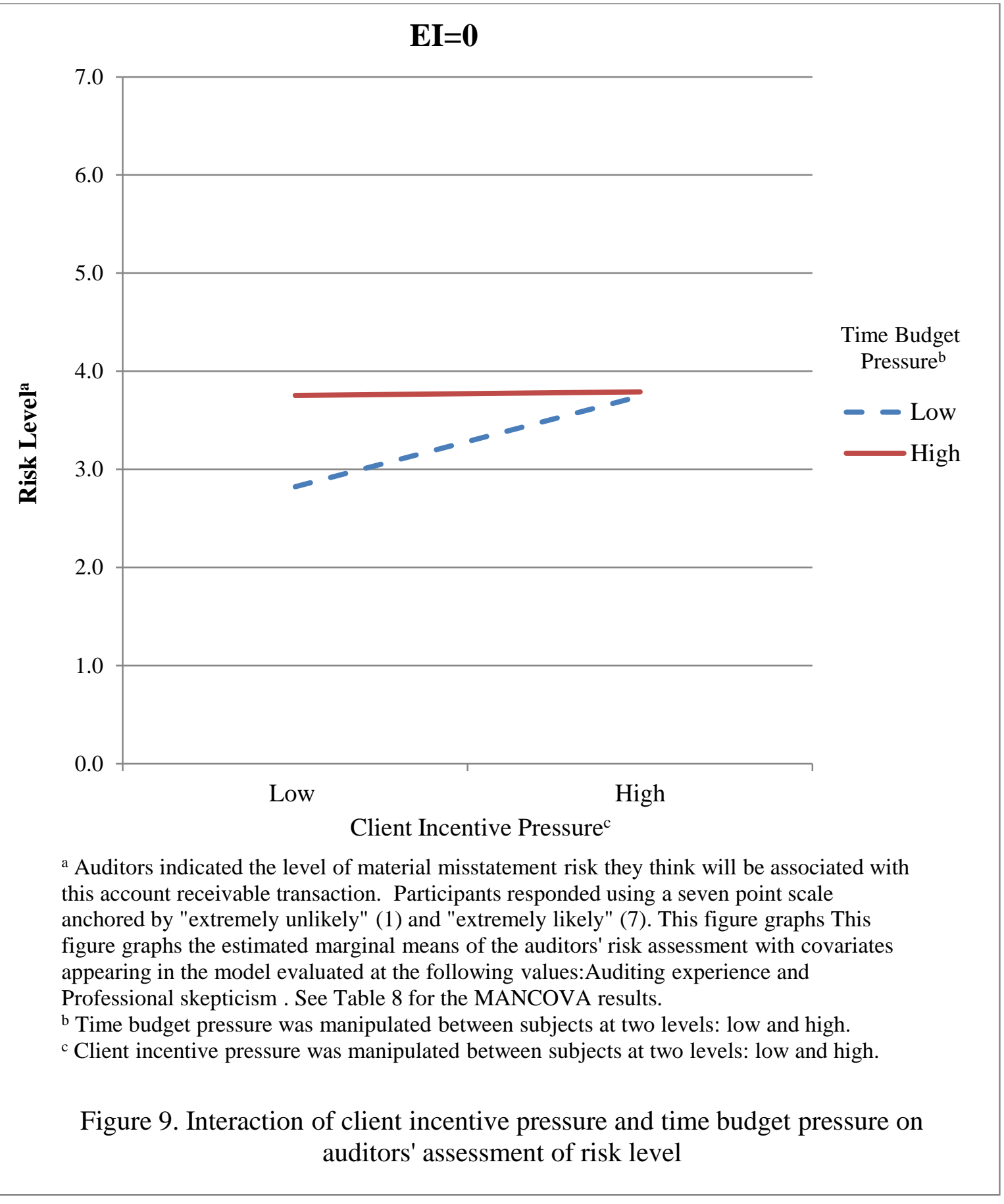




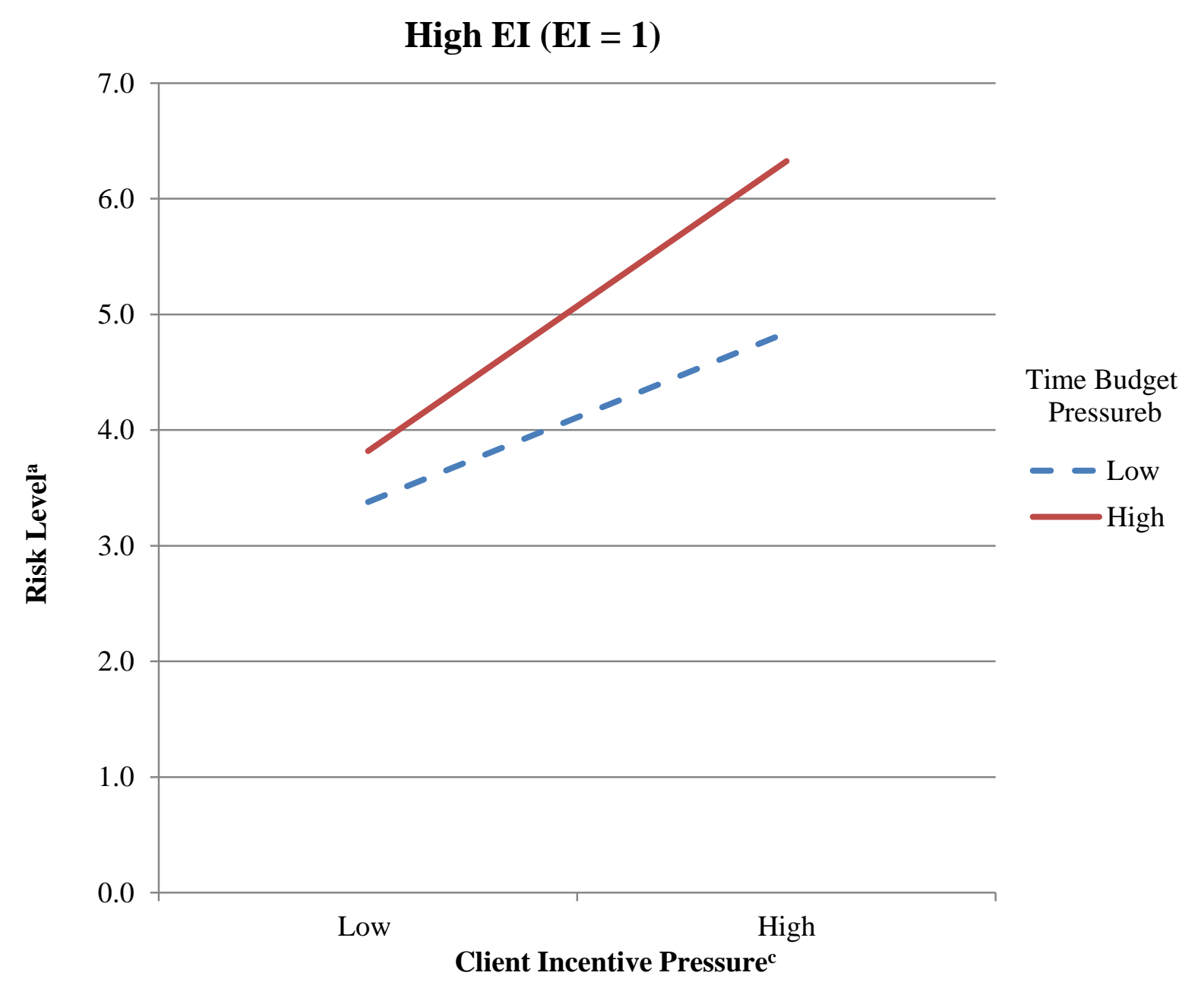

a Auditors indicated the level of material misstatement risk they think will be associated with this account receivable transaction. Participants responded using a seven point scale anchored by

"extremely unlikely" (1) and "extremely likely" (7). This figure graphs This figure graphs the estimated marginal means of the auditors' risk assessment with covariates appearing in the model evaluated at the following values:Auditing experience and Professional skepticism. See Table 8 for the MANCOVA results.

b Time budget pressure was manipulated between subjects at two levels: low and high.

${ }^{\mathrm{c}}$ Client incentive pressure was manipulated between subjects at two levels: low and high.

Figure 10. Interaction of client incentive pressure and time budget pressure on auditors' assessment of risk level 


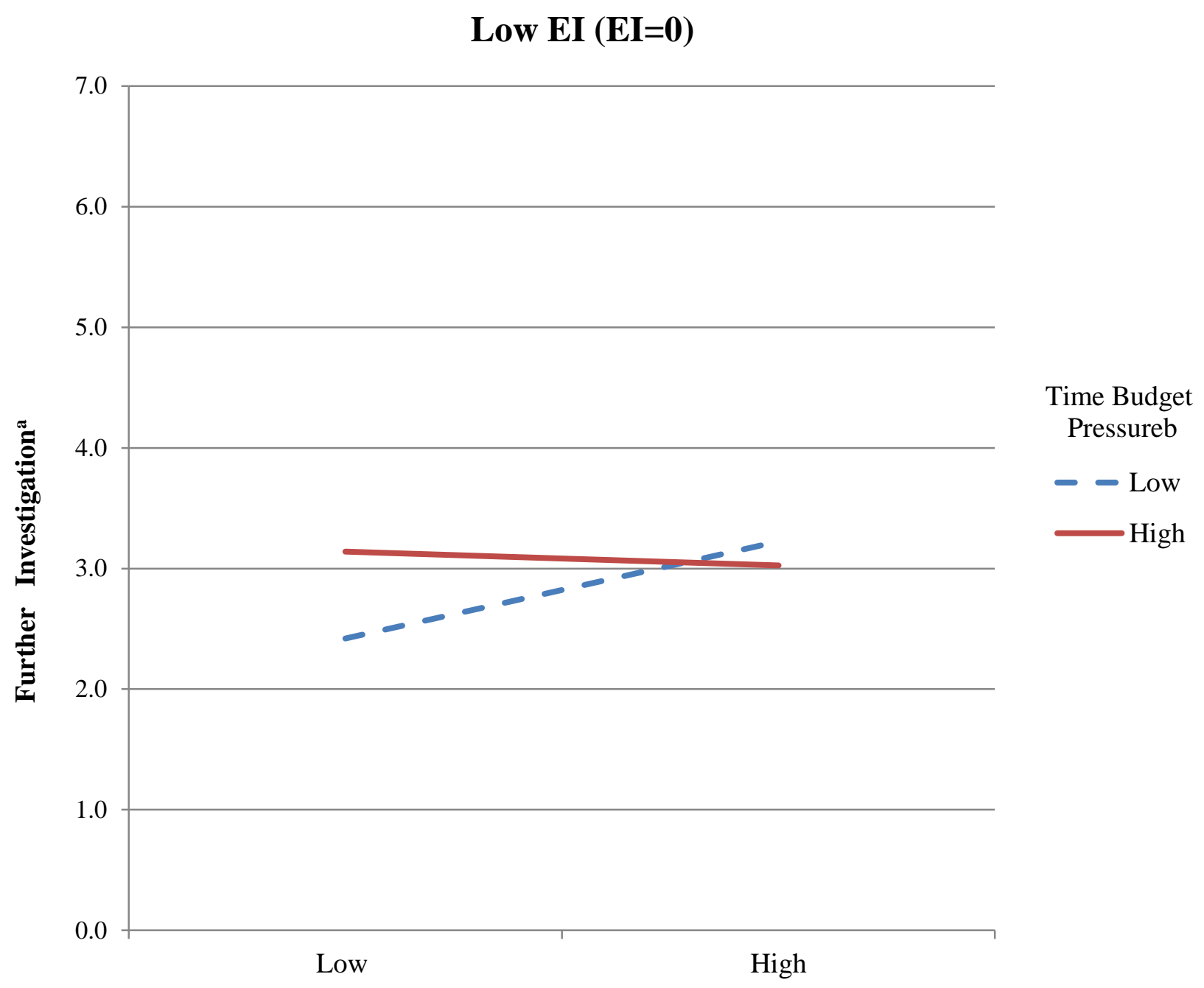

Client Incentive Pressure ${ }^{c}$

${ }^{\text {a }}$ Auditors indicated the likelihood that additional time and effort that would be spent to further investigate this questionable transaction. Participants responded using a seven point scale anchored by "extremely unlikely" (1) and "extremely likely" (7). This figure graphs the estimated marginal means of the likelihood of additional investigation with covariates appearing in the model evaluated at the following values:Auditing experience and Professional skepticism. See Table 8 for the MANCOVA results.

${ }^{\mathrm{b}}$ Time budget pressure was manipulated between subjects at two levels: low and high.

${ }^{\mathrm{c}}$ Client incentive pressure was manipulated between subjects at two levels: low and high.

Figure 11. Interaction of client incentive pressure and time budget pressure on auditors' assessment of the likelihood of additional investigation 


\section{High EI $(\mathbf{E I}=1)$}

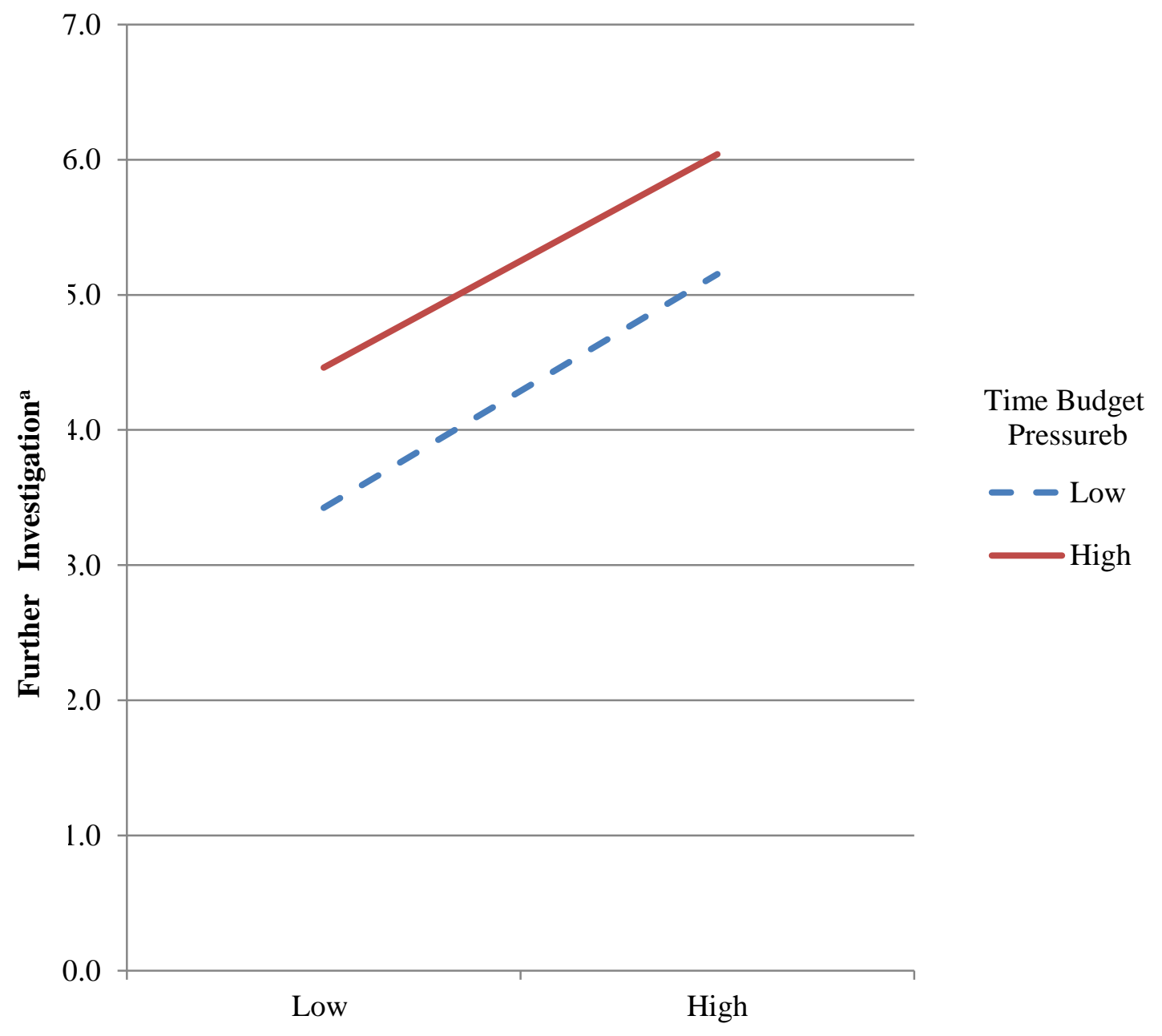

Client Incentive Pressure ${ }^{c}$

${ }^{a}$ Auditors indicated the likelihood that additional time and effort that would be spent to further investigate this questionable transaction. Participants responded using a seven point scale anchored by "extremely unlikely" (1) and "extremely likely" (7). This figure graphs the estimated marginal means of the likelihood of additional investigation with covariates appearing in the model evaluated at the following values:Auditing experience and Professional skepticism. See Table 8 for the MANCOVA results.

$\mathrm{b}$ Time budget pressure was manipulated between subjects at two levels: low and high.

${ }^{\mathrm{c}}$ Client incentive pressure was manipulated between subjects at two levels: low and high.

Figure 12. Interaction of client incentive pressure and time budget pressure on auditors' assessment of the likelihood of additional investigation 


\section{Low EI(EI=0)}

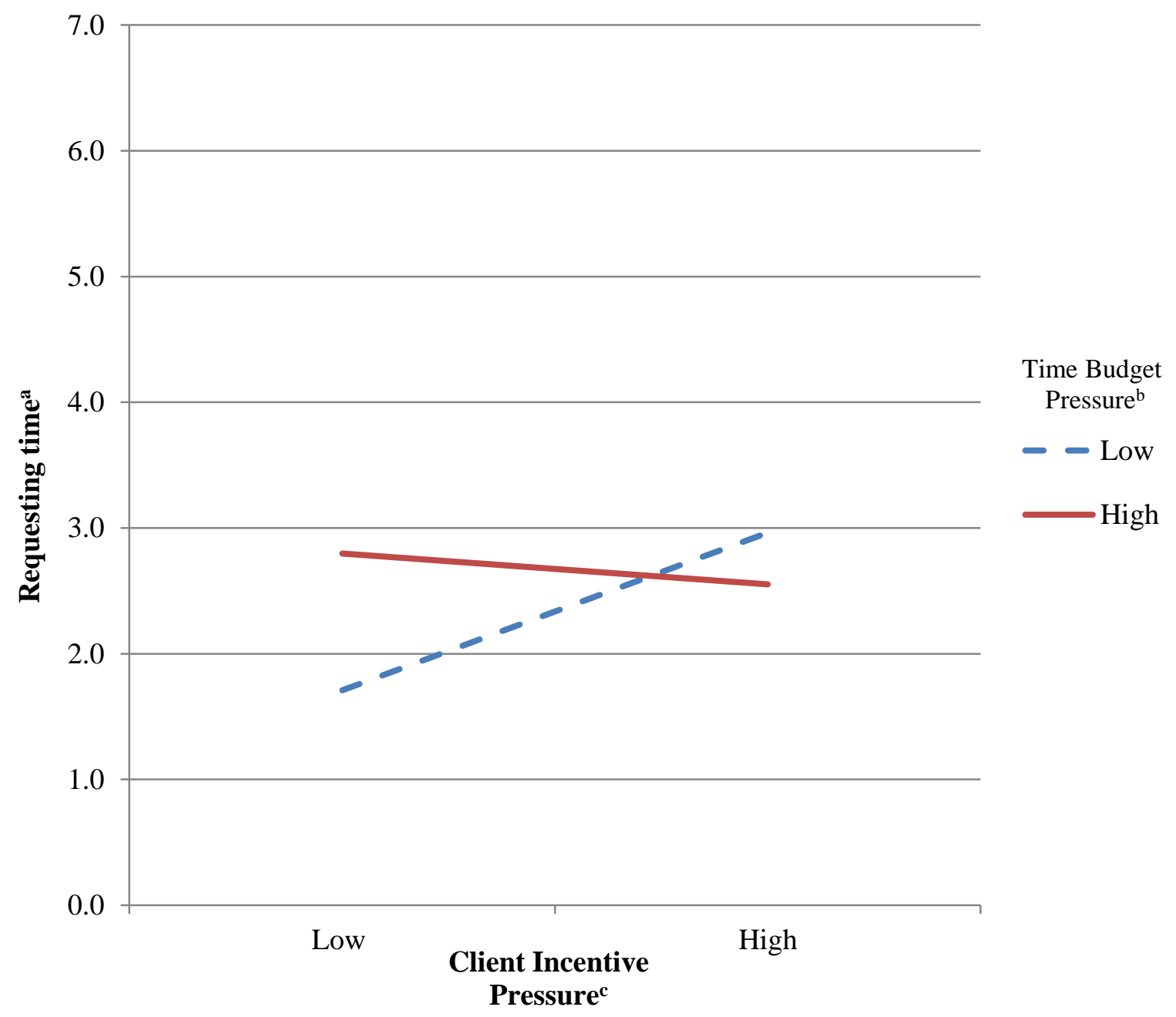

a Auditors indicated the likelihood that that requesting the manager in charge of the audit for extra time before making a final recommendation. Participants responded using a seven point scale anchored by "extremely unlikely" (1) and "extremely likely" (7). This figure graphs the estimated marginal means of the likelihood of requesting extra time with covariates appearing in the model evaluated at the following values:Auditing experience and Professional skepticism . See Table 9 for the MANCOVA results.

b Time budget pressure was manipulated between subjects at two levels: low and high.

${ }^{\mathrm{c}}$ Client incentive pressure was manipulated between subjects at two levels: low and high.

Figure 13. Interaction of client incentive pressure and time budget pressure on auditors' assessment of the likelihood of requesting extra time 


\section{High EI (EI=1)}

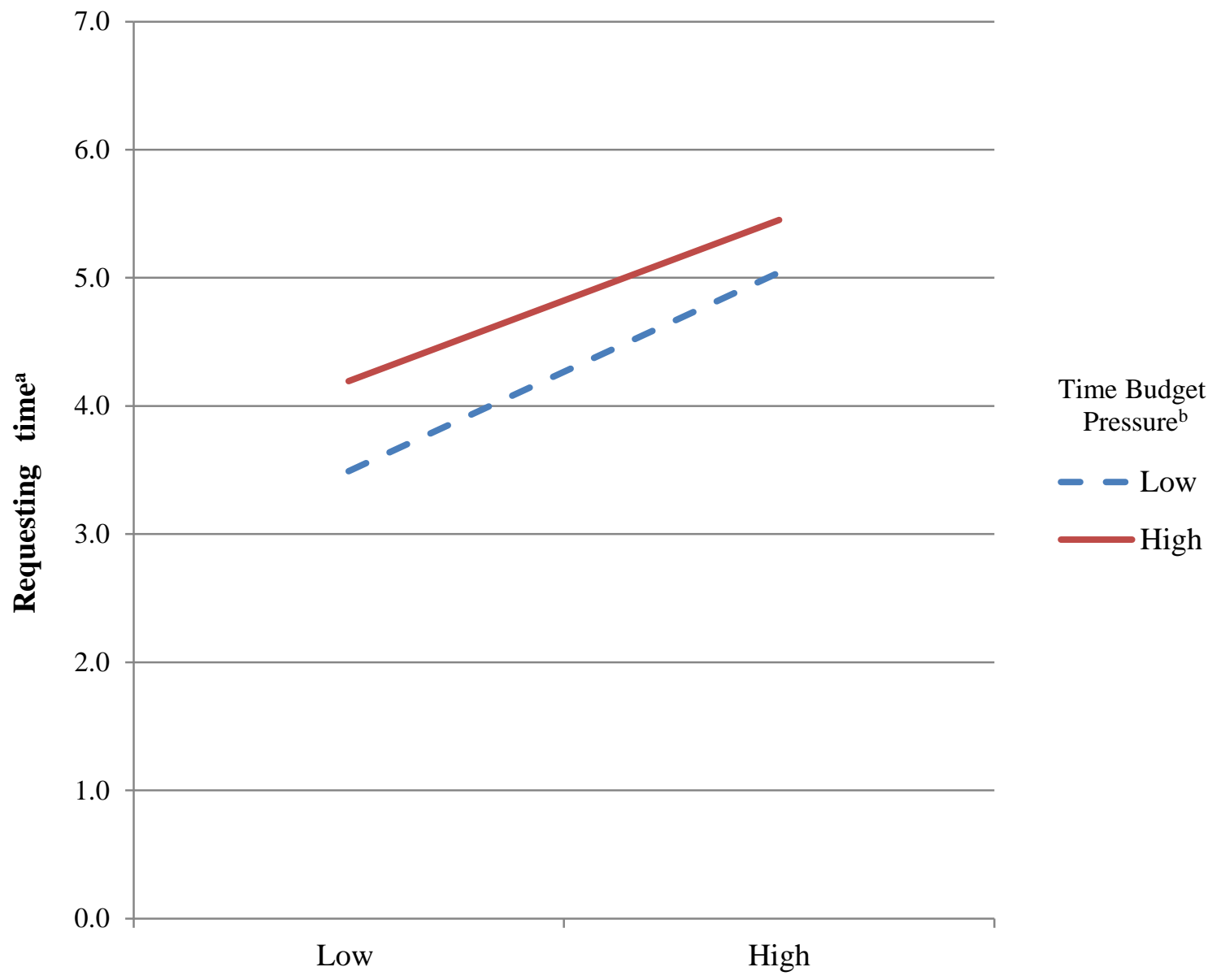

Client Incentive Pressure ${ }^{c}$

${ }^{a}$ Auditors indicated the likelihood of requesting the manager in charge of the audit for extra time before making a final recommendation. Participants responded using a seven point scale anchored by "extremely unlikely" (1) and "extremely likely" (7). This figure graphs the estimated marginal means of the likelihood of requesting extra time with covariates appearing in the model evaluated at the following values:Auditing experience and Professional skepticism. See Table 9 for the MANCOVA results.

$\mathrm{b}$ Time budget pressure was manipulated between subjects at two levels: low and high.

${ }^{\mathrm{c}}$ Client incentive pressure was manipulated between subjects at two levels: low and high.

Figure 14. Interaction of client incentive pressure and time budget pressure on auditors' assessment of the likelihood of requesting extra time 


\section{Low EI $(\mathbf{E I}=\mathbf{0})$}

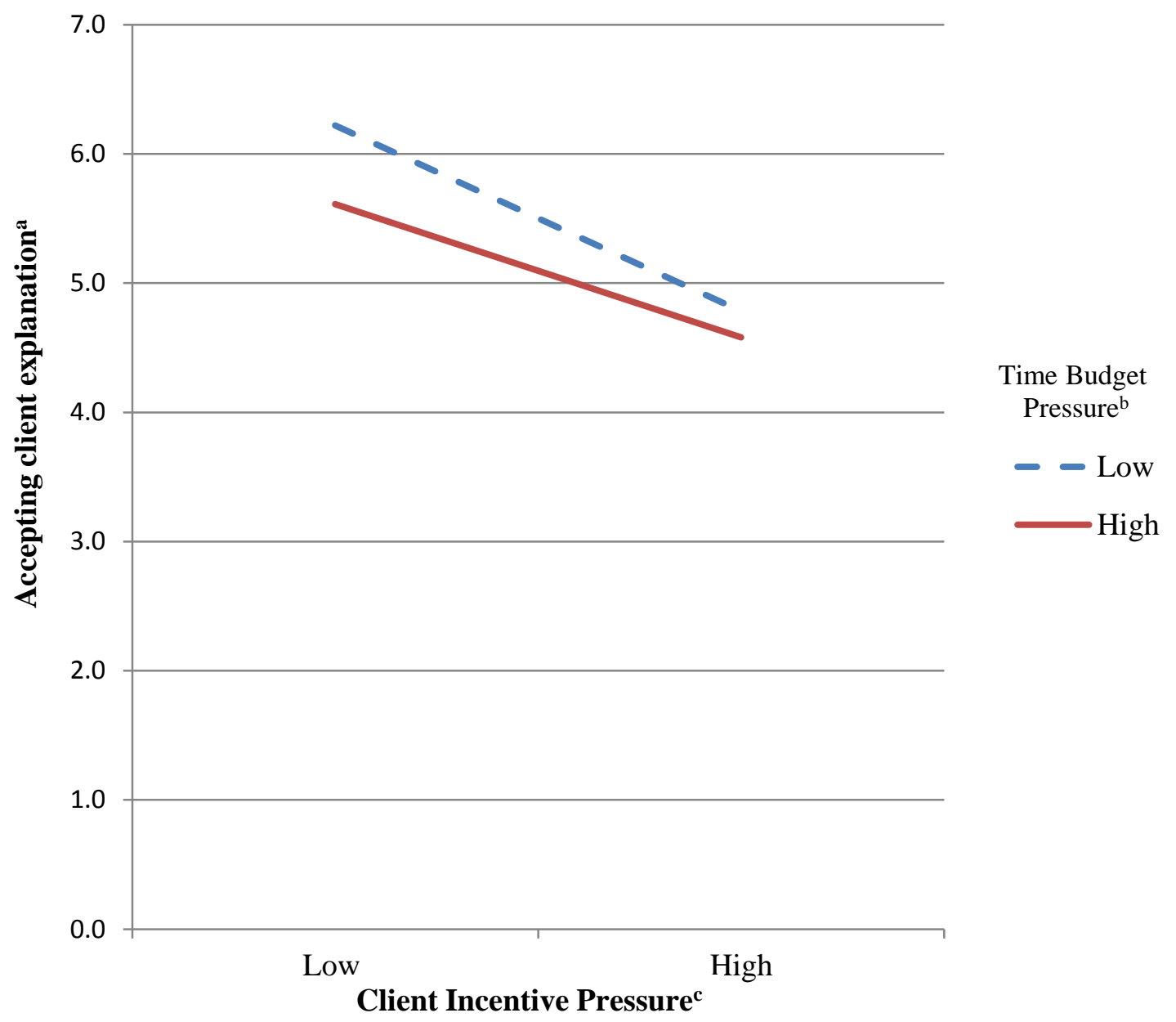

${ }^{a}$ Auditors indicated the likelihood of accepting the client's explanation of the missing sales report and not investigate the matter further. Participants responded using a seven point scale anchored by "extremely unlikely" (1) and "extremely likely" (7). This figure graphs the estimated marginal means of the likelihood of accepting the client's explanation with covariates appearing in the model evaluated at the following values:Auditing experience and Professional skepticism . See Table 9 for the MANCOVA results.

${ }^{\mathrm{b}}$ Time budget pressure was manipulated between subjects at two levels: low and high.

${ }^{\mathrm{c}}$ Client incentive pressure was manipulated between subjects at two levels: low and high.

Figure 15. Interaction of client incentive pressure and time budget pressure on auditors' assessment of the likelihood of accepting the client's explanation 


\section{High EI $(\mathbf{E I}=1)$}

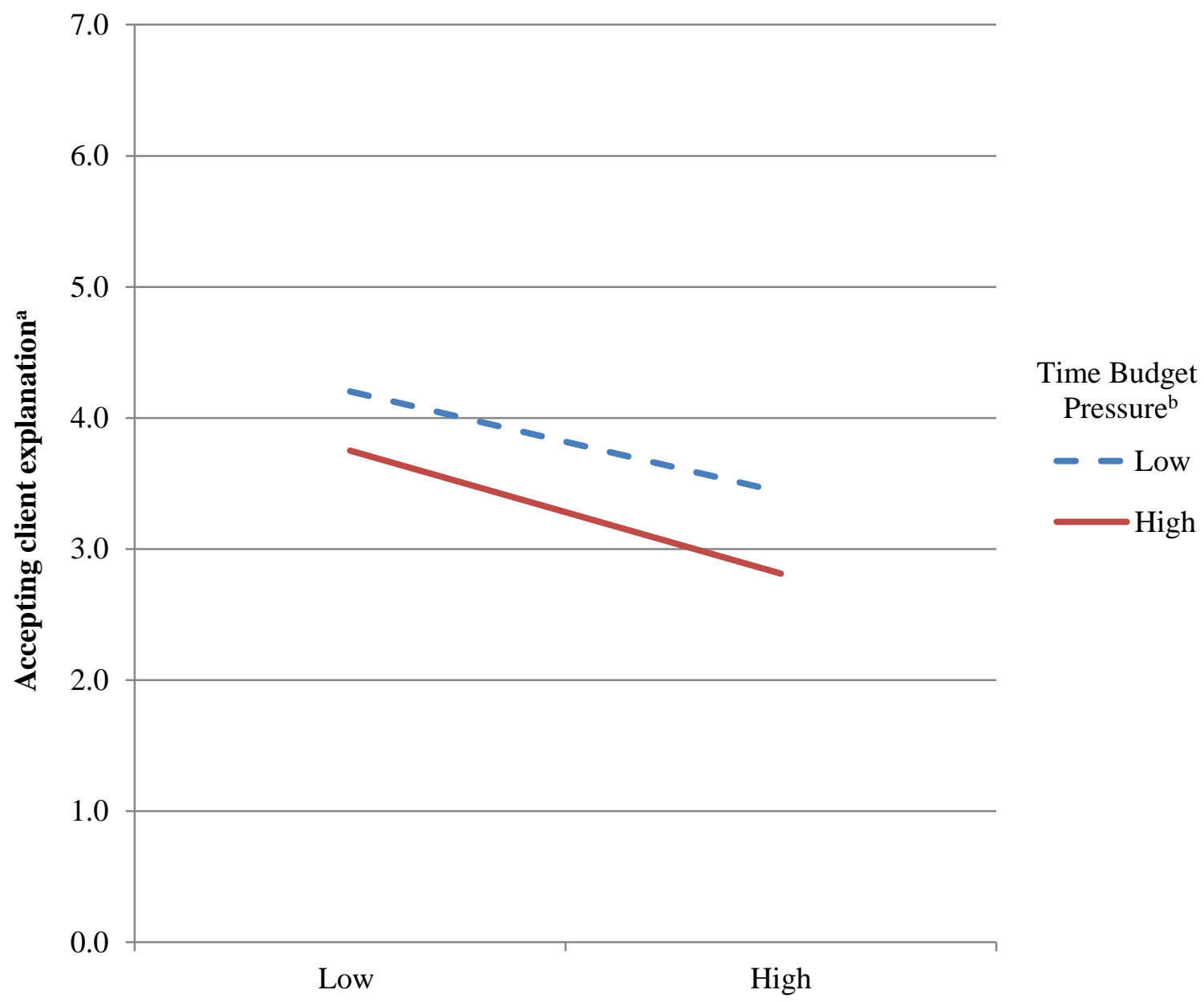

\section{Client Incentive Pressure ${ }^{c}$}

a Auditors indicated the likelihood of accepting the client's explanation of the missing sales report and not investigate the matter further. Participants responded using a seven point scale anchored by "extremely unlikely" (1) and "extremely likely" (7). This figure graphs the estimated marginal means of the likelihood of accepting the client's explanation with covariates appearing in the model evaluated at the following values:Auditing experience and Professional skepticism. See Table 9 for the MANCOVA results.

${ }^{\mathrm{b}}$ Time budget pressure was manipulated between subjects at two levels: low and high.

${ }^{c}$ Client incentive pressure was manipulated between subjects at two levels: low and high.

Figure 16. Interaction of client incentive pressure and time budget pressure on auditors' assessment of the likelihood of accepting the client's explanation 